
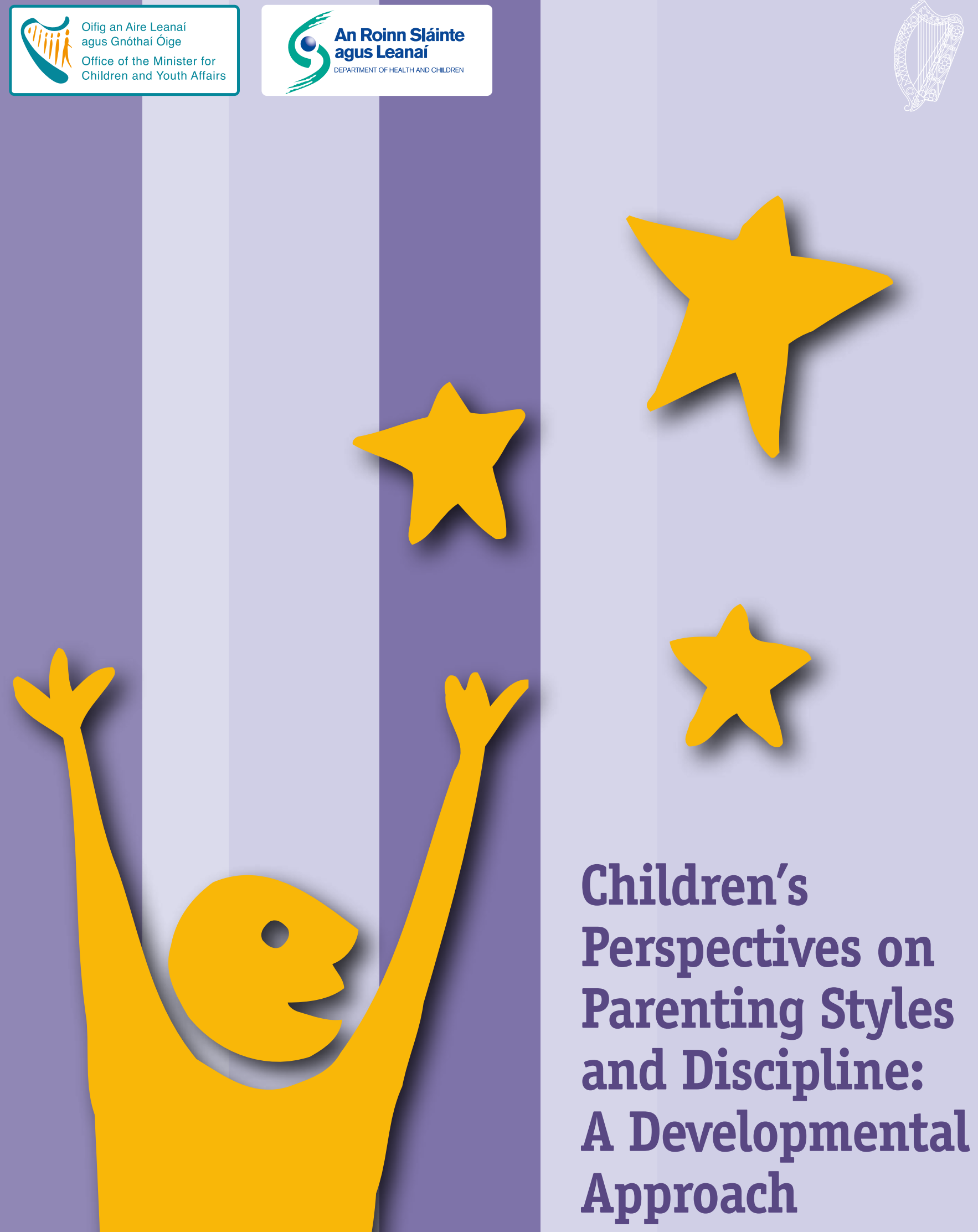

The National Children's

Strategy Research Series 



\section{Children's Perspectives on Parenting Styles and Discipline: A Developmental Approach}




\section{The authors of this report are:}

Elizabeth Nixon, School of Psychology and Children's Research Centre, Trinity College, Dublin, and Ann Marie Halpenny, Centre for Social and Educational Research, Dublin Institute of Technology.

Research assistance was provided by Irene Loughran.

Copyright (c) Minister for Health and Children, 2010 Office of the Minister for Children and Youth Affairs Department of Health and Children Hawkins House

Hawkins Street

Dublin 2

Tel: +353 (0)1 6354000

Fax: +353 (0)1 6743223

E-mail: omc@health.gov.ie

Web: www.omcya.ie

Published by The Stationery Office, Dublin

All rights reserved. No part of this publication may be reproduced, stored in a retrieval system, or transmitted, in any form or by any means, electronic, mechanical, photocopying, recording or otherwise, without the prior permission in writing of the copyright holder.

For rights of translation or reproduction, applications should be made to the Head of Communications, Office of the Minister for Children and Youth Affairs, Hawkins House, Hawkins Street, Dublin 2, Ireland. 


\section{Contents}

ACKNOWLEDGEMENTS vi vi

EXECUTIVE SUMMARY

$\begin{array}{lr}\text { Study objectives } & 1\end{array}$

Methodology 1

Key findings 2

Parenting roles 2

Parental control and discipline $\quad 2$

Rationales for and against physical punishment 3

Key features of effective discipline 3

Childhood and parenthood compared 3

Conclusions 4

1. INTRODUCTION 5

Overview of study 6

Socio-demographic context $\quad 6$

Listening to children and children's rights in Ireland $\quad 7$

$\begin{array}{ll}\text { Policy and legislative context relating to the physical punishment of children } & 7\end{array}$

Developments in Ireland $\quad 7$

International developments $\quad 8$

Research context $\quad 9$

Aims of the study 9

$\begin{array}{ll}\text { Approach to the research } & 10\end{array}$

2. LITERATURE REVIEW 11

Effects of parents on children's development $\quad 12$

Parental responsiveness 12

Parental control $\quad 12$

$\begin{array}{ll}\text { Parenting styles } & 13\end{array}$

$\begin{array}{ll}\text { Parental discipline } & 14\end{array}$

Physical punishment 15

$\begin{array}{ll}\text { Developmental considerations } & 16\end{array}$

$\begin{array}{ll}\text { Researching children's perspectives } & 17\end{array}$

$\begin{array}{ll}\text { Children's perspectives on family and parenting roles } & 18\end{array}$

$\begin{array}{ll}\text { Children's perspectives on physical punishment } & 19\end{array}$

$\begin{array}{ll}\text { Conclusion } & 19\end{array}$

3. METHODOLOGY 21

Qualitative approach $\quad 22$

Sampling approach and recruitment $\quad 22$

Data collection method 23

Focus group 'Topic Guide' $\quad 25$

Socio-demographic questionnaire $\quad 25$

Ethical issues $\quad 25$

Informed consent $\quad 25$

Confidentiality and limits to confidentiality $\quad 26$

Profile of children $\quad 26$

Profile of family backgrounds $\quad 27$

Data analysis $\quad 28$ 
4. PARENTING ROLES

What parents do

Sustenance and care-giving $\quad 30$

Protection 30

Breadwinning $\quad 31$

Guidance $\quad 31$

Authority 32

Emotional support $\quad 32$

Shared activities $\quad 33$

Facilitating autonomy $\quad 33$

Summary $\quad 34$

Age-related patterns in parenting roles $\quad 34$

Changing parent roles $\quad 34$

Changing child roles $\quad 35$

Quality of parent-child relationship $\quad 36$

$\begin{array}{ll}\text { Gender-related patterns in parenting roles } & 37\end{array}$

Gendered nature of parenting roles $\quad 37$

Parenting girls and boys $\quad 38$

$\begin{array}{ll}\text { Key findings } & 39\end{array}$

5. PARENTAL CONTROL AND DISCIPLINE 41

Nature of parental rules and regulations $\quad 42$

Social conventional rules $\quad 42$

Safety-related rules $\quad 42$

Moral rules $\quad 42$

Summary $\quad 43$

Parental monitoring and checking strategies $\quad 43$

Verbal communication $\quad 43$

Parents as all-knowing $\quad 44$

Trust in parent-child relationships $\quad 44$

Physical proximity $\quad 45$

Summary $\quad 45$

Parental discipline strategies $\quad 45$

Power-assertive discipline strategies $\quad 45$

$\begin{array}{ll}\text { Inductive discipline strategies } & 46\end{array}$

Love-withdrawal strategies $\quad 46$

Summary $\quad 46$

Physical punishment $\quad 46$

How does slapping make children feel? $\quad 47$

$\begin{array}{ll}\text { Why do parents use physical punishment? } & 47\end{array}$

$\begin{array}{ll}\text { Rationales for physical punishment } & 47\end{array}$

$\begin{array}{ll}\text { Rationales against physical punishment } & 48\end{array}$

Should physical punishment be banned? $\quad 49$

Summary $\quad 50$

Key features of effective discipline strategies $\quad 51$

Loss of privilege $\quad 51$

Instructional value $\quad 51$

Consistency

Fairness $\quad 52$

Summary $\quad 52$

Age-related patterns in parental control and discipline 53

Summary $\quad 54$ 
Gender-related patterns in parental control and discipline $\quad 54$

Gendered nature of parental control and discipline $\quad 54$

Disciplining girls and boys $\quad 54$

Summary $\quad 55$

Key findings $\quad 55$

Effective discipline: What works? What doesn't work? $\quad 56$

6. CHILDHOOD AND PARENTHOOD COMPARED 57

Parental responsibilities $\quad 58$

Parental rights $\quad 59$

Parental right to regulate and monitor children's behaviours $\quad 60$

$\begin{array}{ll}\text { Parental right to use physical punishment } & 61\end{array}$

Children's rights and responsibilities $\quad 61$

Childhood: A time for fun $\quad 62$

Key findings $\quad 63$

7. DISCUSSION AND CONCLUSIONS 65

Revisiting the theoretical and policy context for the study 66

Rights and responsibilities in families $\quad 66$

Parental control and discipline $\quad 67$

$\begin{array}{lr}\text { Physical punishment } & 69\end{array}$

$\begin{array}{ll}\text { Rationales for physical punishment } & 69\end{array}$

$\begin{array}{ll}\text { Rationales against physical punishment } & 70\end{array}$

Perspectives on banning parental use of physical punishment $\quad 70$

Methodological strengths and limitations of the research $\quad 70$

$\begin{array}{ll}\text { Conclusions } & 71\end{array}$

$\begin{array}{ll}\text { REFERENCES } & 73\end{array}$

\section{APPENDICES}

Appendix 1: Information Sheet for Parents, Parental Consent Form and Questionnaire 82 Appendix 2: Information Sheet for Children and Child Consent Form $\quad 84$

Appendix 3: Topic Guide for Focus Groups $\quad 85$ 


\section{Acknowledgements}

We wish to express our sincere thanks to all of the children and young people who participated in this study. Also, thanks to the parents of the children who gave consent for their child to be invited into the study. Our thanks also to school personnel, teachers and principals, without whom the study would not have been possible.

We would also like to acknowledge and thank the Office of the Minister for Children and Youth Affairs for providing funding for the study.

Special thanks go to Irene Loughran for her assistance in the access and recruitment process, fieldwork and transcription.

Finally, thanks to Professor Sheila Greene and Mary 0'Hora of the Children's Research Centre, Trinity College, Dublin, for their support and advice.

Elizabeth Nixon, TCD and Ann Marie Halpenny, DIT 


\section{Executive Summary}

The overall aim of this study was to explore children and young people's perspectives on parenting styles and discipline. The study was carried out against the backdrop of changing trends in Irish society, most notably, changes in family routines and relationships. Little is known in the Irish context about children's views of different parenting styles and, in particular, about the views of children in respect of physical punishment by their parents.

In line with the ethos of the National Children's Strategy, the research involved consulting directly with children to explore their perspectives on parenting styles and discipline. A qualitative approach was adopted, involving focus group interviews with children and young people aged between 6 and 17 years. The study was carried out jointly by the School of Psychology and Children's Research Centre, Trinity College, Dublin, and the Centre for Social and Educational Research in the Dublin Institute of Technology, and was commissioned by the Office of the Minister for Children and Youth Affairs.

\section{Study objectives}

The broad aim of the research was to examine parenting styles and discipline from a child's perspective. Specifically, the following questions were addressed:

- What are children's perspectives on the nature of parenting roles?

- What are children's perceptions of the effects of different parenting styles and disciplinary strategies, including physical punishment, on their lives?

- How do children position themselves within the family and what is their understanding of their rights and responsibilities within the family?

- Do children's understanding and perspectives change over time (i.e. as they become older)?

- What are children's perspectives on legislation and policy relating to physical punishment in the home?

\section{Methodology}

Given the paucity of previous research into children's perspectives on this issue, the study is essentially an exploratory investigation that seeks to uncover meaning and perceptions. Focus groups were the chosen method for the study since they represent an effective research method by which various issues can be explored with children and young people within a peer group setting. Moreover, the use of focus groups with children acknowledges children as experts and important informants on their perspectives. Topics discussed in the focus groups included children's views on parenting and child roles in the family, parental control and monitoring, and parenting strategies of discipline and use of physical punishment.

Thirty focus groups were conducted with 132 children, aged 6-17, from two class groups in primary schools (1st and 4th class) and two class groups in secondary schools (1st year and Transition Year). The gender composition of the sample was almost equal, with 67 boys and 65 girls. The perspectives of children in four age groups, ranging from early childhood to late adolescence, were explored in order to identify developmental patterns in children's views on parenting styles and discipline. 


\section{Key findings}

\section{Parenting roles}

- Children's descriptions of what parents do in a family revealed a variety of parental roles: providing sustenance, protection, emotional and financial support; monitoring and regulating children's behaviour; sharing activities; guiding and teaching; and facilitating children's independence and autonomy.

- A number of themes emerged pertaining to developmental patterns in parenting roles. Younger children highlighted parental activities such as providing sustenance, protection and basic care to their children, and sharing activities with their children. Providing practical assistance with schoolwork and support in learning new skills were also important.

- In contrast, older children emphasised the importance of parental guidance, emotional support and authority. The parents' role in facilitating autonomy and independence was also emphasised within the adolescent groups. Adolescent descriptions of 'parents as guides' reflected values and expectations that were important to parents, such as getting a good education, being mannerly and knowing right from wrong.

- Parent and child roles were perceived as changing over time, with dependence upon parents decreasing with children's increasing age. In the context of adolescents' need for autonomy and independence, parenting at this stage brought novel challenges for regulation and control of behaviour at a time when the likelihood of risk-taking behaviour may be heightened.

- Children's experience of parenting did not reflect genderless practices in all families. Certain aspects of the parenting role were more closely aligned to either mothers or fathers. Child effects were also identified, with boys and girls evoking different types of interactions with their parents (such as distinct monitoring and regulating activities) and parents engaging in distinct activities with their sons and daughters.

\section{Parental control and discipline}

- Parents represent important figures of authority and control for their children. Key aspects of this role were perceived as involving the monitoring and checking of children's activities and whereabouts, enforcing limits and boundaries, and disciplining children.

- A key message to emerge was that rules were necessary in order to protect children from harm and to promote their well-being. Parental rules and regulations relating to social conventions (such as being polite), morality and 'being a good person', school and academic work, and avoidance of risk and safety issues were highlighted in children's narratives.

- Parental monitoring of children's behaviour and whereabouts was facilitated largely through talking, asking questions and via mobile phones. Parents were also perceived as 'all-knowing' and attentive to familiar and unfamiliar patterns of behaviour. Children's narratives emphasised the importance of trust and negotiation in parent-child relationships with regard to supporting more effective parental monitoring of older children's behaviour.

- Older children emphasised the need for parents to negotiate rules and regulations with their adolescents, rather than imposing restrictions upon them as might be done with younger children.

- Discipline strategies identified by the children were classified into three categories: power-assertive responses, which includes the removal of privileges, time-out or grounding, being allocated extra chores and physical punishment; inductive responses, involving communication about behaviour and its consequences, and reinforcement of positive behaviour; and love withdrawal, where parents express their disappointment in their children with the intention of inducing feelings of guilt and regret for misbehaviour. 


\section{Rationales for and against physical punishment}

- Parental use of physical punishment had the result of making children feel bad in some way, including feeling sad, upset, unloved, sore, scared, angry and embarrassed. Children considered that parents tended to use physical punishment as a last resort, especially when their children were repeatedly defiant, or when parents were feeling out of control or frustrated.

- The context of the child's misbehaviour was central to whether children endorsed parents' use of physical punishment. Among some older children, physical punishment was acceptable when they put themselves in situations of risk. In general, physical punishment was considered to be more acceptable and effective when used with younger rather than older children.

- A pivotal argument against parental use of physical punishment expressed by children was that physical punishment did not involve parent-child communication and children were less likely to learn from the disciplinary encounter. Children also expressed the view that physical punishment had the potential to cause serious physical injury or emotional distress to a child, or to damage the parent-child relationship.

- The majority of children did not agree that physical punishment should be legally prohibited. Children made reference to the right of parents to use physical punishment with their children and the complexity of implementing a ban on physical punishment in the home. Some children, however, did favour the legal prohibition of physical punishment by parents, pointing out that such prohibition would protect children whose parents used physical punishment excessively or severely.

\section{Key features of effective discipline}

- Grounding children, restricting their activities (e.g. not being allowed to watch TV) and depriving them of privileges (e.g. pocket money) were effective ways of deterring children from repeating misbehaviour. Physical punishment was considered less effective as a form of discipline since the consequences of being slapped were relatively short-term compared with the consequences of being grounded or having privileges removed.

- Four principles underpinned effective discipline:

loss of privilege (being deprived of something that was of value to the child); instructional value (affording the child an opportunity to learn about the consequences of their behaviour);

consistency (delivering discipline in a consistent manner and following through with appropriate action); and

fairness (adopting discipline strategies that reflect fair-mindedness and a sense of justice).

\section{Childhood and parenthood compared}

- Childhood was conceptualised as a social status that was clearly distinct from adulthood and parenthood, in terms of dependency, responsibility, rights and fun. In general, children expressed the view that parenthood was difficult because of the high levels of responsibility involved in the lifelong obligation to care for and protect children.

- There was general consensus among most children that parents had the right to regulate, control and discipline them, although older children were more likely to question and even resist parents' authority and power.

- In contrast, children were less clear about the nature of children's rights within families. Young children (aged 6-8) lacked a clear concept of children's rights. Older children emphasised the need for their right to privacy to be balanced with parents' right to monitor and regulate their activities. Across all age groups, children reflected upon a variety of responsibilities which they held within their families, such as a responsibility to care for younger siblings and to contribute to household chores. 


\section{Conclusions}

It is clear that children have a seminal contribution to make to our understanding of parenting in Ireland. Children's ability to articulate their views on parenting, as reported in this study, suggests that family policy development could benefit from a child-centred ethos, which takes account of the developmental needs and rights of individual children within their families.

Messages arising from this research could usefully inform the development of a public information campaign on safe and effective discipline of children. Children's views on these issues could also be incorporated into existing parenting programmes that seek to provide support for parents. Enhancing parents' awareness of their children's perspectives on parenting roles, discipline and punishment may help to curb practices which children deemed to be inappropriate and harmful. On the other hand, the prevalence of inductive disciplinary practices highlighted in this study suggests that there is scope for building on existing practices in order to promote an ethos of effective, constructive and positive disciplining of children. 
1 INTRODUCTION 


\section{Overview of study}

The present study aims to explore, from a child's perspective, key issues arising from children's experiences of parenting styles and discipline. The study is carried out against the backdrop of changing trends in Irish society, most notably, changes in family routines and relationships. To date, a large body of research has investigated the effects of parents' behaviours on their children. Parent-child interaction is linked to a number of child outcomes, including levels of selfconfidence and self-esteem, the quality of their close relationships and their emotional well-being (Parke and Buriel, 1998). However, little is known in general about children's views of different parenting styles and, in particular, about the views of children in respect of physical punishment by their parents. Children's views on parenting styles and discipline are best understood within the social and cultural context in which they are generated. Thus, the aim of the present study is to explore children's perspectives on these issues within an Irish context.

The focus is first upon contextual features that are relevant, both directly and indirectly, to parenting styles and discipline strategies adopted by families in Ireland. Reflection on current practice and legislation, against the backdrop of international research and policy frameworks, is invaluable in informing the development of effective policy responses to the changing sociocultural contexts in Irish contemporary society. It is clear that attitudes to parenting and discipline have changed, most notably over the last two decades. In the section below, we provide a brief overview of some developments across related areas of socio-cultural contexts.

\section{Socio-demographic context}

Over the last decade, Irish society has continued to experience a growth in the variation of family forms. Tovey and Share (2000) draw attention to some of the most notable changes in the Irish socio-demographic context, which include a marked decline in marriage, birth and fertility rates; an increase in cohabitation; marriage and childbirth at a later age; increased births outside marriage; smaller family sizes; and greater numbers of people remaining single. According to the latest Census of Population in 2006, fewer than one in five households in Dublin City are now made up of the traditional family of husband, wife and children, and this decline in traditional family households is also reflected, though in a less marked way, nationwide (Central Statistics Office, 2007). More specifically, cohabitation has risen sixfold over the past decade, from 31,298 people in 1996 to 189,240 in 2006, making it the fastest-growing family unit (Iona Institute, 2007). The number of lone parents is up $80 \%$ since 1986 , with 190,000 lone parents now resident in the country (Iona Institute, 2007). Overall, the national average for parental separation is $13 \%$, but rises to almost 20\% in Dublin and Limerick. The changing role of fathers in Irish society has also received increasing attention from a number of researchers (McKeown, 2001; Kiely, 1995 and 2001). Kiely (2001) points out that although the role of fathers as providers remains predominant in Ireland, attitudes to fathers' involvement with their children have altered. In particular, Kiely highlights a shift from viewing the father, in the main, as an authority figure and provider to a perspective which places greater emphasis on the contribution of fathers to care-giving within the family and to increased emotional involvement with their children.

Changing family contexts are likely to exert influences on parenting styles and practices, which, in turn, reflect on children's psychological well-being. A 2006 report on student behaviour in secondary schools in Ireland highlighted dramatic social changes and alterations in lifestyle patterns in contemporary Ireland (Department of Education, 2006). Specific examples of such developments include changes in the power attributed to authority figures and altered perspectives on the status granted to young people. Yet, there is little knowledge available on how such changing contexts are experienced by children and their families. Insight into children's experiences of parenting practices is, therefore, both invaluable and imperative given the significant impact that parenting styles and parental discipline responses exert on child outcomes 
and children's psychological well-being in general. Such influences have been widely documented in the research literature in the UK, USA and Australia (Smith et al, 2005; Gershoff, 2002; Parke, 2002; Eisenberg et al, 2001). Furthermore, the way in which children actively process their parents' actions and roles may help to account for pathways observed between family dynamics and developmental outcomes (McHale et al, 2002).

\section{Listening to children and children's rights in Ireland}

In relation to children's rights, a major development within the Irish legislative context was the ratification of the United Nations Convention on the Rights of the Child in 1992. The Convention represents the most complete statement of children's rights and provides an internationally agreed framework of minimum standards necessary for the well-being of the child (UN, 1989; Children's Rights Alliance, 1998). The State, having ratified the Convention, has a binding obligation under international law to ensure that its terms are honoured, which means ensuring that the rights guaranteed by the Convention are accorded to all children within Ireland.

More recently, another significant development has been the debate on whether it is necessary to provide further protection and promotion of children's rights through an amendment to the Irish Constitution. A 2007 report published by Barnardos, entitled The Case for Constitutional Change, suggests that at present there appears to be much public confusion regarding the extent of children's rights in the Irish Constitution (Barnardos, 2007). The authors go on to argue that although the present Constitution makes express reference to the rights of the family, these provisions make little express provision for the rights of the child. Recent debates have highlighted the potential for conflict to arise in terms of ensuring accord between provisions pertaining to the rights of the family and those pertaining more specifically to the independent rights of the child.

Over the last decade in particular, we have witnessed a growing emphasis on children's rights to be consulted regarding issues that affect them. The publication of Ireland's National Children's Strategy in 2000 (Department of Health and Children, 2000) and the establishment of the Office of the Minister for Children in 2005 (now the Office of the Minister for Children and Youth Affairs, OMCYA) have generated possibilities for greater coherence in policy-making for children and their families. A primary objective of the OMCYA is to improve the lives of children under the National Children's Strategy and to give children a stronger voice on issues that affect them. An important outcome of this objective is the inclusion of children's views as part of research and policy development.

\section{Policy and legislative context relating to the physical punishment of children}

\section{Developments in Ireland}

In Ireland the family has been protected under the Constitution, where it receives recognition as 'the natural and fundamental unit group of Society, as a moral institution possessing inalienable and imprescriptible rights, antecedent to all positive law' (Article 41.1.1). In 1995, the Commission on the Family was established by the Minister for Social Welfare 'to examine the effects of legislation and policies on families and make recommendations to the Government on proposals which would strengthen the capacity of families to carry out their functions in a changing economic and social environment. The establishment of the Commission reflected a growing awareness at policy level of the need to place the development of family policy higher on the political agenda. In the Final Report of the Commission on the Family, entitled Strengthening Families for Life, a number of wideranging recommendations were outlined, with relevance across all areas of policy (Commission on the Family, 1998). A key recommendation was the enhancement of support, by the State and agencies of the State, for parents in carrying out their responsibilities. Specifically, it was highlighted that policies should support parents in their choices in relation to the care of their 
children and enable them to be the best parents they can be by giving them practical help with child-rearing and equipping them with knowledge and skills. Arising from these recommendations, the Family Support Agency was established in 2003 with the objectives of promoting continuity and stability in family life, fostering a supportive community environment for families at a local level and supporting families in the context of family transition. The Family Support Agency also undertakes research and provides and disseminates information about parenting and family issues.

The UN Convention on the Rights of the Child lays out a clear set of principles and minimum standards for treatment of the world's children. Article 19(1) states that children must be protected from 'all forms of physical or mental violence' while in the care of parents and others (UN, 1989). With specific regard to parenting practices and the discipline of children, the policy focus to date within the Irish context has emphasised the importance of increasing parents' knowledge and understanding of their children's behaviour and of identifying and supporting appropriate parental responses to problematic child behaviour. As mentioned above, the establishment of the Family Support Agency in 2003 represents a significant and positive move towards promoting and supporting information about a range of family issues, including parenting. Moreover, in keeping with recommendations arising from the National Children's Strategy, a number of initiatives have been taken in relation to developing quality parenting programmes. Such initiatives include the piloting of parent support services throughout the country by the Health Service Executive (or Health Boards, as they were at that time) and the establishment of family resource centres nationwide.

These developments seek to place greater emphasis, therefore, on supporting parents in terms of effectively dealing with child behaviour problems, rather than promoting a ban on practices such as the physical punishment of children. Notwithstanding this, a number of significant legislative changes related to the physical punishment of children have been documented within the last decade. Three key changes are noted in Ireland's Second Report to the UN Committee on the Rights of the Child (National Children's Office, 2005), as follows:

- Section 12 of the Criminal Law Act, 1997 abolishes the power of a court to impose a sentence of corporal punishment;

- Section 246 of the Children Act, 2001 makes it an offence for a person who has custody, charge or care of a child to wilfully assault or ill-treat a child;

- Section 24 of the Non-Fatal Offences Against the Person Act, 1997 abolishes the common law rule under which teachers had immunity from criminal liability for physically punishing pupils.

At present, the physical punishment of children within the home continues to be a legal practice in Ireland, with the common law defence 'reasonable chastisement' serving as a defence to both a criminal prosecution and a civil claim. As pointed out by Shannon (2005), Section 24 of the Non-Fatal Offences Against the Person Act, 1997 provides the only exception to this defence, as it abolishes any rule of law which might provide a teacher with immunity from criminal prosecution with regard to the physical punishment of a pupil. The concept of 'reasonable chastisement' has been challenged within the European Court of Human Rights (Council of Europe, 2007). Specifically, the Court found that the corporal punishment of a young English boy by his stepfather was degrading punishment, in breach of Article 3 of the European Convention on Human Rights (A v. United Kingdom, 1998). While prosecution against the stepfather had failed prior to this in a UK court, the European Court found that the domestic law allowing 'reasonable chastisement' failed to provide children with adequate protection and 'effective deterrence'.

\section{International developments}

A world study on violence against children was carried out in 2004 to investigate the extent to which children were subjected to violence. The study was lead, on behalf of the UN SecretaryGeneral, by Paulo Sérgio Pinheiro who was appointed as Independent Expert and findings and recommendations were presented to the UN General Assembly in October 2006. Recommendations arising from the investigation have set 2009 as the target date for achieving the global abolition 
of the corporal punishment of children. Specifically, the study examined violence against children across a number of settings, including home and family, schools, care and justice systems, the workplace and the community. Key findings include the fact that much violence against children remains hidden because children may be afraid to report incidents of violence and abuse. Moreover, acts of discipline administered through physical and sexual harassment are often considered as acceptable, especially where the physical effects of such acts are not clearly visible. Also highlighted is the fact that 53,000 children are estimated to have died worldwide in 2002 as a result of homicide, most frequently at the hands of parents. With regard to the prevalence of physical punishment in the home, findings from the report estimate that between $80 \%$ and $90 \%$ of children experience such punishment.

Physical punishment of children is currently prohibited in all settings in 18 out of the 47 Council of Europe Member States - namely, in Austria, Bulgaria, Croatia, Cyprus, Denmark, Finland, Germany, Greece, Hungary, Iceland, Latvia, the Netherlands, Norway, Portugal, Romania, Spain, Sweden and the Ukraine (Council of Europe, 2008).

Against this backdrop, there is clearly a need to further explore children's and parents' perspectives on parenting styles and discipline in Irish society. In a national study of parents, children and discipline in Britain, key findings indicated that while in practice a majority of parents use minor forms of physical punishment and a notable minority use severe forms, as a matter of principle, most parents reported only conditional acceptance of physical punishment and do not 'feel good' about hitting their children (Ghate et al, 2003). Similar findings were reported in a Scottish national survey of parental attitudes to corporal punishment, which was carried out when consideration was being given to changing the law in relation to physical discipline (Anderson et al, 2002).

\section{Research context}

Clearly, a gap remains in our understanding of the styles of parenting that parents in Ireland adopt, including discipline and punishment approaches. Most of the available information on parenting and discipline styles comes from studies carried out internationally. A comprehensive review of research literature on the discipline and guidance of children concludes, 'There is no universal recipe for effective discipline and while research findings may seem clear, their application to real life is a different matter' (Smith et al, 2005, p. 162). In order to gain greater insight into family experiences of parenting and discipline, studies in the UK and further afield have explored children's perspectives on parental control and discipline (Stern and Petersen, 1999; Save the Children Scotland, 2000; Horton et al, 2001; Horgan, 2002). Smith et al (2005) point out that while findings from these studies are consistent with the more established literature regarding discipline issues, they do challenge commonly held adult beliefs about the impact and effectiveness of physical discipline on children. This present study aims to address a gap in the Irish research context by exploring children's perspectives on the parenting styles and forms of discipline used by parents in Ireland today.

\section{Aims of the study}

The present study was commissioned by the Office of the Minister for Children and Youth Affairs. The broad aim of the research is to examine parenting styles and discipline from a child's perspective. Specifically, the following questions are addressed:

- What are children's perspectives on the nature of parenting roles?

- What are children's perceptions of the effects of different parenting styles and disciplinary strategies, including physical punishment, on their lives?

- How do children position themselves within the family and what is their understanding of their rights and responsibilities within the family?

- Do children's understanding and perspectives change over time (i.e. as they become older)?

- What are children's perspectives on legislation and policy relating to physical punishment in the home? 


\section{Approach to the research}

Three features underpin the approach to this research study on the perspectives of children with regard to their experiences of parenting styles and discipline:

- Focus on children's perspectives: Much research on children's lives tends to rely on adult perspectives, thus limiting the potential contribution that children themselves can make to furthering an understanding of their lives and needs. Greene and Hill (2005, p. 18) point out that it is important that we avoid merely paying lip-service to the idea of listening to children or exploiting what we learn from children about their lives in ways that meet adult agendas only'. To this end, this study consulted directly with children themselves and invited them to reflect on and express their views about parenting styles in contemporary Irish society.

- Use of qualitative methods and analyses: The study adopts a qualitative approach since the focus is on eliciting children's subjective narratives on their experiences of parenting styles and discipline. In particular, using focus group interviews with children facilitated greater access to their experiences, perceptions and feelings since this method allows children and young people to interact with each other and to be actively involved in the process of the research (Hennessy and Heary, 2005). Focus groups can also serve as an innovative approach to understanding children's experiences from a developmental perspective (Mauthner, 1997).

- Adoption of a developmental perspective to understand children's views: The experiences of children in four age groups were explored, ranging from early childhood to late adolescence. Thus, the study adopted a developmental perspective, looking across these age groups to explore developmental patterns in children's views on parenting styles and discipline. 


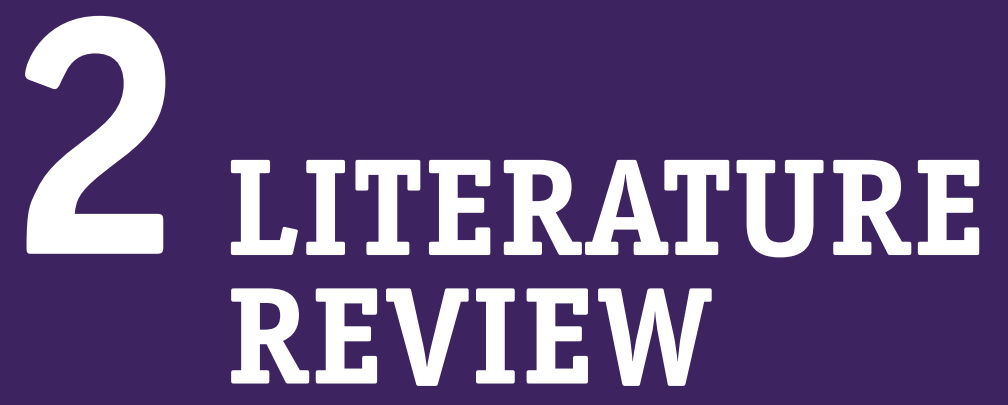


A voluminous body of literature within psychology and social science disciplines clearly attests to the significance of parents in children's lives and the importance of the family as a context for children's development (Parke and Buriel, 1998). This chapter provides an overview of research into parenting and its effects on children's development, discussing the different styles of parenting, parental control and disciplinary techniques, parents' use of physical punishment and the impact on parenting of variations in child characteristics, such as age and developmental status. Finally, to set the research context for the present investigation, a review is presented of the small body of research that has explored children's perspectives on family, parenting roles and parents' use of different disciplinary strategies.

\section{Effects of parents on children's development}

It is generally accepted that the family is a highly influential context for children's development, although peers and other extra-familial influences become increasingly important during early and middle childhood, and adolescence (Parke and Buriel, 1998). Because parents provide a critical environment for children's development, the influence of parenting processes and the quality of parent-child relationships have been a key focus of family research. Furthermore, changes in the demography of the family in many Western societies, coupled with increasing levels of childhood problems, have continued to fuel intensive interest in the topic of effective and responsible parenting (Ramey, 2002).

Early research on parenting effects emphasised the role of parents as models for their children to copy and as disciplinarians and teachers in shaping their children's development. Researchers made clear attempts to understand parenting behaviours and their links to various aspects of child development. While there is no one definitive and comprehensive theory of parenting and how it shapes children's development, clear associations have been found between specific parenting strategies and styles, and various child outcomes (0'Connor, 2002). Two aspects of parenting have emerged from the research as being especially significant. These have been variously described as 'parental responsiveness' and 'parental control' (Symonds, 1939; Baldwin, 1955; Sears et al, 1957; Schaefer, 1959; Baumrind, 1978; Maccoby and Martin, 1983).

\section{Parental responsiveness}

Parental responsiveness refers to the degree of support, warmth and affection that parents display towards their children. Responsive parents praise and encourage their children, while less accepting and unresponsive parents are quick to criticise, punish or ignore their children and are less emotionally available to them. Belsky (1981) has argued that parental warmth and sensitivity to children's needs is the most influential dimension of parenting during infancy, laying the groundwork for healthy development. Warm and responsive parenting has consistently been associated with positive developmental outcomes, such as secure emotional attachments, good peer relations, high self-esteem and a strong sense of morality (Hastings et al, 2000; DeWolff and van Ijzendoorn, 1997; Janssens and Gerris, 1992; Loeb et al, 1980; Ladd and Pettit, 2002).

\section{Parental control}

Parental control refers to the demands that parents place upon their children to be mature and responsible individuals, and the rules and limits that parents set and enforce for their children. The relationship between parental control (also known in the literature as 'parental demandingness') and developmental outcomes is less straightforward than parental responsiveness (see above). While controlling and demanding parents place limits on their children's freedom and monitor their behaviour, less controlling parents are less restrictive and grant children considerable freedom and autonomy.

In recent years, increasing research attention has focused on this 'control dimension' of parenting behaviour, arising from research findings that low levels of parental monitoring and high levels of permissiveness are associated with high levels of problem behaviour (Kerr and Stattin, 2003). 
Indeed, a common theme cutting across studies of delinquency is that parents of such youth tend to have limited knowledge of their children's whereabouts, companions and activities (Patterson and Stouthamer-Loeber, 1984). However, contradicting this, some research indicates that high levels of parental control are not consistently associated with positive developmental outcomes. For example, harsh and inconsistent behavioural control is often associated with antisocial behaviour (Patterson et al, 1989). Together, these findings suggest that parental control is important, but the manner in which it is enforced may influence its effectiveness.

\section{Parenting styles}

The combination of parental control with parental responsiveness is known as 'parenting style'. Research on parenting styles represents the main approach to the study of parent effects on children's development. This typological approach has examined the intersection of the warmth/ acceptance and control dimensions of parenting behaviour, giving rise to four specific parenting styles or clusters of child-rearing practices (see Figure 1):

- The authoritative parenting style is represented by high levels of control and maturity demands, in the context of nurturance and open communication. Discipline usually involves the use of reason and power, but not to the extent that the child's autonomy is severely restricted.

- The authoritarian parenting style, in contrast, is identified by high levels of control and demands of the child, coupled with low levels of nurturance. Authoritarian parents engage in low levels of communication with their children, rarely explaining why compliance is necessary. These parents often engage in strong punitive tactics whenever children deviate from their standards (Baumrind, 1967 and 1968).

- The permissive-indulgent parenting style is characterised by high levels of nurturance and warmth, and low levels of control and maturity demands. This parenting style could be described as an accepting, but lax style of parenting - parents rarely exert control over their children's behaviour and do not closely monitor their activities.

- The permissive-neglectful parenting style is identified by low control and low responsiveness. This style has often been termed 'uninvolved parenting' (Maccoby and Martin, 1983; Teti and Candelaria, 2002).

Figure 1: A two-dimensional classification of parenting styles

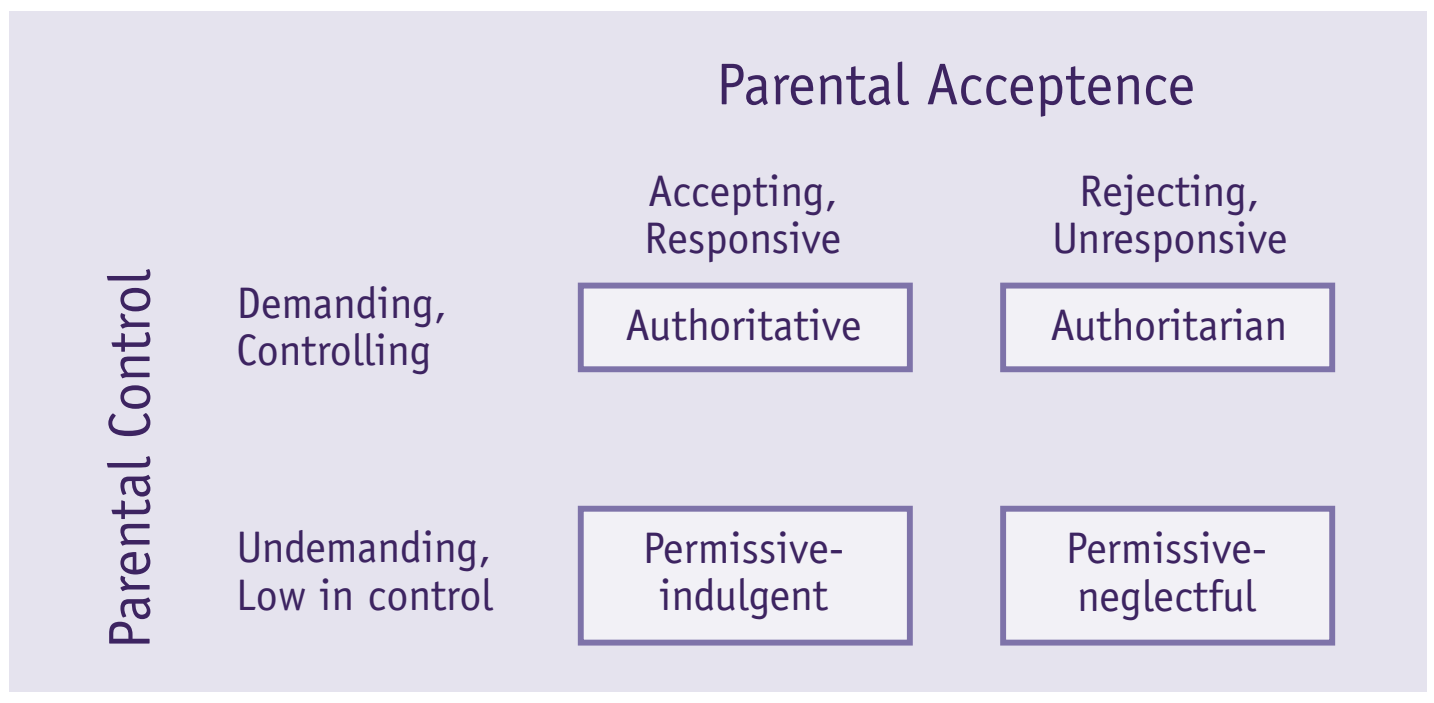

Source: Maccoby and Martin (1983)

Research testing this typology of parenting styles against positive developmental outcomes has been remarkably consistent. The criteria for positive developmental outcomes have, of course, varied somewhat across the studies, but 'model children' have been generally defined in terms of being cooperative, friendly, emotionally stable, dependable, good citizens and good scholars 
(Maccoby, 1992). Children of permissive-indulgent parents exhibit high levels of impulsivity and aggressiveness, and lack self-control and independence (Baumrind, 1967). The uninvolved or neglectful parenting style has been associated with high levels of aggression and externalising anti-social behaviours (Patterson et al, 1992). Thus, the lack of control associated with both styles of permissive parenting affects children in different ways.

In contrast, a plethora of research has indicated that authoritative parenting, combining reasonable demands and control within a responsive and accepting environment, has been linked with positive child outcomes and children's well-being across a range of domains of functioning, such as social competence, behaviour and academic performance (see, for example, Steinberg et al, 1989; Dornbusch et al, 1987). Together, these findings suggest that parental control is important and beneficial to children's development. However, research also consistently indicates that an authoritarian parenting style, also consisting of high levels of parental control but in the context of low support and acceptance (low warmth and lack of clarity of communication), is not well associated with positive developmental outcomes. Thus, the context within which parents achieve appropriate regulation and control appears to be a crucial factor in mediating the effectiveness of parental control.

One caveat is important in interpreting these research findings. Increasingly, it is recognised that what defines optimal development goals for parents may vary depending on the specific culture and context within which parents are raising their children (Arendell, 1997). Indeed, more recent research is questioning the applicability of these parenting styles across different contexts and more consideration is now being given to the diversity of ecological niches within which parents and families are nested (McGroder, 2000; Garcia Coll et al, 1995).

To date, only limited research has explored parenting styles within an Irish context. Greene et al (1995) reported parenting values of sociability, independence and self-direction among Irish parents, and high levels of authoritarian parenting styles.

\section{Parental discipline}

Given the significance of parental control to effective parenting, a complementary line of research has focused on the effectiveness of a range of disciplinary techniques that parents use. Through discipline encounters, parents seek to induce children to behave in accordance with parental standards of appropriate behaviour (Baumrind and Thompson, 2002). Thus, discipline is defined as 'the process of teaching children about appropriate behaviours and societal norms and values'. Underpinning effective discipline is the child's ability to internalise the parent's message underlying the discipline encounter. Internalisation has been defined as 'taking over the values and attitudes of society as one's own so that socially acceptable behaviour is motivated not by anticipation of external consequences, but by intrinsic or internal factors' (Grusec and Goodnow, 1994, p. 4). Kochanska (1993) has suggested that internalisation is the ultimate goal of socialisation and the hallmark of competent parenting: children who internalise their parents' disciplinary messages develop societal standards of conduct and an understanding of right and wrong (i.e. a conscience).

Specifically, three types of disciplinary techniques, and their relation to internalisation and children's development, have been examined (Grusec and Goodnow, 1994; Hoffman, 1970):

- Power assertion refers to the threat or actual use of force, physical punishment or withdrawal of privileges.

- Love withdrawal includes withholding attention, affection or approval, or expressing disappointment or disapproval after a child misbehaves.

- Induction (or other-oriented induction) involves the use of reason and explanation to explain the nature of the misdeed and how it affects the rights and feelings of others.

Hoffman (1970) concluded that neither love withdrawal nor power assertion were particularly effective in promoting internalisation. Induction, on the other hand, fostered moral maturity. According to Hoffman (2000), inductions induce a moderate level of arousal, appropriate for learning. In this state of arousal, the child is more likely to attend to and process the information embedded 
in the parent's explanation. Inductions direct children's attention to the consequences of their behaviour for others and capitalise on children's capacity to feel empathy for another's negative emotion. In contrast, power-assertive and love-withdrawal techniques may over-arouse the child, due to fear of punishment or anxiety about the loss of the parent's love; in this case, the child's attention is likely to be directed to the consequences of the deviant act for the self, rather than for other people. Thus, these techniques contribute to the child's view that the relevant moral standard is external, rather than internal to the self (Hoffman, 1970 and 1983).

Smith et al (2005) highlight the long-term goal of effective discipline as supporting children's development from dependency and external control, to internalisation, ability to take initiative and to be socially responsible. The authors go on to outline six principles or characteristics of effective discipline:

- parental warmth and involvement;

- clear communication and expectations;

- reasoning and setting up logical consequences so that children understand why behaviour is appropriate or inappropriate;

- rules, boundaries and demands for children to internalise rules and limits;

- consistency and consequences;

- being mindful of the contexts in which discipline occurs.

\section{Physical punishment}

One aspect of power assertion that has received particular attention in the literature is the use of physical punishment. Punishment involves the presentation of a negative stimulus following a specific behaviour in order to reduce the likelihood of that behaviour being repeated in the future. Physical punishment encompasses a range of behaviours all of which involve parents' use of physical force directed towards the child. Holden (2002) has highlighted that physical or corporal punishment can range from abusive acts (such as beating) to sub-abusive violence or more commonly spanking and slapping. The majority of the research has focused on the latter, less severe form of physical punishment (slapping), which is also referred to as 'customary physical punishment' (Larzelere, 2000).

Several studies have documented the negative long-term consequences of using physical punishment as a method of family discipline (Smith et al, 2005; Holden, 2002; Straus and Stewart, 1999). One meta-analysis of 92 studies on corporal punishment concluded that physical punishment was only associated with one desirable behaviour - immediate compliance (Gershoff, 2002). Given that most parents seek ongoing as well as immediate compliance, the research indicates that physical punishment is less effective for achieving the goal of ongoing compliance and that there are other unforeseen long-term consequences of physical punishment. This review also provided clear evidence that both parent and child characteristics are important determinants of both the utilisation of punishment and the subsequent effectiveness of punishment (Parke, 2002).

Baumrind (1991) highlights the importance of distinguishing between parents who use physical punishment abusively and those whose use of it is normative in frequency and intensity.

Furthermore, she suggests that while a convincing body of evidence indicates the harm and trauma of physical abuse for children, the impact of what is termed 'non-abusive physical punishment' or customary physical punishment is less well understood (Baumrind et al, 2002; Larzelere, 2000). Her analysis of normative physical punishment indicates that physical punishment was not associated with more detrimental outcomes than verbal punishment, although both types of punishment were associated with poorer developmental outcomes.

An examination of the prevalence of physical punishment remains important from the perspective of the ethics of parenting and children's rights, and the implications for children's well-being. In the National Study of Parents, Children and Discipline in Britain, carried out in 2003 by the Economic and Social Research Council, parents self-reported on the overall incidence of a range of disciplinary 
responses to conflict within the past 12 months and on the prevalence of their use during the child's lifetime (Ghate et al, 2003). Findings indicated that both current attitudes and past childhood experiences and memories of discipline were important in predicting how parents behave with their own children. Over half of the parents who took part in the UK study reported using minor physical punishment (e.g. smacking and slapping) with their child during the past year, while $9 \%$ reported having used severe physical punishment. Parents who employed physical punishment did not do so because of a lack of non-physical alternatives. In fact, they used a greater variety of non-physical disciplinary measures than parents who never used physical punishment. Thus, the report concludes that for many parents physical force is used in child discipline as an adjunct to non-physical methods, not as an alternative. Only 1 in 10 parents found physical punishment 'always' acceptable. Most parents either showed conditional acceptance of physical punishment or rejected it outright, and almost all parents rejected more severe practices, such as hitting with an implement.

One of the arguments frequently raised by adults when encouraged to abandon the threat or use of physical or psychological violence as disciplinary practices is that they have not been provided with better methods. However, findings from the UK study by Ghate et al (2003) cited above do not support this claim. Clarke-Power and Hart (2005) also refute this argument and suggest that constructive, non-violent child discipline is both desirable and available, and should be formulated and applied in a manner that respects human dignity, the rights of the child and child development. According to these authors, child discipline should be an intentional educational process that promotes pro-social behaviour, self-discipline and character development. To this end, they recommend that supportive information, resources and guidance on achieving constructive discipline should be promoted and made readily accessible to families, schools and communities throughout the world.

Research on parenting and discipline in Scotland has indicated that the practice of physical punishment, such as smacking, remains deeply embedded in Scottish parenting culture (Anderson et $a l, 2002)$. The research provides evidence to suggest that, in the course of a generation or so, there have been significant changes in the acceptability of many forms of physical chastisement and that, generally, such punishments are less common and less severe than they once were. However, it also needs to be acknowledged that the specific use of smacking remains very common - up to 8 out of 10 children in the 3-5 age group had been smacked within the past year and about 1 in 5 children of this age within the last week at the time of the study.

Brownlie and Anderson (2006) have indicated that despite anti-smacking campaigns in the UK, the use of physical punishment remains widespread. Permeating parental narratives about discipline was a tendency towards resisting formal instruction or professional guidance in parenting, together with an opposition to State intervention or policies endorsing particular parenting styles. Brownlie and Anderson (2006) suggest that a range of factors, including public opinion, intergenerational trends and the meaning of disciplinary strategies for the parent-child relationship, are integral to our understanding of parents' use of physical punishment. More broadly, Grusec (2002) suggests that the impact of different disciplinary techniques, including physical punishment, depends on a great range of variables (e.g. sex of parent, socio-economic status, nature of the misdeed), as well as a range of child-related variables (e.g. sex, mood, temperament, age and developmental level). In the following section, the impact of child age and developmental level on parenting strategies is specifically considered.

\section{Developmental considerations}

Parenting is increasingly viewed as an interactive parent-child process, rather than solely as a parental action or as 'something that parents do to children'. For example, the effectiveness of a disciplinary technique may depend on how the child perceives the disciplinary message and on the child's willingness to comply with the demands of the parent. Thus, parenting needs to be considered in relation to variations in child characteristics. Of key significance are the age and developmental status of the child, and both are likely, to a very large extent, to influence the concept of 'good parenting' and the effectiveness of various parenting behaviours ( 0 'Connor, 2002). 
Maccoby (1984) has argued that the nature of development constitutes a force to which parents must respond. The changing abilities of the child and the parents' adjustment to those changes in the child's behaviour mean that certain changes occur in parent-child interactions that are significant to the relationship and to the parenting role (Collins and Madsen, 2003). For example, during the transition to adolescence, teenagers seek to achieve a sense of independence and autonomy, and to differentiate themselves from the person they were in the parent-child relationship (Cooper et al, 1983). The shift from a structure of unilateral authority, typical of the parent-child relationship, to one of cooperative decision-making and co-regulation of behaviour facilitates the separation process. However, the period of adolescence may be marked by temporary disturbances in the family systems, as discrepancies emerge between parents' and adolescents' expectations about boundaries. While these perturbations are by no means inevitable, it is mainly when parents become overly lax or overly permissive and uninvolved that adolescents are likely to experience distress and perhaps rebel (Steinberg and Silk, 2002). Changes in the parent-adolescent relationship have implications for how parents regulate and monitor their children's activities. As children become older, they generally spend less time at home and parents must supervise from a distance, collaborating with their children to establish appropriate rules and boundaries about their behaviour (Maccoby, 1984).

Also of relevance is research that has reported how parenting discipline practices appear to vary according to the age of the child. A number of studies have documented that younger children are more likely to be physically punished than older children (Nobes and Smith, 1997; Dietz, 2000; Wissow, 2002). Other disciplinary strategies (such as time-out, deprivation of privileges and induction) are more commonly used with older children than with younger children (Wissow, 2002). Maxwell (1995) reported that New Zealand parents of younger children were more likely to use timeout or physical punishment and less likely to use induction than parents of older children. It has been suggested that physical punishment peaks during toddlerhood and the early childhood years due to the high levels of activity, exploration and drive for independence characteristic of these developmental stages (Durrant et al, 2003). Thus, developmental status represents an important context for parenting behaviour.

\section{Researching children's perspectives}

Strikingly absent from the extensive literature on parenting and parent-child relationships (including parental use of physical discipline) is a focus on children's experiences and perspectives. James (2003) suggests that children's perspectives on parents are an absent presence in the literature and it is only when parenting is under threat in some way that children's views are sought. However, since the beginning of the 1990s, ontological shifts in our concepts of children and childhood have resulted in the gradual inclusion of children's experiences in research agendas (Greene and Hogan, 2005). Sociologists of childhood have argued that childhood should no longer be viewed as a universal and unvarying experience for all children (James, 1998). Children are increasingly recognised as agents in their 'being', rather than as unformed entities in transformation towards adulthood or 'becomings' (Knapp, 1999). Thus, the child is thought of as a person, a social actor, and does not have to be approached from an assumed shortfall of competence, reason or significance (James et al, 1998). This conceptualisation of children and childhood has implications for the way in which research with children (rather than on children) is conducted.

Thus, a model of the child as research partner, whose own experiences, views and understandings are afforded a prominent position, has begun to seep into the research (Hogan et al, 1999). It is interesting to note that these shifts are also beginning to occur in parenting and parent-child relationship theory and research. For example, as highlighted previously, recent theoretical and empirical advances have indicated that 'parenting' is no longer understood as 'something that parents do to children'. Indeed, the effectiveness of parenting styles can more usefully be conceptualised as a transactional bi-directional process, influenced by the nature and quality of the parent-child relationship (Crouter and Booth, 2003). Moreover, reconsidering children as agents 
within their family has indicated that parenting actions relating to control and discipline cannot be considered in isolation from the nature of the parent-child relationship, the child's actions and the developmental context. For this reason, transactional models are best suited to capture the dynamic nature of parenting effects, to examine the importance of children's developmental stages with regard to parenting styles, and how children understand and make sense of their relationships with their parents. Therefore, children's perspectives on parenting have much to offer our understanding of parenting processes.

It is also interesting to note that shifts in how childhood and children are conceptualised within various academic disciplines are increasingly reflected in the policy domain. Relating to this, the United Nations Convention on the Rights of the Child (UN, 1989), ratified by Ireland in 1992, is of major significance. Particularly relevant to research with children is the Convention's Article 12, which states that: 'States Parties shall assure to the child who is capable of forming his or her own views the right to express those views freely in all matters affecting the child, the views of the child being given due weight in accordance with the age and maturity of the child.' Furthermore, Ireland's National Children's Strategy (Department of Health and Children, 2000) was developed to provide clear directions to all those concerned with advancing the status and quality of children's lives in Ireland. Specifically, one of a number of national goals for children reflects the Convention's Article 12 and states that 'Children will have a voice in matters which affect them and their views will be given due weight in accordance with their age and maturity.' Another national goal states that 'Children's lives will be better understood; their lives will benefit from evaluation, research and information on their needs, rights and the effectiveness of services.' Policy developments such as these have contributed to a growing appreciation of the need to focus explicitly on children's perspectives and experiences (Hogan et al, 1999).

\section{Children's perspectives on family and parenting roles}

Within most family research (including much of the research reviewed earlier in this chapter), children have been assigned a position as dependents. Only a handful of studies have explored children's perspectives on family and parenting roles (Nixon et al, 2006; Morrow, 1998; 0'Brien et al, 1996) and their experiences of transitions in family life (Hogan et al, 2002; Smart et al, 2001). A number of qualitative studies have explored children's evaluations of various family configurations. For example, a study based in New Zealand found that over $80 \%$ of its adolescent sample endorsed single-parent households (both mothers and fathers), cohabiting parents, extended family members and same-sex parents and children as families (Anyan and Pryor, 2002). Legal status and the presence of two parents were not important criteria to children at this age, perhaps reflecting adolescents' capacity to think beyond formal bonds and structural features. More recently, Rigg and Pryor (2006) revealed similar levels of acceptance of a range of family forms among a sample of younger children (mean age 11.9 years). A number of UK-based studies have employed vignette methodologies to examine children's acceptance of a variety of family forms (O'Brien et al, 1996; Morrow, 1998). Findings from these studies highlight the centrality of roles and relationships within the family, with less significance accorded to the structure of the family. Similarly, a 2006 study exploring Irish children's concept of 'family' indicated that the way in which family members cared for and loved each other represented key defining features of the family (Nixon et al, 2006).

In terms of children's understanding of parenting roles, research indicates that children have specific ideas about parenting roles within the family (Brannen et al, 2000). In this study, most children suggested that mothers and fathers were equally important despite some differences in terms of roles and relationships. Mothers were providers of emotional support, whereas fathers were described in terms of helping children in the 'outside world'. Morrow (1998) also highlighted the emotional significance of the mother's role. Hendricks (1999) explored New Zealand children's perspectives on fathers, using a range of qualitative methods. Overall, children viewed fathers as contributing positively to their lives in a number of ways. Moreover, children's perspectives on fathers did not adhere to stereotypical roles, with many children reporting that fathers provide emotional support and engage in household chores. 
Drawing on data from an Irish study of children's concept of 'family', Nixon et al (2003) reported age-related differences in how mother and father roles are understood within the family. Thus, younger children (aged 8) described mother roles in terms of caring, meeting a child's basic needs and carrying out household duties. In contrast, the roles of playmate and breadwinner were important descriptors of father roles. These views appear to reflect the traditional gendered division of labour in Irish households. Among older children in the study, however, there was less of a focus on instrumental care-giving roles and roles were interchangeable between mother and father.

Apart from this study by Nixon et al (2003), there has been limited research exploring concepts of family and parenting roles among Irish children and young people. Moreover, while Nixon et al and other studies cited above considered children's perspectives on parenting roles, their views relating to parenting styles and various dimensions, such as discipline, control, nurturance and monitoring, remain unexplored, particularly within the Irish context. This represents a significant gap in our understanding of family life and parenting within contemporary Ireland.

\section{Children's perspectives on physical punishment}

A small number of studies have specifically examined children's views on parents' use of physical punishment as a form of parental control and discipline. Willow and Hyder (1998) reported that children aged 4-7 responded negatively to being smacked and believed that smacking was wrong. In a survey of over 300 children and young people in Scotland (aged 6-17), adjectives such as 'terrified', 'humiliated' and 'unloved' were used to describe their responses to physical punishment (Save the Children Scotland, 2000). Overall, this research indicates that children view the use of physical discipline as wrong, ineffective and physically and emotionally harmful. Furthermore, confusing messages about the use of violence are conveyed to children. A small qualitative study on children's views on physical discipline carried out in New Zealand suggested that children reported negative emotional responses to such punishment, which affected their relationship with the person implementing the punishment. In addition, the children expressed some levels of confusion in assimilating their own beliefs that physical punishment was wrong with the fact that their parents carried out such punishment. This small body of research indicates that an exploration of physical discipline through the eyes of children rather than adults is necessary and important (Holden, 2002).

\section{Conclusion}

This chapter has broadly considered the way in which parents influence their children's development. There is general consensus that an authoritative parenting style and the use of inductive forms of discipline are reliably linked to positive developmental outcomes. However, research also indicates that parents frequently engage in less than optimal forms of parenting, such as using physical punishment. Furthermore, the limited body of research that has explored children's views on parents' use of different disciplinary strategies indicates that children consider the use of physical punishment as harmful to children. Clearly, there is a need for greater understanding of children's perspectives on these issues.

At present, a significant gap exists in our understanding of how children in Ireland reflect on and experience different styles of parenting. Exploring children's perspectives on parenting is consistent with contemporary models of parenting and parent-child relationships, which indicates that how children make sense of their parents' actions and roles may help to account for developmental trajectories between family dynamics and child outcomes. Furthermore, parenting and parentchild dynamics are nested within a developmental context, where the effectiveness of particular parenting behaviours, and the way in which children affect the dynamic of the parent-child relationship, is likely to change as children get older. Therefore, the adoption of a developmental perspective to explore children's understanding of parenting styles and discipline represents an important aspect of the present study. 


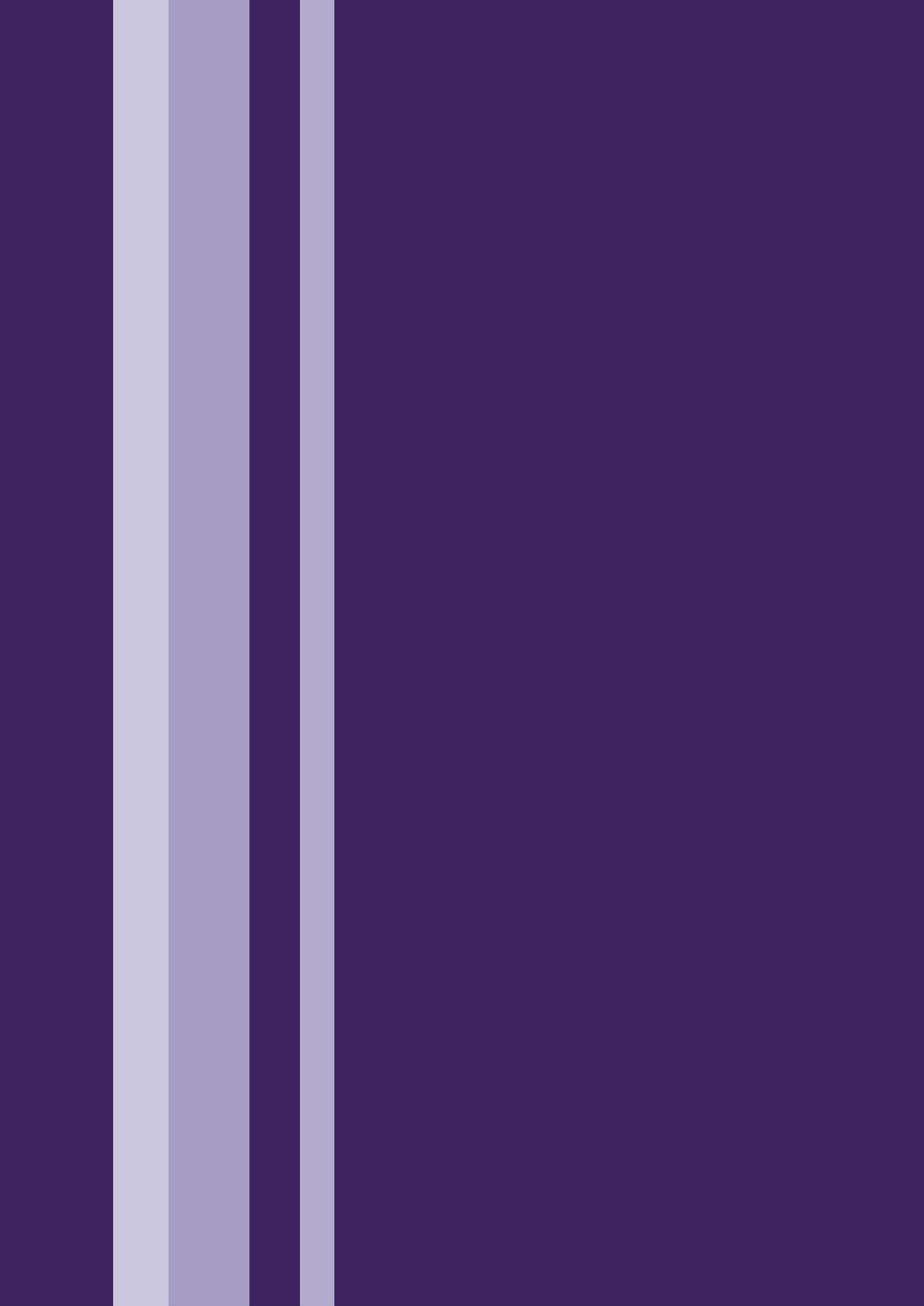


METHODOLOGY 
The methodology adopted for the present study was influenced directly by the core objective of the research, which was the exploration of children's and adolescents' perspectives on parenting styles and parents' use of discipline. Specifically, the research sought:

- to explore children's perspectives on the nature of parenting roles;

- to investigate children's perceptions of the effects of different parenting styles (including parental care and responsiveness) and disciplinary strategies (including physical punishment) on their lives;

- to examine how children position themselves within the family and their understanding of rights and responsibilities within the family;

- to explore children's perspectives on legislation and policy relating to physical punishment in the home;

- to identify patterns in how children's understanding and perspectives change over time (i.e. as they become older).

Given the paucity of previous research into children's perspectives on this issue, the study was essentially an exploratory investigation. A qualitative approach was adopted, where the emphasis was on gaining insight into understanding and perceptions of parental roles and behaviour among children and young people aged between 6 and 17 years. A key outcome of the research is to provide policy-oriented knowledge in relation to children's perspectives on parenting styles and discipline, and physical punishment in particular.

\section{Qualitative approach}

Qualitative research approaches, where subjectivity is valued and participants' accounts are privileged, are increasingly being used to access children's perspectives on issues relevant to their lives (Morrow, 1998; Hill et al, 1996; Greene and Hogan, 2005; Coyne et al, 2006). According to Hogan (1996), a qualitative approach is characterised by openness and inclusiveness, and eliminates many of the constraints imposed by pre-structured quantitative methods and methodologies. As such, adults' expectations and assumptions are set aside in order to pave the way for immersion in children's worlds of meaning and understanding. Within this child-centred qualitative approach, children and young people are positioned as expert informants who can contribute to adults' understanding of important issues, such as parenting, that affect children's lives.

This study of children and adolescents' perspectives on parenting styles and discipline bestowed the status of 'expert' on the young people participating in the research. Furthermore, the use of a qualitative research strategy offered a flexible and open lens through which children's perspectives could be accessed in a rich and meaningful way.

\section{Sampling approach and recruitment}

The approach to sampling did not specifically strive to recruit a nationally representative sample of children and adolescents. Rather, the aim was to recruit a sample of children from different backgrounds to facilitate exploration and representation of a range of experiences. The sample was accessed through primary and secondary schools in three counties in Ireland (Dublin, Westmeath and Monaghan).

Initially, letters were sent to the Principals of 7 primary schools (2 in Westmeath, 2 in Monaghan and 3 in Dublin), informing them about the study and asking whether they would be interested in facilitating the fieldwork phase. These schools were randomly selected from lists of primary schools within each of the counties. Mixed-sex schools were specifically targeted to reduce the overall number of schools that would be needed to ensure a sample of boys and girls. Follow-up telephone-calls with school Principals involved further discussion of what facilitation would entail (i.e. distributing letters of consent and information sheets to parents of children in the school, and allowing the focus groups to be conducted in school during school time). Four schools (2 in Westmeath, 1 in Monaghan and 1 in Dublin) refused the invitation, while 3 schools (1 in Monaghan and 2 in Dublin) agreed to facilitate the study. The reasons for refusal included: parents would not be interested in the study; the research would be disruptive to the school routine; space in the 
school was in short supply; and in two cases, permission had not been granted from the Board of Management of the school. Of the schools that agreed to facilitate the research, one was a junior primary school (from junior infants to 1st class children) and one was a senior primary school (from 2nd to 6th class children). The third primary school had classes from junior infants to 6th class.

Letters were also sent to the Principals of 5 secondary schools ( 1 in Westmeath, 1 in Monaghan and 3 in Dublin). Two of the Dublin secondary schools were single-sex schools (one was an allboys school, the other all-girls), while the remaining 3 secondary schools were mixed-sex schools. Following telephone calls with the school Principals, 4 of the 5 secondary schools agreed to facilitate the research. Both the Westmeath and Monaghan secondary schools, and 2 of the Dublin secondary schools (one mixed and one all-boys) agreed to facilitate the research.

Following agreement with the Principals, information packs were distributed to parents of the children/adolescents in selected classes in each of the schools. In one school, a Transition Year teacher explained about the study to her class and information packs were distributed to those students who expressed an interest. Each pack contained an information sheet about the study, a letter requesting parental consent to allow the researchers to invite their child to participate in the research and a consent form to be signed (see Appendix 1). Appended to each consent form was a brief questionnaire requesting parents to supply basic socio-demographic details about their family (e.g. family structure, ethnicity and socio-economic status).

Table 1 illustrates the approximate number of letters distributed within each of the schools and the corresponding number of children/adolescents who participated. These figures suggest an overall positive response rate of $37.9 \%$, although there was some variation in the response rate across the different schools.

Table 1: Details of response rates according to source of contact

\begin{tabular}{|l|c|c|}
\hline Source of contact & $\begin{array}{c}\text { Approximate no. of } \\
\text { letters distributed }\end{array}$ & $\begin{array}{c}\text { No. of } \\
\text { participants }\end{array}$ \\
\hline Monaghan primary school (1st class and 4th class) & 65 & 38 \\
\hline Dublin Junior primary school (1st class) & 60 & 12 \\
\hline Dublin Senior primary school (4th class) & 54 & 14 \\
\hline Westmeath secondary school (Transition Year) & 4 & 4 \\
\hline Monaghan secondary school (1st year and Transition Year) & 94 & 39 \\
\hline Dublin secondary school 1 (1st year and Transition Year) & 54 & 6 \\
\hline Dublin secondary school 2 (1st year) & 60 & 19 \\
\hline Total & 348 & $132^{*}$ \\
\hline
\end{tabular}

* This figure closely resembles the number of signed consent forms returned to the school. In a small number of cases, consent forms were returned, but the children were absent from school on the day of fieldwork.

Two researchers visited each school to conduct the fieldwork. Children and adolescents who had returned parental consent forms to the school were gathered together in a designated room in the school. The purpose of the study and the nature of participation were explained to the children/ adolescents and they were invited to take part in a focus group discussion. It was emphasised that they were free to return to class and not to participate in the study if they so wished. All children who returned parental consent forms and who were in school on the day of the fieldwork were happy to participate and signed consent forms to this effect (see Appendix 2).

\section{Data collection method}

The research method for the study comprised focus group discussions. According to Hennessy and Heary (2005, p. 236), 'a focus group is a discussion involving a small number of participants, led by a moderator, which seeks to gain an insight into the participants' experiences, attitudes and/or perceptions.' While initially dominant in the area of applied market research, the past two decades 
have witnessed an increased interest among social scientists in focus groups as a qualitative research method (Kreuger, 1994; Morgan, 1996).

Previous research has indicated that focus groups represent an effective research method by which various issues can be explored with children and young people within a peer group setting (Heary and Hennessy, 2002; Morrow, 1998; Nixon et al, 2006). The use of focus groups with children acknowledges children as experts and key informants on their experiences (Levine and Zimmerman, 1996). A plethora of studies have used focus group methods to gather data effectively from children and young people on a range of issues, even sensitive ones. These studies include children's views of alcohol and their awareness of the consequences of its use (Houghton et al, 1998); children's understanding of HIV/AIDS (Peltzer and Promtussananon, 2003); adolescent smokers' experiences of nicotine dependence (0'Loughlin et al, 2002); and perceptions and activities of children with asthma (French et al, 1998). Furthermore, focus groups have also been employed in a series of studies relating to children's perspectives and experiences of family life, which tapped into issues similar to the ones addressed in the present study (Nixon et al, 2006; 0’Brien et al, 1996; Morrow, 1998).

Methodologically, focus group interviews with children and young people present both advantages and disadvantages (Hennessy and Heary, 2005; Basch, 1987). The support offered to individuals in a group setting may facilitate greater openness and exploration of issues than would be possible through individual interviews. Furthermore, individuals are not under pressure to respond to every question (Basch, 1987). Of particular relevance to conducting research with children, the adult-child power dynamic typical of the one-to-one interview becomes more balanced in a group setting (Hennessy and Heary, 2005). Furthermore, focus groups replicate the small group settings that children are familiar with in their classroom (Mauthner, 1997). Focus groups are not, however, without disadvantages, although many of these criticisms have not been supported by empirical evidence (Hennessy and Heary, 2005). Lewis (1992), for example, highlights the possibility of responses being influenced by peer pressure, while Kitzinger (1994) suggests that individuals may be unwilling to share sensitive personal information within a group setting. However, in the present study, given the interest in children's perspectives and understanding rather than their personal experiences per se, this latter disadvantage may be less relevant.

A total of 30 focus group interviews were conducted, with 132 children and adolescents, ranging from 6 to 17 years of age. All focus groups were conducted in the schools by either the two researchers on the study or by one researcher and a research assistant. Within each group, one researcher adopted the role of Moderator and directed questions to the group on the topic of interest. The second researcher adopted a less active role in the group and was not the primary interviewer; rather her role was to observe the group dynamic, monitor the contributions of children to ensure that all respondents got a chance to contribute to the discussion, and seek clarification on specific issues when necessary. The focus groups ranged in length from 20 to 45 minutes and were recorded using a digital recorder.

In terms of group composition, the size of the focus groups ranged from 3 to 8 individuals. Seven of the groups consisted of only 3 children or adolescents, while half of the groups had 5 or 6 participants. With respect to other aspects of group composition, Hennessy and Heary (2005) recommend that homogeneity of age and gender is best; however, they further qualify this by remarking that these guidelines are based mainly on the experiences of authors rather than on the rigorous investigation of factors that facilitate or constrain fruitful group discussions. In order to deal with developmental differences, many authors recommend that participants in a group should be within a 2-year age span to avoid imbalance within the group in terms of ability and needs. All focus groups in the present study contained children from the same class in school and there was no more than a one-year age span within each group.

In terms of the gender composition of the focus groups, Mauthner (1997) suggests that single-sex focus groups work best. However, when children are familiar with each other, mixed-sex groups may work well (Hill et al, 1996). In the present study, 17 of the focus groups were mixed-sex and 13 were single-sex groups. The decision pertaining to the gender composition of the groups was largely driven by the logistics of conducting the focus groups within the constraints of the school 
setting. To minimise disruption, each focus group consisted of children from the same class; thus while this ensured that there were no large age discrepancies within any group, it was not possible to arrange single-sex groups all of the time. However, it was considered that these mixed-sex groups could work as well as single-sex groups because these boys and girls were already from the same class and so were familiar with each other.

\section{Focus group 'Topic Guide'}

The topic guide for the focus groups was organised under a number of general areas and participants were not asked about details of their own family circumstances or their own parents. The following broad issues were discussed, with further details given in Appendix 3:

1. Roles in the family, particularly mother and father roles and distinctions between them.

2. Care and support in the family, including how parents respond to and are sensitive to children's needs.

3. Control in the family, including how parents monitor and discipline their children.

4. Parental strategies of punishment, including 'acceptable' forms of punishment and methods of verbal and physical punishment.

5. Perceptions of the effectiveness and impact of different parenting strategies and the factors associated with their use.

6. Perspectives on the comparison between childhood and parenthood, and rights and responsibilities in families.

It is important to note that the focus groups did not proceed through a rigid sequencing of question-and-answer exchanges. Also, the discussion was not wholly constrained by the structure of the individual schedule. Thus, while children's stories and ideas not directly related to the topic under discussion sometimes dominated the sessions, each of the broad topic areas outlined above was addressed within each of the groups.

\section{Socio-demographic questionnaire}

General baseline data relating to the children's family backgrounds were collected by means of a brief questionnaire ( 4 questions) addressed to parents. This was appended to the parental consent form (see Appendix 1). Overall, it was considered that it would be more appropriate to try to elicit this information from adults rather than children, given the group context of the researchers' contact with participants. All parents who consented to their children participating in the study completed the brief questionnaire.

The questionnaire sought information from parents on household composition/family structure; country of origin of children and parents; and current occupation of main wage-earner in the home (to determine social class). Alongside this information, the child's age and gender were recorded. This information was important in providing a general profile of the family contexts of the children and young people who participated in the study. The purpose of eliciting this information was not to link individual responses of children directly with their own family backgrounds.

\section{Ethical issues}

Procedures relating to ethical issues (such as informed consent, confidentiality and privacy) and ensuring children's safety and well-being were salient issues throughout the research process. The Children's Research Centre's General Guidelines for Good Research Practice with Children (Whyte, 2006) underpinned the research and the study was subject to review and approval by the Ethics Committee within the School of Psychology, Trinity College, Dublin. Each of the main ethical issues is now considered.

\section{Informed consent}

Accessing children and young people's views through research involves a process of gaining the consent of gatekeepers (such as school Principals) and parents, and then the children and young 
people themselves. In the present study, it was essential that parents' permission was sought for children's participation in the research process and researchers only approached particular children to inform them about the study and invite them to participate on receipt of a signed parental consent form. Children were given sufficient opportunity to opt in or out of the study and it was emphasised to them at the outset, as well as in the 'Information Sheet for Children' (see Appendix 2), that they were free not to participate in the study and that they may withdraw their participation at any time. It was also emphasised to the children that they would not be asked specifically about their own family experiences during the focus group discussions. All children whose parents had given consent for their child's participation and who were present in school on the day of the fieldwork agreed to take part.

\section{Confidentiality and limits to confidentiality}

A number of issues concerning confidentiality arise when involving children in focus group discussions. In the present study, although it was explicitly stated that children would not specifically be asked about their own family experiences, it was clear throughout the discussions that they drew heavily upon their own experiences. Thus, as other researchers have documented, children moved back and forth between normative general accounts and experiential accounts of parenting (Mayall, 2001). Therefore, although information about specific families was not directly elicited, it was clear that their own family experiences served as key contexts for their perspectives on parenting generally.

In the context of a focus group, confidentiality could not be absolutely guaranteed since disclosure of perspectives and experiences by participants is shared with all group members. However, children were requested at the beginning of every focus group to respect the privacy of the group discussion and not to discuss what had been said with others outside the group. This aspect was also covered in the 'Information Sheet for Children' (see Appendix 2). Furthermore, it was acknowledged that involvement in a focus group discussion may potentially cause upset to some participants. In the event of a child becoming upset, procedures were in place to intervene, whereby the Moderator would leave the focus group with the child and call the issue to the attention to the child's teacher or parent. Finally, participants were informed that publications or presentations based on the research would not contain any identifying information and their names would be changed to preserve anonymity.

Further limits to confidentiality emerge in instances where children and young people disclose information that indicates that they or others may be at risk of child abuse. Also, other issues may arise during discussions that generate worry or concern for the researchers about the safety and well-being of a child. Thus, in the present study, it was explained to the children that in the event of such a disclosure, appropriate measures would have to be taken (such as informing a teacher or parent/guardian); however, children were re-assured that no action would be taken without first consulting with them.

Given the topics covered in the focus groups (see Appendix 3 ) and particularly the questions relating to children's perspectives on physical punishment, the researchers were particularly aware of the possibility that in the course of the discussions on physical punishment, children could disclose parenting behaviours that indicated they were being physically harmed in some way. The publication Children First: National Guidelines for the Protection and Welfare of Children served as a guideline for procedures in terms of noting and recording incidents of abuse (Department of Health and Children, 1999). Throughout the course of the focus groups, the researchers were required to make a reasonable judgement about whether the children's accounts of physical punishment involved excessive force in handling. No concerns relating to physical abuse of any of the participants arose.

\section{Profile of children}

In total, 30 focus groups were conducted with 132 children, aged 6-17, from primary and secondary schools. Response rates across the 4 different class groups varied: 9 focus groups were conducted with children in 1st class; 5 focus groups with children in 4th class; 10 focus 
groups with children in 1st year; and 6 focus groups with students in Transition Year. The gender composition of the sample was almost equal, with 67 boys and 65 girls.

Table 2 illustrates the number of boys and girls across the 4 class groups who participated in the focus groups.

Table 2: Number of participants, by gender and class group

\begin{tabular}{|l|c|c|c|}
\hline Class group & Boys & Girls & Total \\
\hline 1st class & 15 & 21 & 36 \\
\hline 4th class & 14 & 14 & 28 \\
\hline 1st year & 29 & 15 & 44 \\
\hline Transition Year & 9 & 15 & 24 \\
\hline
\end{tabular}

Table 3 shows the age profile of the participants by class group. Overall, the ages of the participants ranged from 6 to 17 years.

Table 3: Age profile of participants, by class group

\begin{tabular}{|l|c|c|c|}
\hline Class group & Minimum age & Maximum age & $\begin{array}{c}\text { Mean age } \\
\text { (s.d.) }\end{array}$ \\
\hline 1st class & 6 & 8 & $\begin{array}{c}6.89 \\
(0.46)\end{array}$ \\
\hline 4th class & \multirow{2}{*}{9} & 11 & $\begin{array}{c}9.68 \\
(0.54)\end{array}$ \\
\hline 1st year & 12 & 14 & $\begin{array}{c}12.81 \\
0.50)\end{array}$ \\
\hline Transition Year & 15 & 17 & $\begin{array}{c}15.83 \\
0.56)\end{array}$ \\
\hline
\end{tabular}

\section{Profile of family backgrounds}

Three aspects of children's backgrounds and family contexts were explored: family structure; whether there was a wage-earner in the family and if so, their occupation; and ethnic background of child and parent. Almost all children ( $85 \%)$ lived with both of their parents $(n=112)$. An additional 3 children (2\%) lived in a two-parent family, where one parent was a step-parent. 17 children lived in a single-parent family: for 10 children (8\%), their parents had separated or divorced, while 7 children (5\%) lived with their single, never-married mother.

In almost all households $(97 \%)$, at least one parent was employed $(n=128)$. In almost $70 \%$ of these families, the main wage-earner was identified as the father $(n=89)$. Only 4 households did not have a wage-earner: 3 of these were headed by a single mother, while the mother in the fourth household was a full-time student. Table 4 shows the main wage-earners within the households.

Table 4: Identity of main wage-earner within the households

\begin{tabular}{|l|c|c|}
\hline Identity of wage-earner & Frequency & $\%$ \\
\hline Father & 89 & 67.4 \\
\hline Mother & 26 & 19.7 \\
\hline Both parents & 12 & 9.1 \\
\hline Step-father & 1 & 0.8 \\
\hline No wage-earner in household & 4 & 3.0 \\
\hline
\end{tabular}


The occupation of the main wage-earner within each household was classified into one of 7 social class groups, as outlined by the Central Statistics Office. Where both parents were identified as wage-earners within the family, the individual whose occupation was ranked higher was selected for that family. As seen in Table 5, over one-third of the sample was classified in the higher professional and managerial/technical social classes. Just over one-fifth of the sample was categorised in the semi-skilled and unskilled social classes.

\section{Table 5: Social class classification of families}

\begin{tabular}{|l|c|c|}
\hline Social class & Frequency & $\%$ \\
\hline Professional workers & 6 & 4.5 \\
\hline Managerial and technical & 41 & 31.1 \\
\hline Non-manual & 13 & 9.8 \\
\hline Skilled manual & 34 & 25.8 \\
\hline Semi-skilled & 23 & 17.4 \\
\hline Unskilled & 5 & 3.8 \\
\hline All others gainfully occupied, and 'unknown' & 10 & 7.6 \\
\hline
\end{tabular}

Finally, in terms of country of origin of children and their parents, the majority of the sample $(93 \%)$ were Irish $(n=123)$, while 5 children were of Eastern European origin and 3 children were of African origin (see Table 6).

Table 6: Country of origin of parents and children

\begin{tabular}{|l|c|c|}
\hline Country of origin & Frequency & $\%$ \\
\hline Irish* & 123 & 93 \\
\hline Other Western European & 1 & $<1$ \\
\hline Of African origin & 3 & 2 \\
\hline Of Eastern European origin & 5 & 4 \\
\hline
\end{tabular}

* Two of the Irish children came from mixed-race marriages, but both had Irish mothers and had been raised in Ireland.

\section{Data analysis}

The discussions in all focus groups were transcribed verbatim and prepared for coding and analysis. Initially, analysis involved thorough and repeated readings of the data in order to gain an overall sense of the key findings. Transcripts were broken down into smaller meaningful chunks of data by a process of open coding, and themes relating to behaviour, attitudes, feelings, etc. were identified and collated (Braun and Clarke, 2006). Themes were refined by the method of constant comparison as analysis progressed and new concepts and the characteristics that comprised them emerged. The coding and analysis was conducted as a joint activity by the two researchers to facilitate the transparency of the interpretive work inherent in qualitative analysis.

The findings are presented in Chapters 4-6. The perspectives of the children and young people are illustrated throughout by the use of quotations taken direct from the transcripts. These are reproduced with minimal editing in order to represent the spoken word. Names are not used in the text, but the class group and, in most cases, the gender of the child is identified. 
4 parenting roles 
Children's descriptions of parenting roles are discussed here, including the distinct, yet interchangeable nature of mother and father roles, and their understanding of how these roles change over time. As a starting point for the focus groups, children were asked to reflect on parents' roles in a family. In describing the myriad of functions that parents were expected to perform, the nature of mother and father roles were elucidated separately, highlighting both unique and similar features. What emerged clearly from the analysis of the children's narratives is that there is no standardised pattern for how parenting roles are played out within Irish families. Instead, the roles that parents perform are associated with structural features of the family, such as household composition and work circumstances, and in some instances are clearly linked to the age and gender of the child.

\section{What parents do}

The starting point for this analysis was an exploration of children's descriptions of what parents do in a family. Following a review of the responses, eight themes were identified - sustenance and basic care-giving; protection; breadwinning; guidance; authority; emotional support; shared activities; and facilitating autonomy. Each of these is explored below.

\section{Sustenance and care-giving}

'They give you shelter and food.' [1st year, boy]

A key function fulfilled by parents is the provision of sustenance to their children. Sustenance parenting acts are those that are designed to promote survival and biological integrity, such as the provision of nutrients, shelter and conditions for the maintenance of health (Bradley, 2002). In addition to general descriptions such as 'taking care of the family' and 'looking after us', children provided numerous examples of basic care-giving acts carried out by parents. These could be grouped broadly into three categories: provision of food, promotion of health and provision of an adequate home. By far the most common description of basic care-giving was the provision of food and nourishment to children. Children in all groups referred to the parents' role of cooking for and feeding their children: 'Parents have to take really good care of their children ... give them healthy food' [4th class, boy].

A second sub-theme related to children's health and the parents' role in looking after children if they are sick or have an accident. Children described how if they were sick, parents would bring them to the hospital or doctor, or give them medicine. Also, in the event of an accident, it was a parent's job to make the child feel better and attend to any injuries, as this exchange with girls in 1st class illustrates:

Researcher: How do parents look after their children?

C1: 'By feeding them and if they fall they normally put a plaster on them.'

C2: 'If they fall, like if I fall off my bike my mam will just run out and put, get me up.'

C3: 'They'd look after you to make sure you don't fall or anything.'

Finally, children described parents' role in providing a home and shelter for them - 'a roof over your head' - and ensuring that children were clean, warm and comfortable. Related to this, a range of housekeeping tasks emerged which children expected parents to perform. These included cleaning the house, doing the dishes and laundry, tidying up and, more generally, having responsibility for running of the household: 'Keep them clean and make sure they're comfortable' [4th class, boy].

\section{Protection}

'You know that you're safe with them.' [1st year, girl]

A second key role fulfilled by parents was that of protection and security. Children described the parents' role in keeping their children safe and ensuring they are not in danger. Younger children, in particular, provided examples of how their parents might keep them safe, such as holding their 
hand when crossing the road or keeping a watchful eye over them when in public. These actions on the part of parents were considered important for two reasons: to ensure the child did not have an accident and/or was not kidnapped: 'Say if you were like playing in a park, they would look at you, make sure no one would steal you. And say you were on holidays and went swimming, they would look at you because you might sink and you might die' [1st class, girl].

Older children, on the other hand, described parents as sources of safety and protection in less concrete terms: the focus for them was on feeling safe: 'Look after you and protect you and make you feel safe' [1st year, girl].

\section{Breadwinning}

'Goes out to work to get money, to pay for the house and all the things you need.' [1st class, girl]

The theme of breadwinning referred to the financial support provided by parents as they worked to earn money to buy whatever was necessary to feed and look after the children: 'Go out working and get money to feed the child' [1st year, boy].

In addition to paying for essential items, such as food and a house, children also described how parents buy less essential items for their children, such as clothes, shoes and 'nice things': 'My ma buys me gel when I need it' [1st year, boy].

Related to this theme was the idea of 'working all your life to support your kids' and that it was a parent's responsibility to 'provide for you until you're 18'. Thus, the parent's role as breadwinner was considered as an ongoing role, which was likely to continue into early adulthood.

\section{Guidance}

'To guide their children through childhood, up till they're 18, to make sure like, that after 18 they can behave themselves.' [1st year, boy]

The theme of parents as guides emerged within the two older age categories of participants (i.e. 1st year and Transition Year secondary school students) and in the youngest age category (1st class). Within this 'guidance' theme, parents' roles as teachers and guides for their children were highlighted. Also reflected within this theme were children's perspectives on some of the goals and values that parents have in raising their children. Among the younger group, children described how parents help them learn (e.g. by assisting with homework) and teach them different skills (e.g. cooking, driving and cycling), as seen in the following comments from boys in 1st class:

'If we're starting new sort of sums and for homework, they help us to do them.'

'They teach us. Daddy teaches us and Mammy ... how to drive the car.'

Similarly, a girl in 1st class commented: 'They help you when you're starting to go on, with no retainers on your bike; they kind of give you a head start.'

Among the older children, there was less emphasis on practical help and assisted performance of skills. Instead, adolescents described how parents provided guidance to their children that reflected some of the different values and goals that parents themselves have for their children. Thus, adolescents described parents as moral guides for their children, teaching them 'right from wrong' by setting a good example and talking to them about the parameters of acceptable and unacceptable behaviour, as these boys in 1st year commented:

'Well, parents kind of have to set examples, for like the children.'

'They kind of tell you the way you should be.'

In addition, adolescents also reflected that having good manners and getting a good education were values and goals that parents transmitted to their children, as reflected by this exchange with boys in the Transition Year group: 
Researcher: What do you think the role of parents in a family is?

C1: 'Most parents look out for their kids really and just make sure they get a good education and stay safe and that.'

C2: 'To make sure their kids grow up well and to be mannerly.'

\section{Authority \\ 'They should have like boundaries ... but not too strict.' [1st year, boy]}

The role of parents as figures of authority and control in the family was highlighted in all of the focus groups. While issues pertaining to parental authority and control were separately explored in depth within each of the focus groups (see Chapter 5), authority roles did form part of the general discussion on parenting roles. Within this theme, distinct categories of parental behaviour were described, including monitoring and checking behaviour, setting boundaries, and strategies for disciplining children. The youngest children focused on monitoring activities of parents, such as checking where children are going and instructing them to be home by a specified time. A typical comment was, 'Say when you're going out to play, they ask you where you're going and to be back at a certain time or something like that' [1st class, girl]. Among the older children, there was some focus on parents' checking activities, such as asking questions and checking where the child is going and with whom: 'They ask you who you're going with, see if they know the people you're going with' [Transition Year, girl].

Adolescents described parents as the 'head of the family' and 'authority figures' within the family. Dominant within the adolescent discussions around this theme was the importance of parental control, disciplining children when they behave unacceptably and setting boundaries. Some typical comments from the Transition Year group included:

C1: 'They can't just let you away with murder, you know. They have to know when they have to tell you to stop.'

C2: 'Whenever, like if you're misbehaving or that, they'll just reel you in a bit.'

C3: 'Like if you wanted to go to a disco or go shopping with your friends or something, and if you had to go to like a birthday or something, they'd tell you No and you'd have to go to a family thing.'

C1: 'They should limit you, like where you're allowed to go whenever you're out.'

Thus, parental control was seen as necessary and good within families. Specifically, the use of parental control was considered important to prevent children from engaging in risk behaviour and to keep them safe, as this boy in 1st year said: '... so that they know that they're not going out drinking or doing drugs.'

Within this theme, the importance of fairness and balance also arose in the discussions among the older age group. Thus, while control was important, an appropriate balance between leniency and strictness was endorsed by the children. An ethic of fairness, where children were given a chance to earn trust and negotiate appropriate boundaries, was also considered to be an important feature of parental authority and control. A boy in 1st year described 'ideal parents' in the following way: 'A parent that would be compromising, but not too lenient.'

\section{Emotional support}

'If you're ever in trouble, they're there for you.' [Transition Year, girl]

Another key theme that emerged was that of emotional support from parents and the affectional bond between children and parents. While this theme was common across the four age groups, there was variance in how children of different ages experienced emotional support. The youngest children highlighted how parents show their affection and love their children unconditionally: 'They love you even if you are being bold, but if you're good they love you even more' [1st class, girl]. Among the 4th class and secondary school students, children described parents' roles in 
ensuring that children are not experiencing problems at school or with friends: 'They check on you if everything is $\mathrm{OK}$, like if you are sad or something' [4th class, girl].

Children also highlighted the importance of parental availability and security in their parents' commitment to them. The love of parents for children was considered to be unconditional and not contingent on the good behaviour of the child.

'Make them feel safe, like encouraging us that they're there for us.' [1st year, girl]

'It doesn't matter how long you're grounded for as long as like ... you know your mam and dad love you.' [1st class, girl]

The importance of reciprocal trust between children and parents, and parents having a positive relationship with their children was central to being 'a good parent'. Children felt emotionally supported when they trusted in their parents' love and availability, but also when their parents trusted them: 'To know that you can talk to them and trust them and they trust you' [Transition Year, girl].

The significance of open communication and listening to each other (e.g. 'parents that listen instead of shouting') also emerged as key features of emotional support, as this girl in Transition Year commented: '... to be able to talk to your children and that they would be able to come back to you if they had a problem.'

\section{Shared activities}

'They bring them to loads of nice places.' [1st class, boy]

The role of parents as companions for their children emerged within a number of the focus groups, particularly within the two youngest age categories (1st class and 4th class). Within this theme, children described how parents spent time with their children and brought them to nice places, such as for walks or to the shops. Typical comments from the 4th class group were:

C1: 'If they've spare time, they can bring you to leisure plex.'

C2: 'Yeah, nice places like the Phoenix Park.'

Less frequently, the older children described how parents brought them out places, such as out for dinner or for a game of golf: 'And they have to bring you out sometimes ... bring you out for dinner sometimes' [1st year, girl].

More commonly, adolescents described their parents' role in transporting them to and from activities (such as football practice) rather than sharing activities with them.

\section{Facilitating autonomy}

'Like the parents have to let you experience new things and stuff like that.' [Transition Year, girl]

A final theme, which emerged exclusively within the two older age categories, pertained to the parents' role in facilitating children's autonomy and independence. Adolescents described the importance of parents giving their children space, freedom and privacy:

C1: 'Don't be too overprotective because if you're too overprotective, then they won't get to do anything and then they might feel left out in school.' [Transition Year, girl]

C2: 'Let their child have freedom.' [Transition Year, girl]

'Keep a bit of privacy for your child, give them space.' [1st year, boy]

However, appropriate boundaries, as described in the authority aspect of the parents' role (see p. 32), reflected an important context for facilitating autonomy and independence. Thus, because control is considered an important aspect of a parent's role, children recognised that the extent to which parents granted freedom was inevitably constrained by certain limits: 'Someone who had their limits for their child, but they give their child a certain level of freedom as well' [1st year, boy]. 


\section{Summary}

In summary, eight themes emerged in children's descriptions of parental roles: sustenance and basic care-giving; protection; breadwinning; guidance; authority; emotional support; shared activities; and facilitating autonomy. These themes highlight the diversity of roles that parents are expected to perform for their children. Most commonly, children referred to the role of parents in protecting and fulfilling the basic care-giving needs of children and in providing guidance, authority and emotional support to their children. While the majority of the themes emerged across the four age categories, it was clear that the relevance of specific parental roles varied for children of different ages. This issue is addressed below.

\section{Age-related patterns in parenting roles}

Almost all of the descriptions of parenting roles emerged across each of the four age categories. There were three exceptions:

- sharing activities was not mentioned in any of the Transition Year focus groups;

- facilitating autonomy and independence was mentioned only by the secondary school groups;

- the role of parents as guides did not arise in any of the 4th class groups.

Different emphases in children's descriptions of parental roles were apparent across the four age groups. Dominant within the 1st class and 4th class groups was the description of parents as providers of basic necessities, such as food and shelter. All other themes emerged less frequently across these younger age categories. In contrast, the roles of emotional support, guidance and authority dominated the secondary school groups. This may reflect the reduced significance of basic care-giving interactions among the older groups and may be an indication that adolescentparent relationships had become less organised around dependency and care-taking.

Children were also directly asked how parents' roles change over time. Not surprisingly, younger children had less to say about this and a number of them in 1st class and 4th class groups stated that parents' roles did not change as children grew older. However, in all groups, perceived agerelated changes in parenting roles and in parent-child relationships were described (see below).

\section{Changing parent roles}

Changes in parent roles came about largely as a result of decreased dependence on the part of the child. A plethora of examples were provided about how younger children need higher levels of care-giving, while parents do not have to do as much for their older children. For example, a boy in 1st year commented: 'You have to pay more attention to them when they're younger ... and less attention when they get older.'

Among the younger age group (1st class), examples included the need for babies to be fed and have their nappies changed:

C1: 'When you're a baby they eat you; when you're not a baby, when you're older, you eat yourself.'

Researcher: You're able to feed yourself, very good.

C2: 'When you're a baby, they have to change your nappy. You don't have to learn your name anymore [when you are older].'

Other differences in changes in parent roles included changes in the type of play that parents engage in with their younger and older children: 'When you were young, say, your dad will probably, if you're a young girl ... play Barbie with you, but now you're not into Barbie, they'd play something else with you' [1st class, girl].

Among the older age groups, children also described how parents have fewer practical tasks to carry out in taking care of their children. More commonly, however, older children described how parents' roles changed in terms of how they monitor their children and manage discipline and authority. There was lack of consensus in whether parents engage in more or less monitoring behaviour, or 
were more or less strict, as their children get older. On the one hand, some adolescents reflected that parents engage in less monitoring of their children over time and they become more lenient. Furthermore, there was a perception in some groups that parents allow their adolescents more freedom and worry less about them. Typical comments from the 1st year group included:

C1: 'They care less when you're older, like they don't be as strict when you're older.'

C2: 'Yeah, they're more lenient when you're older. They have to let them go. They'll never stop being their parents. but they'll like have to let them go.'

On the other hand, children believed that parents worry more, or worried about different issues, as children got older, as this Transition Year girl observed: 'They still have to worry. It's just different kinds of worries. When you're young, they just worry about, I don't know, school stuff, and then now they worry when you're out and stuff.'

However, while parents grant children greater levels of responsibility and more freedom as they get older, there was also a perception that parents of adolescents had to be more concerned about serious issues than parents of younger children, such as adolescents' engagement in risk behaviours or not working hard at school or doing well in examinations. Typical comments from boys in 1st year included:

'They become more flexible. Instead of coming in at 9 o'clock, they let you come in at 10.'

'They could get stricter. As you get older, now when you grow up, you start to drink more often, they could become stricter and say "Come in earlier". They don't want you messing, or study for school, you've a big test, things that are more important.'

'Mmm, I think you get more responsible and they let you stay out longer.'

'Like, as you get older it starts getting more and more serious. It'll start off that they're just looking after you, but then ... when you're going out, they have to actually make sure that you're alright.'

Changes in parental discipline strategies were also highlighted in one of the Transition Year groups. This involved the increased use of communication and a more democratic approach to discipline, where consequences of actions are explained to children. Issues relating to changes in parental discipline strategies are addressed more fully in Chapter 5.

In summary, children described how parents' roles changed over time as children required less direct practical care. Furthermore, as children get older, parents grant their children more freedom. However, children acknowledged that parents continue to worry about them, although the nature of their concerns changes over time. There was lack of consensus about whether parents became more or less strict with their children as they became older: on the one hand, children perceived that parents become stricter as their children are exposed to greater risk as they get older, while, on the other, some children perceived that parents become more lenient as they facilitate their children's increasing independence.

\section{Changing child roles}

A theme relating to changing child roles also emerged through the focus group discussions. Specifically, two sub-themes were evident: the first was to do with higher levels of responsibility for children over time and the second related to increasing levels of independence and autonomy.

The first sub-theme, pertaining to higher levels of responsibility for children over time, emerged across the four age categories. Children described how they exhibited less dependence on their parents as they got older and were better able to take care of themselves and be left alone: 'Well, if they're teenagers about 13 or 14, they can still mind them, but they can care for themselves a bit' $^{\prime}$ [4th class, girl]. Children also perceived that they take on and are given more responsibility as they get older. For example, children reflected on how they are expected to contribute more to the running of the household or to take care of their younger siblings. A girl from 4 th class commented, 'Maybe when you get older, you might have to mind your baby sister or brothers', while a girl in Transition Year said, 'You have to have your own sort of responsibilities at home as well. You can't rely on them to do everything'. 
In the second sub-theme, pertaining to increasing levels of independence and autonomy, children described how they were able to do more things outside their home. The youngest children described how teenagers are 'allowed out more', while the older age groups described how teenagers have more responsibility and sense, and are allowed greater freedom and independence. However, increased independence also brought with it increased opportunity for young people to engage in risk-taking behaviour, and thus had implications for parents' roles as they attempted to regulate their children's growing independence in the context of risk-taking behaviours. Typical comments from the 1st year group included:

C1: 'You wouldn't hear of like little kids getting into trouble, but when you're a teenager, you often hear of teenagers [getting into trouble].'

C2: 'On some sides it'd get easier, but on some sides it'd get harder. It's like really balanced out when you're a teenager.'

Researcher: Tell us what gets harder then as you get older, from a parent's point of view.

C1: 'Well, they get into more trouble in school and like.'

C2: 'Yeah, but when they're younger, they need more attention to do stuff, like feed them and stuff.'

C3: 'I suppose when you're a teenager, you want more freedom so you have to compromise.'

C4: 'You go out more and stay up later, and you have to compromise a time.'

In summary, children described how their role changed in relation to their parents as they got older. Children were less dependent on their parents for direct practical care and were increasingly likely to take on responsibilities for their own care and to contribute to the running of the household. In addition, children strive for more freedom and autonomy outside the home, a situation to which parents are required to adjust, by either maintaining their control and authority or by yielding to co-regulation of their adolescents' behaviours and activities. Furthermore, as discussed below, the quality of the parent-child relationship represents a key mediator underpinning parental responses to changing child roles in the family.

\section{Quality of parent-child relationship}

A final theme that permeated the discussions among the secondary school groups was the significance of the quality of the parent-child relationship in mediating changing parent and child roles in the family. Overall, adolescents perceived that their previous experience of continuous presence and patterns of care-giving by their parents set the context for familiarity with each other, which underpinned closeness in parent-adolescent relationships. The views of two children in the 1st year group summed this up:

C1: 'You still have the same relationship, but you kind of become closer through the years.'

C2: 'Parents get to understand you more as time goes on and they get to realise how you're carrying on and your behaviour and all. Yeah, like they know when something's wrong and they know whenever you're not feeling well.'

Parent-adolescent relationships became increasingly characterised by friend-like qualities, such as trust and openness in communication. Comments from the Transition Year group included:

'And whenever you get older, they're there, just like if you need to talk to them and they become more your friends.'

'I think it changes as you get older. You probably get closer.'

'Yeah, I think it's more of a friendship as you get older than when you're younger.'

In summary, adolescents described shifts in the quality of the parent-child relationship, which set a context for changing parent roles. In contrast to exchanges where parents asserted their authority and power, features of the parent-child relationship (such as familiarity with each other, trust and openness of communication) paved the way for more democratic approaches to parental regulation. 


\section{Gender-related patterns in parenting roles}

Demographic changes in the family over the past number of decades mean that families are increasingly characterised by diversity in how roles and responsibilities are organised. Throughout the focus groups, the division of parental roles and responsibilities between mothers and fathers was explored, yielding insights into children's perspectives on the gendered nature of parenting roles.

\section{Gendered nature of parenting roles}

A prominent theme within the discussion of parenting roles was the distinct nature of mother and father roles. Dominant descriptions of father roles included working outside the home, earning money, household maintenance, gardening and as a playmate:

C1: 'Well, dads are better at hammering, like, nails into wood and all that.' [1st class, girl]

C2: 'Yeah, dads are good at fixing.' [1st class, girl]

'Well, mams are normally busier, so my dad kind of plays with us more. But it's not our mom's fault because somebody has to do the work and all.' [1st class, girl]

'Most of the time, the dad goes to work and gets the money.' [1st year, boy]

In contrast, dominant descriptions of mother roles reflected traditional home-making roles, such as cooking, cleaning and a variety of other household chores: 'Moms can clean dirty spots better than dads' [1st class, girl].

Furthermore, a prevalent theme was that mothers do more and are more competent in taking care of the children. The majority of the children considered that mothers are better at cooking, cleaning, washing the dishes, doing the laundry and shopping. Mothers were also likely to be more involved than fathers in taking care of the children:

C1: 'Mam's more ... soft.' [1st class group]

C2: 'She can look after you when you're not well and all that.' [1st class group]

'They [mothers] do more. You sort of go and sit down with your mom instead of your dad.' [1st year, boy]

'The majority of mothers are multi-taskers. They remember everything and dads just don't.' [Transition Year, girl]

In other respects, however, children defined parenting as genderless and did not differentiate between mothering and fathering. In all of the groups, some children expressed the view that mothers and fathers were involved in similar aspects of parenting and that mother and father roles were interchangeable. Younger and older children provided examples of how both their mothers and fathers took care of them and carried out basic care-giving activities. In some cases, mothers and fathers carried out the same tasks; in other cases, mothers and fathers adopted complementary roles, as a boy in 1st year said: 'They kind of do the same job to the children in the house.'

Within the older groups, adolescents contrasted the organisation of mother and father roles in contemporary families with the traditional 'father as breadwinner, mother as homemaker' division of labour in families. One boy in Transition Year commented: 'It depends on the case. I'm sure there are some men like that, that don't want to help out, but in modern families the fathers take more control.' Again, in a number of cases, adolescents reflected that the organisation of mother and father roles varied from family to family and depended on a variety of circumstances, such as whether the parents were working outside the home. As a girl in Transition Year said: 'It sort of depends on the family I think... you know every family is different, but I'd say generally it's [mother and father roles] the same.'

Thus, it appears that children adopt an egalitarian model as the ideal. In reality, however, children experienced distinct mother and father roles, which in many cases approached the traditional model of family roles, with fathers as providers and mothers as home-makers. 
In summary, while many of the children endorsed the view that mother and father roles are (or at least ought to be) interchangeable, traditional gendered division of labour within the family - with fathers as breadwinners and playmates, and mothers as care-givers - strongly permeated the focus groups. Thus, in the main, children's experience of parenting did not necessarily reflect parenting as a genderless practice. Given the group context within which the data were collected, it was not possible to ascertain the link between children's perspectives on this issue and their own household structure. While children from a range of family contexts were represented in the sample, it is worth noting that the majority of participants came from families where they lived with both of their parents (i.e. not separated or step-families).

\section{Parenting girls and boys}

A final factor that emerged throughout the focus groups was the role that the gender of the child played in influencing parents' roles. Thus, children highlighted the distinct experiences that sons and daughters have in families, and the differential treatment that boys and girls received at the hands of their parents. Children did not consider that parents cared any more or less about their sons or daughters, and in general the same care-giving roles applied to boys and girls. However, younger children highlighted some distinct roles for girls and boys; for example; parents buy different clothes for their boys and girls, and parents have to do girls' (but not boys') hair: 'It's not really the same because your mummy brushes your sister's hair ... She washes her hair different, she has to go the whole way down' [1st class, boy].

Across the different age groups, children also perceived that parents engaged in different activities with their sons and daughters, and encouraged their children in different ways:

'Like they'd be encouraging boys to, you know, like work on the farm and that, and girls to play with dolls.' [4th class, girl]

'With girls, they have to go shopping all the time.' [4th class, boy]

Researcher: So what do parents have to do with their boys?

'Play football.' [4th class, boy]

Children perceived that parents (mostly mothers) favoured shopping with their daughters, while parents (mostly fathers) were more likely to engage in or watch sporting activities with their sons: 'My dad's a male, He'd be like interested in what I'm interested in more than my mam. He'd watch football matches and things like that. Maybe we'd share more. Boys share more with their fathers' [1st year, boy].

Thus, in terms of shared activities, children considered that boys and girls have needs and interests that are specific to their gender and the matching of specific aspects of mother and father roles with the specific needs of boys and girls is important. This gender-matching trend also emerged with respect to support functions of parents. A small number of children across the older age groups suggested that girls are generally closer to their mothers, while fathers carry more responsibility for their sons:

'Well, if when they grow up it's the ma's responsibility to look after the girl and the dad's to like ... all those awkward questions - for girls they ask their mam and for boys they ask their da.' [1st year, boy]

'My dad's kind of different with me and my sister because he can talk to me a bit more.' [1st year, boy]

However, not everybody was in agreement with this perspective. There were numerous examples of children who reported that they got on better with the parent of the opposite sex or got on equally well with both of their parents.

By far the most dominant domain of parenting where children highlighted the different treatment of boys and girls was in relation to control and regulation. However, there was little consensus across the groups about differential regulation of sons and daughters. One perspective argued that 
parents are stricter with their daughters and more 'laid back' with their sons, as these comments from boys in Transition Year group illustrate:

'I have two sisters and my parents go a little harder on my sisters. Sort of, "We don't want you going out late at night because bad things can happen".'

'Probably I would say fathers would be more protective of the girls.'

Researcher: Why do you think that is?

'Because they were boys once. They know what boys are like.'

Thus, children perceived that parents considered daughters to be more vulnerable, while sons were in a better position to look after themselves: 'I think the parents kinda think that the boys can sorta like fend for themselves quicker than girls' [1st year, girl]. On the other hand, some children considered parents to be stricter with their sons because of their greater propensity to get into trouble: 'Boys might be more rowdy than girls and they might have to be reprimanded a couple of times' [1st year, boy].

In summary, children highlighted the way in which parents may treat boys and girls differently through the opportunities and types of interactions they provide and encourage. Furthermore, differential treatment may occur in either the degree or manner that parents supervise their children. However, there was little consensus across the groups as to whether parents placed more overall restrictions on daughters than on sons, or whether they monitored their sons or daughters more closely.

\section{Key findings}

- The focus of this chapter was on children's descriptions of what parents do in a family. Eight key themes were identified, highlighting the wide-ranging scope of parents' roles: providing sustenance and care, protection, emotional and financial support, monitoring and regulating children's behaviour, sharing activities, guiding and teaching, and facilitating children's independence and autonomy.

- Parents represent important figures of authority and control for their children. This role entailed monitoring and checking their children's activities and whereabouts, enforcing limits and boundaries and disciplining children. Among the older group, the importance of parental control to protect children from harm was highlighted; however, a fair approach to authority and control was also endorsed by the adolescents.

- A number of themes emerged pertaining to age-related and developmental patterns in parenting roles. Dominant for the younger age groups were parental activities of providing sustenance, protection and basic care to their children, and sharing activities with them. Practical assistance with school work and support in learning new skills were also important.

- In contrast, parental roles relating to guidance, emotional support and authority were of greater significance among the older age groups. Adolescents' descriptions of 'parents as guides' reflected values and expectations that were important to parents, such as getting a good education, being mannerly and knowing right from wrong. The parents' role in facilitating autonomy and independence was also emphasised within the adolescent groups.

- Children reflected on how parent and child roles changed over time in families. Children's dependence on parents lessened over time, resulting in fewer demands in terms of direct practical care. However, in the context of adolescents' need for autonomy and independence, parenting at this stage brought fresh challenges for regulation and control of behaviour at a time when the likelihood of risk-taking behaviour was heightened.

- Children's experience of parenting did not reflect genderless practices in all families because certain aspects of the parenting role were more closely aligned to either mothers or fathers. Furthermore, the gender of the child also represented a source of child effects on parenting. It appeared that boys and girls evoked different types of interactions with their parents (such as distinct monitoring and regulating activities) and parents engaged in distinct activities with their sons and daughters. 


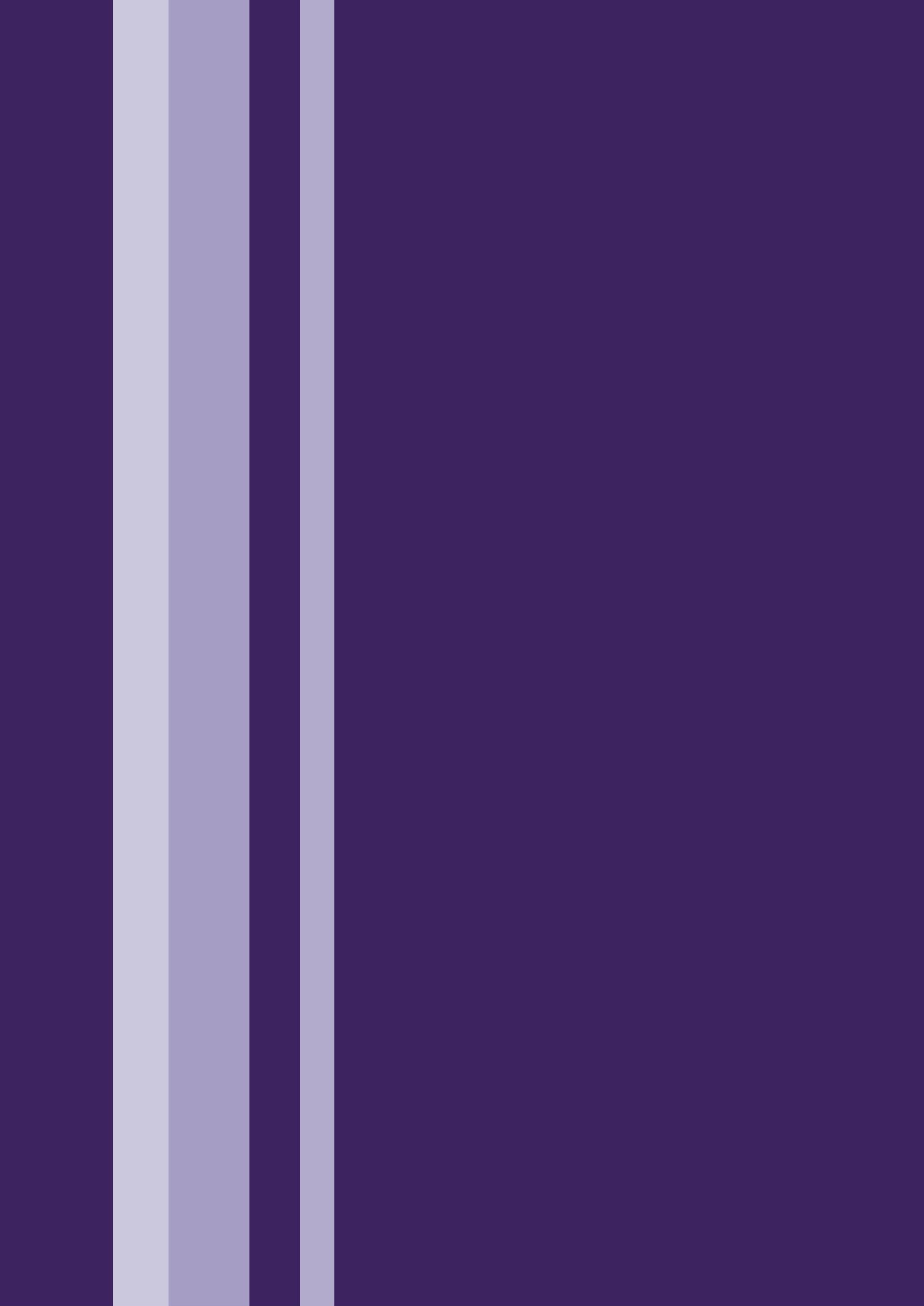




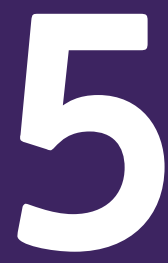

PARENTAL CONTROL AND DISCIPLINE 
This chapter focuses more specifically on children's perceptions of the control and discipline strategies that parents adopt in response to their children's behaviour. Findings are presented across three broad headings: the nature of parental rules and regulations; discipline strategies adopted by parents; and parental use of physical punishment.

\section{Nature of parental rules and regulations}

All children readily identified parental rules and regulations across a wide range of areas or domains of their experiences. Coding of narratives identified specific domains to which rules were linked. Across all age groups, children highlighted rules pertaining to social conventional behaviours, moral behaviours and safety-related behaviours. In addition, younger children placed emphasis on rules related to damaging or breaking property or possessions, while older children (1st year onwards) highlighted rules related to school and peer and media influences. Children's descriptions of rules and regulations with reference to these particular domains are presented below.

Most frequently mentioned in children's interviews were rules relating to social conventional behaviours. For younger children, these rules prohibited them from 'doing bold things' such as kicking a ball or skateboarding in the house, or breaking and damaging toys and fragile objects in the home. A number of children in the younger age groups also mentioned rules prohibiting 'bad manners', with specific reference to behaviours such as shouting at parents, snatching things, answering back and using bad language. Social conventional rules for older age groups were linked to behaviours such as not eating in front of the television, keeping rooms tidy and adhering to agreed bedtime arrangements.

Across all age groups, the importance of safety was emphasised in the rules that parents enforced. Within the younger age groups, children described rules alerting them to the dangers of wandering too far from home, talking to strangers, crossing the road without looking and riding bicycles without helmets. As children's age increased, so too did the frequency of parental rules related to risk behaviours, such as staying away from alcohol and drugs, and not staying out after dark. Most children acknowledged the need for parents to establish rules in order to ensure that they would be safe. As discussed in Chapter 4, children's narratives also demonstrated that they had a clear appreciation that risk behaviours were a source of stress and anxiety to their parents.

Less frequently across all age groups, children made reference to parental rules designed to guide and control children's behaviour with reference to moral well-being. Many of the children talked simply of rules that emphasised the importance of not hurting others. Among the younger age groups, the importance of sharing with others, not fighting with or bullying siblings, and not stealing were also emphasised. In addition, children in the older age groups specified the importance of not getting into trouble with authorities (e.g. teachers, police) and not annoying or disturbing elderly people.

Not surprisingly, as children's age increased, greater emphasis was placed on parental rules and regulations relating to school (this emerged from 1st year onwards). Children made reference to parental rules related to school behaviour, such as the need to work hard in school and complete homework on time. Some children also highlighted parental rules that emphasised the need to be in school on time and rules warning of the dangers of dropping-out of school.

Parental rules linked to psychological well-being and protection from negative peer and media influences were highlighted in the narratives of children in the older age groups. Children described parental prohibitions that centred on possible negative influences, such as peer pressure and inappropriate media programmes. Children talked of rules forbidding them to 'hang around with certain people'. 


\section{Summary}

In summary, children identified a broad range of rules across different areas of behaviours, including moral, social conventional and safety-related domains of behaviour. Children in the youngest class group (1st class) emphasised rules prohibiting breaking and damaging property and possessions. In contrast, rules pertaining to school attendance and effort at school, and avoidance of negative peer and media influences, were emphasised by the older class groups (1st year and Transition Year). There was consensus among the majority of children, regardless of age, that rules were necessary and beneficial to their safety and well-being.

\section{Parental monitoring and checking strategies}

Allied to the theme of parental rules and regulations, the theme of monitoring and checking children's behaviour and their whereabouts was explored in the focus groups. Children identified a range of approaches that parents adopted in order to keep track of where they were and what they were doing. Findings are discussed below under the headings of verbal communication; parents as all-knowing; trust in parent-child relationships; and physical proximity.

\section{Verbal communication}

Verbal communication was cited most frequently by children as the way in which parents monitored their behaviour. As a girl in Transition Year commented: 'They [parents] like to always know where they [children] are going and what time they are going to be in at ... to know that you always have your phone with you and that they can contact you.'

Verbal communication included asking children questions, using mobile phones or relying on the accounts of others (e.g. teachers, neighbours) for information regarding children's activities. Most children referred to parents talking to them and asking them direct questions in order to ascertain where they were and what they were up to. In some cases questions were direct: 'You get a million questions before you go out ... what time will you be in and do you need a lift and that kind of thing' [Transition Year, girl].

In other cases, questioning was more subtle, with parents using indirect questions to elicit information about children's whereabouts and behaviour: 'Like they wouldn't bring it up fully ... they'd just let on stuff ... like you might be out and they might say, "What happened?" They wouldn't be asking you "Oh, did you do this or did you do that?" ' [1st year, girl].

Mobile phones were also mentioned as a means of communicating and children highlighted the usefulness of phones for letting parents know where they were and for ensuring their own safety.

'Well, I never used to have a mobile phone and we never used to be able to keep in contact and mammy never used to know where I was like. And then I got a phone and she always knows where I am and if she needs to ring, she'll ring me.' [1st year, boy]

'If they're very worried about you and you have your phone, they could ring you and if you don't answer they'd probably know what you were doing ... because like you'd know if they were ringing you if it was on loud and all and so like they'll know that you're doing something wrong [if you don't answer the phone].' [4th class, boy]

In contrast to direct communication between children and their parents, a smaller number of children reported that their parents consulted with other adults or siblings in order to provide a check on the behaviour of their children. Examples of these monitoring behaviours included parents talking to teachers about child misbehaviour in school and neighbours informing parents of children's whereabouts. Parents were also perceived to monitor their children's behaviour by keeping an eye on the friends they were keeping company with: 'I know my parents trust me ... They say they trust me fully, but they said they just mightn't trust the [other] people. Like, they know my friends and they like my friends and all that, but they just like say you don't know what anyone else will do and they say "I'm just worried for you". So that's why like if you don't do it, then nothing can happen you and you'll be grand' [Transition Year, girl]. 


\section{Parents as all-knowing}

Some children described their parents as being 'all-knowing' and having 'secret powers' with regard to monitoring and checking their behaviours. One boy in 1st year said, 'I don't know ... They just know everything ... It's sort of a weird thing with parents... They just sort of know', while a boy in Transition Year said, 'Like, it's just like she has eyes in the back of her head and she just knows where I'm going'.

A number of children across all age groups also underscored the ability of parents to accurately read their behaviours to inform themselves of their children's whereabouts and activities. Being attentive to patterns of familiar behaviour made it possible for parents to detect any unexpected changes in children's routines. One boy in 4th class commented, 'When you come back, you'll always have to come back and they'll know what you've been doing ... Maybe if you're kind of queasy, they'll know that you went to the pub'. Another boy in Transition Year said, 'They can smell the smoke off them. My ma can smell smoke from anywhere... She smells it from next door almost. Even though the doors and windows are closed, she can still smell it'.

Inherent in these narratives was children's view that where there has been a history of a close parent-child relationship and where parents have been familiar with patterns of their children's behaviour from the early years through middle childhood and into adolescence, an understanding of where children might be and when they might be in trouble or at risk of danger is inherently available to parents. As one boy in 1st year said, 'Say if you went over to this friend's house nearly every day and then you didn't go over for a while, they'd ask you "Did you fall out with them?" or something like that'.

\section{Trust in parent-child relationships}

Across most age groups but most notably within the older age groups, children identified the history of the relationship between parent and child as significant in terms of facilitating parental monitoring behaviours. Specifically, trust between children and their parents was perceived to be very significant with regard to facilitating more appropriate and effective monitoring of older children's behaviours. Children also emphasised the necessity of being able to demonstrate to parents through the history of their behaviours that they could be trusted to act sensibly when not in their company: 'As you get older they might trust you more, whereas when you were younger they wouldn't trust you as much ... because you haven't proven to them that you can be trusted' [1st year, boy].

Parallel to this theme of the significance of trust in relationships, some children drew attention to the increasing facility that they now had to deceive and lie to their parents with regard to their whereabouts: 'If my ma rings me and asks me where I am, I know I can lie to her. But, like, if my da rings, I can't lie to him' [Transition Year, boy].

Children openly acknowledged and accepted that where trust in the child-parent relationship was lost, the consequences for them were serious and prolonged, as expressed by this girl in the older age group of Transition Year: 'If you like say to your parents that you are going somewhere and you're not going there... well, that's the trust broken for a long time and you have to expect that they are going to check up on you and make sure that you are there if you say you're going there. But if they have the trust all along, then they'll not be as harsh on you.'

For older children, the establishment of trust was a prerequisite to effective monitoring and developing children's sense of responsibility. A boy in Transition Year expressed it thus: 'Kids have to be trusted, you know. You read sometimes about home drug-testing and things like that and you think, well it's obviously going to be something wrong with the family dynamic here if the parents are going behind their kid's back to do something like that. Trust your kids ... you know, give them responsibility.'

Children's narratives further revealed that building trust in relationships with parents was a process that extended across the history of the relationship. 


\section{Physical proximity}

For some children in the youngest age group, physical proximity to parents was referred to as the best means that parents had to monitor and check the whereabouts and behaviour of their children. These younger children described parents seeing them through windows if they were in the garden, using cameras to see what they were doing and, in general, described in a very limited way parents' ability to know what their children were up to: 'When you are out the back and they are looking through the window' [1st class, girl]

\section{Summary}

In summary, children's narratives drew attention to the different strategies that parents adopted in order to monitor and check on their children's behaviour. Verbal communication was used across all age groups. The subtleties of parental monitoring were expressed in children's accounts of parents having secret means of knowing where they were and what they were up to. The development of trust in the child-parent relationship was also highlighted as facilitating greater ease with regard to parental monitoring of their child. The general pattern that emerged was that as children's age increased, so too did the significance that they placed on the quality of the child-parent relationship in facilitating parental monitoring.

\section{Parental discipline strategies}

Children's views on the kinds of discipline responses and strategies that parents adopt in response to child misbehaviour were explored in the focus groups. Discipline strategies identified by children can be categorised under the broad headings of power-assertive discipline strategies; inductive discipline strategies; and love-withdrawal strategies.

\section{Power-assertive discipline strategies}

Power-assertive discipline strategies were mentioned predominantly in children's interviews with regard to the discipline responses they experienced. Among the strategies mentioned by children were the removal of privileges (e.g. toys, treats, pocket money, television time), time-out or grounding, being allocated household chores and physical punishment.

Many children described parents removing privileges such as, for example, not being allowed to watch television or not being given pocket money: 'With pocket money, you'd really want it. You'd be looking forward to it. So if you wanted it, you wouldn't get up to stuff, especially if you wanted it for a game or something' [1st year, girl]. Younger children described having favourite toys confiscated in response to bad behaviour. For older children, parents tended to confiscate their mobile phones, computers or computer games: 'Like if it's your mobile - you know how young ones can't live without their mobile with their friends contacting them' [1st year, boy].

A majority of children also reported parents using 'time-out' as a method of punishing misbehaviour. Time-out across all age groups involved being sent to one's room and not being allowed to leave for an agreed period of time. For some younger children, time-out also involved having to sit on a 'bold step' or 'bold chair' for a period of time: 'Putting them [children] on the stairs for 7 or 6 minutes ... because my mam puts me on the step how old I am, for how many minutes' [1st class, boy].

Children within the older age groups highlighted 'grounding' as a discipline strategy frequently employed by parents. In most cases, being grounded involved being prohibited from going out to socialise and spend time with friends: 'You can't go anywhere whenever you are grounded, so you can't really do anything' [4th class, boy].

In a small number of cases, children mentioned being prohibited from visiting extended family members, such as grandparents or aunts. Being allocated extra household chores was also mentioned by children, most notably in the older age groups. Such strategies involved children having to clean the house, to tidy their rooms and generally having to take on added responsibility around the house: 'I think they should make you do chores around the house or something like, and ground them like, and then they'd have to do work for punishment' [1st year, boy]. 
The final category of power-assertive discipline strategies was the use of physical punishment by parents. Children's views on and responses to physical punishment by parents will be addressed later in this chapter.

\section{Inductive discipline strategies}

Inductive discipline strategies were mentioned by children to a lesser extent in focus groups. Among these strategies, children highlighted communication and talking things through and the reinforcement of positive behaviours. Inductive discipline strategies were also associated with children's greater abilities to internalise standards and expectations and to self-monitor, as illustrated by this exchange between a boy in 1st year and the Researcher:

C: 'Like they might give you an incentive, like money, if you get As in your exams.'

Researcher: And do they have rules about that?

C: 'Not really rules ... like you just know, like the rule is up here in your head ... they're just common sense.'

In particular, younger children highlighted the use of more positive discipline strategies, such as receiving treats in order to reinforce desirable behaviours, as described by a girl in 1st class: 'If you were being good, mammy might just do lots of surprises.'

The importance of reasoning and explaining the consequences of behaviour was also underscored in these narratives. Generally, inductive discipline strategies were mentioned to a much greater extent among the older age group of children, who emphasised the benefits and greater effectiveness of communicating with children in order to challenge or change inappropriate behaviours. A boy in Transition Year commented: 'When you get older, things just become bigger and bigger and they can just talk to you more as an adult ... so they don't have to sort of treat you like a kid. They can treat you like an adult and say like, "I don't want you being like that ... that's bad", instead of just freaking out ... and they just talk to you more like an adult. They communicate more.'

\section{Love-withdrawal strategies}

A third category of discipline responses mentioned by only a small minority of children was that of love withdrawal. Children described parents becoming upset and expressing their disappointment in response to misbehaviour. For most children, this had the effect of making them feel very guilty about their behaviour, as this girl in Transition Year recalled: 'I think it's worse though if they're disappointed in you ... That kills me. And if they're giving out to you and they're talking in a real low voice and you're kind of like "OK, what's going on now? Why aren't they shouting at me?" Keeping it very polite and formal and then they're like "Right, I'll talk to you later on", and they turn around and in the back of my head is "Roar at me, please".'

\section{Summary}

In summary, children identified three distinct types of discipline strategy adopted by parents: love withdrawal (such as expressing disappointment), inductive methods (including reasoning and communication) and, most commonly, power-assertive methods (such as withdrawal of privileges or grounding). Physical punishment, a further example of a power-assertive method of discipline discussed by the children, is dealt with below.

\section{Physical punishment}

In this section, we focus on children's perspectives on the use of physical punishment by parents children's responses to and feelings about its use as a discipline strategy and their understanding of why parents may use it; their perspectives on the rationales for and against physical punishment; and their views on banning it. 


\section{How does slapping make children feel?}

Physical punishment was described by the children in the focus groups as slapping or smacking children in response to their misbehaviour. Most children drew a clear distinction between giving a child a smack or a light tap, and a slap causing an injury or leaving a mark on the child. The latter form of punishment was deemed unacceptable by children. Overall, children were of the view that slapping and using physical punishment had the effect of making children feel bad in some way. Younger children listed a range of responses to such punishment (sadness, unloved, mad and upset), all conveying negative effects. One child in the youngest age group also indicated that he would feel 'embarrassed' in response to being slapped. Other children mentioned that they would feel sore, scared or upset. Only one child said that being slapped would make him regret his misdeed. Children in the older age group also described negative responses (hurt, sad, mad) and one child described it as a form of 'physical abuse'.

\section{Why do parents use physical punishment?}

In response to questions about why parents might slap or smack a child, children's views centred on child behaviours that involved 'repeatedly disobeying' or disregarding the wishes of a parent and parental anger, loss of control or frustration. Some children described situations where a parent used physical punishment in order to 'get the attention' of a child.

'If the child was like constantly in the wrong, after the parents keep constantly telling them not to do something, they go ahead and do it anyway.' [1st year, girl]

'Because they're getting sick of you, and if you're being bold nearly all of the time they'll just get sick of you and they'll go "Right, I think I better slap you".' [1st class, girl]

A number of children across different age groups were of the view that physical punishment was a last resort to parents: 'It's not a good way, I think. Like there's other ways of doing it without hitting them. I think they're just hitting them out of rage... They don't know what to do, so they just hit them' [Transition Year, girl]. Thus, physical punishment is more likely to be used by parents when 'they can't do anything else' and they employ this strategy as a result of their frustration or anger.

\section{Rationales FOR physical punishment}

A key argument expressed in favour of physical punishment was its potential effectiveness with regard to controlling behaviour. More specifically, some children emphasised that by slapping a child as punishment, parents were better able to correct more serious behaviours and set boundaries so that children would not repeat misbehaviours.

'Just to set some boundaries, like, at a young age ... so that you don't do anything worse when you're older.' [1st year, boy]

'Because if you slap them they wouldn't do it again ... If someone's being bold, she'll slap them and if she says "Next time you do it, it will be ten times harder". ' [1st class, girl]

For children in the youngest age group, slapping was viewed as an effective way of 'teaching you to be good'. Other children highlighted the threat of being slapped as a deterrent for younger children from repeating misbehaviour: 'I think it's more a threat, because if like [you] slap a little kid and they're about to do something bad, like afterwards, you can just use that as an example and like threaten them' [1st year, boy]. One boy in the older age group (Transition Year) described the effectiveness of physical punishment in quite extreme terms, as follows: 'You can beat it [misbehaviour] out of their system ... You can scare it out of them.'

The context of the misbehaviour and punishment was central to whether children expressed rationales for or against parents' use of physical punishment. Age-related patterns were also evident in determining the kind of contexts that children described. For younger children, these contexts involved behaviours such as being cheeky to parents or breaking things: 'Like, you'd feel a bit, mmm, like, it deserves you that you got slapped because you're being really bold and don't do anything bad or you'll get another one' [1st class, girl]. 
With increasing age, there was more detailed qualification with regard to the precise situations in which parents should be allowed to use slapping or smacking as a form of discipline. Contexts in which physical punishment was acceptable according to the views of children were described with reference to danger and health-risk behaviours.

'It depends what it is. If it's something silly, like you didn't make your bed or something, and they slapped you anyway. But say if you were caught smoking or something, maybe for that' [1st year, boy]

'Like with my dad, he hates drugs to bits and if he ever found out that I was on drugs, I'd understand if he turned around and hit me ... [Lads] like stoned after taking cannabis or something like that, and their father sees them and they come back out and say "Me da beat $m e^{\prime \prime}$, but they deserve it if they're going to go round smoking hash and taking tablets and doing other drugs ... I think they're liable to get a beating.' [Transition Year, boy]

Researcher: What about younger children ... you know you were saying that if a kid puts their hands in the fire?

C1: 'Yeah, but that's like the same thing as drugs ... You know they're going to end up hurting themselves.' [Transition Year group]

C2: 'It's better for the parents to give them a little slap than actually putting their hand into the fire and getting third-degree burns... It's like the two wrongs don't make a right, but sometimes a little wrong just helps them on the way.' [Transition Year group]

Thus, children in the older age groups endorsed parental use of physical punishment in contexts where children's safety and health is at risk.

\section{Rationales AGAINST physical punishment}

Despite discussion of rationales for the use of physical punishment (see above), children across all age groups expressed their widespread disapproval of the use of physical punishment by parents. Generally, children in the older age groups volunteered more detailed comments and qualifications when voicing their opinions on this topic. A small number of children in the youngest age group stated their views in simple terms, indicating their belief that physical punishment was not effective as a discipline strategy as it did not deter children from repeating misbehaviour.

One key argument against physical punishment for these younger children was the notion that physical punishment did not involve communication between parent and child, and therefore, for some children, the message was less likely to 'get through'.

'Because if you slap, they might be still doing it again. But if you punish them, they'll be listening to you:' [1st class, girl]

Researcher: What do you think about physical punishment ... you know, parents slapping their children?

C1: 'I don't think it's good'. [1st class group]

Researcher: Do you not? Why not?

C2: 'It's hurting people.' [1st class group]

C1: 'Yeah and it doesn't really get through.' [1st class group]

An older girl in 1st year expressed the view: 'It's easier for people to talk it out because you learn more than just if they hit you. The pain would go away. But if they ground you, they can ground you for a week.'

A second predominant rationale, expressed by children of all ages, against the use of physical punishment was the potential for causing injury and pain to a child: '[It's] a bad idea ... because they might hurt you really hard" [1st class, boy].

Related to their concerns about causing physical pain and injury, a number of children expressed the view that physical punishment also had the potential to cause emotional distress and in some cases was likely to damage the relationship between a child and their parents, as this exchange between a boy in 1st year and the Researcher illustrates: 
C: 'I think it ruins the relationship between the son and the parent if the parent hits him.' Researcher: And do you think that parents slapping the child works as a way of punishing them? C: 'They think it does, but it doesn't.'

Researcher: OK, but why doesn't it work?

C: 'Because the children will grow up hating their parents.'

There was some ambivalence in the narratives of children who felt that although physical punishment might be effective in correcting misbehaviour, the risk of more negative consequences was also high: 'Well, it stops them from being bold, but it could upset them and they might run away' [4th class, boy].

Yet another argument against physical punishment was that slapping or smacking children had the potential to reinforce bad behaviour or could generate more aggressive responses in children. A boy in 1st year said, 'Like if you hit them, they might consider doing more drastic things like running away or anything like that', while a boy in Transition Year commented, 'Mind you, my parents were very big into the "Hit you and you'll never do it again" system. But I don't think it worked well because I just spent from about 12 to 15 [years] just trying to get them riled and then they stopped after that because there was just no point'.

Children were also aware of the possibility that being exposed to physical punishment by their parents might, in turn, encourage them to adopt similar practices with their own children.

'It's a bit stupid because if they're using physical punishment on you, when you have kids you're going to learn from them, so then maybe you'll hit your kids.' [1st year, girl]

'No, because then, when they're older, they could be real cross if they get hit and all that, and then they could hit their own children.' [1st year, boy]

Children in the older age groups objected to the imbalance in power which they felt was inherent in parental use of physical punishment: 'If they get hit ... it shouldn't be happening because they can't stand up for themselves' [1st year, boy].

Overall, children displayed insight into the reasons why parents might adopt physical punishment as a discipline strategy. As outlined earlier, many children felt that a light tap or slap at times was an appropriate and effective response to a child's misbehaviour, especially in situations where children were in danger. However, a number of children also expressed the view that although a parent might not have the intention of hurting their child, the risk of slapping a child harder than intended was not worth the potential overall effectiveness of physical punishment as a discipline strategy: 'And if you smack them really hard, and you meant to smack them on the leg or something and you got them up on the shoulder and it was a really hard slap, then it might really hurt you. And if you cry, you might give your mam a headache, so I don't think slapping is worth it' [1st class, girl].

\section{Should physical punishment be banned?}

Of those children who were asked whether they would agree with the idea of banning physical punishment in the home, the majority expressed the view that they would not agree with this. There was a substantial degree of ambivalence in children and young people's responses to this question. One of the strongest arguments against banning physical punishment was the complexity involved in terms of monitoring and assessing the severity of the physical punishment and the reluctance of children to report their parents to authorities in cases where the physical punishment was severe: 'They probably wouldn't [want to have their parents arrested] because they wouldn't want to see their moms and dads getting hurt' [1st year, boy].

Children also elaborated on their views that physical punishment should not be banned by indicating that, in some cases, physical punishment was necessary in order to correct and challenge certain misbehaviours. One boy in 1st year stated, 'If you deserve it, like, you know you're going to get it for what you're after doing. If it's illegal, then you're just going to try to do it again', while a boy in Transition Year said, 'Oh yeah, like if you get into a fit, especially in public, if you get into like a serious temper tantrum, then a slap will bring you back down'. 
A key issue emphasised by many children when reflecting on the possibility of banning corporal punishment in the home was the clear distinction which they themselves drew between banning physical punishment in the home and banning physical punishment in schools. A number of children expressed the view that parents had 'a right' to punish their children physically because they had responsibility for the child. Inherent in these arguments was the sense that children trusted their parents not to abuse the power they had over them in terms of administering physical punishment. This same trust, however, was not afforded to teachers, as this exchange with children in one 4th class group illustrates:

Researcher: And what's the difference between a teacher hitting a child and a parent hitting a child?

C1: 'Because they don't really know them very well and they're not related to them.'

C2: 'Because, em, 'cos like your mam and dad own you, so they can hit you once or twice and a teacher doesn't own you. They just teach you.'

Children who argued in favour of banning physical punishment in the home tended to focus on the risks to the child, such as the pain inflicted, the potential for serious injury and the potential for causing emotional distress to the child. Some children qualified their arguments in favour of banning physical punishment in the home by excluding instances of a light slap or tap, as opposed to smacking in order to hurt the child, as seen in this exchange with children in one 1st year group:

Researcher: Say you were able to vote whether you could use physical punishment in the home or not?

C1: 'I would vote ... for no physical punishment ... not for hitting on the hand, but not too hard.'

C2: 'Yeah, I'd vote no [physical punishment]'.

C3: 'I'd vote no punishment 'cos it's not nice hitting children very badly ... You might hurt them.'

Central to children's arguments for banning physical punishment was the risk that some parents might abuse their right to physically punish their child, as described by this boy in the Transition Year: 'It's probably some parents abuse it though ... that's what I think it would be ... they just abuse it completely and say "Aw well, they're my kids... I can do this". I don't think that should be allowed.

\section{Summary}

In conclusion, children's views on physical punishment were complex and displayed considerable ambivalence. There was consensus that slapping has the effect of making children feel bad in some way. Children drew a clear distinction between giving a child a light tap or slap, and inflicting more severe physical punishment, which left a mark on the child's skin or caused injury. This latter form of physical punishment was indisputably considered to be unacceptable. In terms of effectiveness, many children acknowledged that physical punishment, specifically a light tap or slap, was often effective and successful in terms of correcting or challenging misbehaviours. However, most children, particularly older children, qualified this by adding that the misdeed must be serious and warrant a severe parental response. Children also acknowledged that parents tended to slap their children more in contexts where no alternative strategy was available to them and where children were engaged in dangerous or health-risk behaviours.

In contrast to this, many children expressed disapproval of physical punishment, emphasising the potentially negative and harmful effects, such as pain inflicted, emotional distress and damaging consequences for child-parent relationships. Of those children who were questioned about their views on banning physical punishment, the majority in the youngest class group indicated that they were against banning physical punishment. There was greater discrepancy among the older class groups on the issue of banning physical punishment. 


\section{Key features of effective discipline strategies}

Salient features associated with effective discipline strategies are outlined below under the headings of loss of privilege; instructional value; consistency; and fairness.

\section{Loss of privilege}

Overall, there was some consensus that grounding children and having privileges removed (e.g. taking away their computer or mobile phone) were the most effective disciplinary strategies. Many children felt that for a discipline strategy to be truly effective in preventing or changing inappropriate behaviour, it was necessary for such strategies to have a substantial effect on the child's sense of deprivation or loss of privilege. A number of children mentioned that having something confiscated - something that they valued and depended on on a daily basis - was effective in deterring them from repeating misbehaviours. One of the most frequently cited objects to be removed from older children, and most notably from girls, was their mobile phone: 'If you spend a lot of time playing it and it's taken away from you, you'd get very annoyed about it. Like teenagers, taking their mobile phones from them. They use it nearly every day, so they wouldn't want it taken off them again' [Transition Year, girl].

While most children felt that being grounded, sent to their room or being confined in some way was useful as a strategy, some children pointed out that they had ways of overcoming these strategies, for example, by watching television in their rooms or playing with games that they still had access to despite being confined to their rooms:

'If she [mother] sends you up to your room and you're supposed to be doing your homework, I just watch telly or do something else, not me homework.' [1st class, boy]

'Well, there isn't much point in grounding someone if they're still allowed to do everything ... like play with Playstation, watch TV.' [1st year, boy]

Thus, being sent to one's room was an effective discipline strategy if it was 'an empty room so they [children] couldn't do anything'. Where children were confined to their room and did not have access to their games and other distractions, they were more likely to learn not to repeat their misdeeds.

'Putting me to my room [stopped me doing it again]. There's nothing to do in your room. But when you get a slap, you can just run off and do what you want.' [4th class, boy]

'Because it's good for you if they put you in your room, like you'll always find something else to do ... It doesn't really teach you a lesson. But if they take something away from you that you really like, then you know you're not going to do it again.' [1st year, girl]

Comparing various discipline strategies, it was clear that being grounded was considered more effective than being slapped because of the prolonged sense of deprivation it entailed for the child. In contrast, the consequences of being physically punished were considered to be relatively short-lived.

'I think, it's grounding [is most effective] because, say, when they smack you, you get it over very quickly and then you ask "Can I go out" and she might say "Yes". And then you might do it again and then it will keep on happening. But if you get grounded, you're not able to go out and you'll not do anything.' [1st class, girl]

'I think grounding is ... more likely because, $\mathrm{mmm}$... grounding, it's like you're not allowed to go out and a slap is just once.' [4th class, girl]

\section{Instructional value}

A second key feature underpinning effective discipline was the instructional value inherent in the approach. Across all age groups, some children emphasised that it was important that children could learn what behaviours were acceptable and not acceptable as a result of their experience. Younger children expressed this idea simply as: 'Learn them [meaning 'teach them'] ... Tell them what to do and what not to do' [1st class, boy]. Other children reflected on how they were more likely to learn not to misbehave because they would know that they would be punished as a consequence: 'Because they'll never do it again, because they'll know what's going to happen' [1st class, boy]. 
Some children expressed the view that having to do chores around the house was a more constructive way of parents enforcing discipline that involved some kind of an instructional component. Older children placed more emphasis on the importance of 'getting through to children' in terms of the discipline strategies used by parents: 'Like it [slapping] doesn't really get through ... By getting hit, you're obviously going to do it again ... both the parents and the child" [1st year, girl].

For many of the older children, parental strategies and responses that involved communication and explanation were deemed to be more effective than, for example, slapping or using physical punishment.

\section{Consistency}

Many children across all age groups expressed the view that in order for a discipline strategy to be effective, it had to be implemented consistently and followed through. Children drew attention to parents threatening punishment in response to misbehaviour, but not following through on these threats, which resulted in children being able to justify misbehaviour or believing that, in fact, they had done no wrong.

'Sometimes they go through with it, like, but if they say they're going to do it and they don't then, you don't believe that you've done anything wrong.' [Transition Year, girl]

'They take stuff away from me, but then the next day they just say "Go and play with it".' [4th class, boy]

Among the older children, and linked to children's increasing ability to deceive and manipulate their parents with increasing age, children gave accounts of 'getting round parents' to restore privileges or property before the time limit imposed as part of the disciplinary procedure: 'When $I^{\prime} m$ bored and I have nothing to do, like, say she took my Playstation away, I'd be hanging around the kitchen and that's where she is and then she'd be aggravated by me and then she'd just give it back to $m e^{\prime}$ [1st year, boy].

'Giving in' to children in this way and not seeing a strategy through to the agreed period of time was seen by children as detracting from its effectiveness. Younger children also highlighted the need for parents to be consistent over time in their responses to certain behaviours and to repeatedly refuse to allow certain behaviours in order for children to learn what was, or what was not, acceptable: "If you wanted to call for your friend, you just say "No" and then next day "No" and the next day "No", until you learn not to be bold" [1st class, boy].

\section{Fairness}

The concept of fairness, especially with regard to an appropriate match between the misdeed and the punishment, was important to most children in terms of how effective they considered parental discipline strategies to be. Regardless of the type of discipline strategy adopted, children were clearly of the opinion that if they were punished unfairly, they did not learn from such a strategy. One example of perceived unfairness in discipline strategies was where a child was blamed in the wrong for the misdeed of a younger sibling: 'Say your brother knocked over a plant and then he blamed it on you, your mom might slap you and that wouldn't be fair... If you had a young brother or sister, you'd normally get the blame' [1st year, girl].

Children also protested that when they believed they had not actually done anything very bold or wrong, being punished harshly resulted in feelings of greater anger and resentment, rather than actually preventing them from engaging in such behaviour in the future.

\section{Summary}

In summary, four features of effective discipline strategies were highlighted: loss of privilege; instructional value; consistency; and fairness. While the perceived effectiveness of these different strategies was somewhat dependent on the context, there was some consensus among the children that removing privileges and grounding children were the most effective discipline strategies. 


\section{Age-related patterns in parental control and discipline}

As highlighted in Chapter 4, children described how parental roles on monitoring, control and discipline changed as children got older. On the one hand, there was the suggestion that parents engaged in less monitoring of their adolescents' behaviour as developmental change brought with it increased autonomy and independence. Indeed, most children agreed that it is not possible for parents to regulate the behaviour of older children to the same extent as it is when they are younger. Children highlighted the need for parents to allow greater flexibility and scope for negotiation in terms of the rules they apply to older children and to provide them with opportunities for developing greater autonomy through experimenting with the world: 'A young child you just have to tell them "No, bad". And then as they get older, you just have to reason with them more and let them experiment more with the world, I suppose. Let them have their own experience and get used to $i t^{\prime}$ [Transition Year, boy].

On the other hand, as also discussed in Chapter 4, some children highlighted that older children may need greater degrees of parental monitoring and rules pertaining to different issues since adolescents may be more likely to engage in different risk behaviours than younger children: ' $I$ think it changes because when you're younger, it's more "Sit down and have manners" and now it's more "Don't drink, don't do drugs, don't go mad" " [Transition Year, girl].

In terms of discipline strategies, many children perceived the appropriateness and effectiveness of discipline strategies to vary according to the age of the child in question. Some children considered that punishments were more frequently administered to younger children because they may have less capacity to self-monitor and internalise parental standards and expectations than older children: 'You're supposed to be smarter when you're bigger because when you're smaller you don't know what you're doing' [4th class, boy].

Conversely, other children expressed the view that punishments were 'more serious' for older children and that older children are 'grounded for longer' when compared to younger children. Children from 4th class onwards placed more emphasis on the notion of internalising rules and standards, and being more responsible for one's misdeeds than younger children did. Children also drew attention to the ability of older children to internalise parental rules and standards. As a result, close guidance and direction was less necessary for older children: 'Whenever you were young, your parents said "Behave yourself" and they just kept saying that, so they expect you to learn it and now they kind of trust you a little bit more and they don't say that anymore and they're on about stuff like they are actually worried that you would do ... because they expect you to know how to behave' [Transition Year, boy].

Many children were of the view that physical punishment was more effective when used with younger children rather than older children because young children lack the capacity to rationalise and internalise standards. In contrast, older children can self-monitor to a greater extent and thus physical punishment no longer serves the purpose of enforcing parental expectations. Children also gave examples of older age groups being 'bigger and stronger' than their parents and, as a result, physical punishment may not hurt older children enough to change their behaviour. A pattern that emerged in some of the older children's accounts was a subtle shift in the balance of power in relationships with parents. Thus, as they become older, children have the capacity to respond to being physically punished: 'If you're older and they hit you, then they're just going to get shouted at. But if they slap a little kid, everyone thinks it's normal' [Transition Year, boy].

Children in the Transition Year group also expressed resistance to being disciplined by having privileges removed because they had a greater sense of ownership over their possessions, such as mobile phones, which they may have purchased for themselves:

Researcher: And do you think that [taking away possessions] works well for younger children or would it work as well for people of your age?

C1: 'They can't really take anything away from us.'

Researcher: What about mobile phones?

C1: 'I bought it meself.'

C2: 'They could try to take mine, but I just wouldn't give it to them.' 
Generally, among the older groups there was greater awareness of how the effectiveness of a discipline strategy was contingent on the situations in which it arises and also on the individual child characteristics, such as temperament, age and gender. Equally significant in determining the extent to which a discipline strategy was effective was the relationship between the child and parent.

\section{Summary}

In summary, the age of the child emerged as a key factor in discussing the nature and effectiveness of parental disciplinary and control strategies. The extent to which parents can regulate their children's activities was highly dependent on their age and developmental stage. Children considered that parents may have to discipline their younger children more frequently, given their relative inability to self-regulate their behaviour, when compared with older children and adolescents. Children considered that distinct strategies may be used more at some stages of development, but not at other stages. For example, it was suggested that physical punishment may be more effectively used by parents of younger children, while older children may benefit more from inductive techniques, which encourage the internalisation of parental values and standards.

\section{Gender-related patterns in parental control and discipline}

\section{Gendered nature of parental control and discipline}

There was little consensus in children's views on whether parental roles on discipline and control were aligned to mothers or fathers. A number of children described differences in the patterns of discipline responses of their parents, with one parent being perceived to be either stricter or more lenient than the other: 'My father would be an awful lot more strict on me than my mother. Mammy would kind of like shout at you, but a few minutes later it would ... blow over. Whereas daddy. He's kind of schizo. One minute he's in a rage and the next minute he's all nicey nicey, and then he's angry again and you just go "Where are you?" ' [Transition Year, girl].

However, such differences were more to do with individual differences across households rather than being related to the gender of either parent. No clear gender differences emerged in terms of the extent to which mothers and fathers used physical punishment.

\section{Disciplining girls and boys}

As discussed in Chapter 4, clear distinctions between how parents discipline their sons and daughters were not evident and most children expressed the view that parental regulation and monitoring of their behaviour was similar for boys and girls. A small number of children felt that parents were stricter with boys and that parents needed more rules to regulate 'rough' behaviour: 'Sometimes boys are rougher than girls and you have to be stricter with the boys' [1st class, girl].

A small number of children in the 1st class and 1st year focus groups expressed the view that, in general, boys experienced stricter discipline and more physical punishment than girls: 'A mammy doesn't go too hard on a girl like the boy. They'd pull a boy by the ear, but not pull a girl by the ear' [1st class, boy].

Conversely, other children felt that parents were stricter on girls than on boys, that girls got grounded more than boys and, for a minority of children, that girls got slapped more than boys. This was related to a heightened sense of protection which parents felt towards their daughters and the restrictions they placed on their daughters' freedom: 'Like, my brother is exactly 13 months older than me, so he's 17 and I'm 16. And he can go out at weekends and go out night-clubbing and all that, and yet if I want to go to the cinema - "What? What cinema?". Like, if it's during the day or something and it's "No, you can't go" and I'd be like "Why?" and they'd say "You have to go tidy your room"' [Transition Year, girl]. 


\section{Summary}

In summary, no clear gender patterns emerged in terms of whether mothers or fathers were more likely to discipline their children or whether they were likely to use distinct strategies. Similarly, no clear differences emerged in terms of how parents monitor and discipline their sons and daughters. Thus, the relationship between gender of the parent and child, and how discipline is managed in parent-child relationships, is nebulous. It is likely that individual differences in relationships and roles within families are more significant mediators of parental disciplinary strategies than parent or child gender per se.

\section{Key findings}

- The focus of this chapter was on children's perspectives on the monitoring and discipline strategies that parents employ with their children. All children across all age groups easily identified parental rules and regulations relating to social conventions, such as being polite, morality and 'being a good person', school and academic work, peer relations, avoidance of risk and safety issues.

- A key message emanating from the discussions was that 'rules were necessary and good' in order to protect children from harm and to promote their well-being.

- Most commonly, talking, asking questions and contact via mobile phones were the means by which parents monitored their children. The relational history between children and their parents underpinned a perception of parents as 'all-knowing' and attentive to familiar and unfamiliar patterns of behaviour. In addition, where trust had been established in the parent-child relationship, this facilitated more effective parental monitoring of older children's behaviour.

- Older children emphasised the need for parents to negotiate rules and regulations with their adolescents, rather than imposing restrictions on them as might be done with younger children.

- Children identified three categories of discipline strategies adopted by parents: (1) powerassertive responses, which included the removal of privileges, time-out or grounding, being allocated extra chores and physical punishment; (2) inductive responses, involving communication about behaviour and its consequences, and reinforcement of positive behaviour; and (3) love withdrawal, where parents express their disappointment in their children with the intention of inducing feelings of guilt and regret for misbehaviour.

- Parental use of physical punishment in response to child misbehaviour had the result of making children feel bad in some way, including feeling sad, upset, unloved, sore, scared, angry and embarrassed.

- Children were of the view that parents tended to use physical punishment as a last resort, especially when their children were repeatedly defiant, or when parents were feeling out of control or frustrated. Thus, the context of the child's misbehaviour was central to whether children endorsed parents' use of physical punishment.

- Among some older children, physical punishment was acceptable when they put themselves in situations of danger or risk to their health. By and large, however, physical punishment was considered to be more acceptable and effective when used with younger rather than older children.

- Across all age groups, children expressed widespread disapproval of the use of physical punishment by parents. A central argument expressed by the children was that physical punishment did not involve parent-child communication and therefore children were less likely to learn from the disciplinary encounter. Secondly, children expressed the view that physical punishment had the potential to cause serious physical injury or emotional distress to a child, or damage the parent-child relationship.

- The majority of children did not agree that physical punishment should be legally prohibited. Some children were of the view that parents had a right to use physical punishment with their children, a right which children trusted their parents would not abuse. Furthermore, the complexity in implementing a ban on physical punishment, especially in the home, was highlighted.

- Some children did, however, favour the legal prohibition of physical punishment by parents. These children argued that such prohibition would protect children whose parents used physical punishment excessively or severely. 


\section{Effective discipline: What works? What doesn't work?}

Four principles underpin effective discipline:

- Loss of privilege: Effective discipline involved losing or being deprived of something that was of value to the child. Grounding children, restricting children's activities (such as not being allowed to watch TV) and depriving them of privileges (such as pocket money) were effective ways of deterring children from repeating misbehaviour. Physical punishment was considered less effective as a form of discipline because the consequences of being slapped were relatively short-term compared with the consequences of being grounded or having privileges removed.

- Instructional value: Inherent in effective discipline was a clear message to children about acceptable versus unacceptable behaviour, and a clear rationale for why they were being disciplined. Discipline strategies that afforded children an opportunity to learn about the potential deleterious consequences of their behaviour were considered most effective.

- Consistency: Effective discipline was delivered in a consistent manner and parents' intention to discipline was always followed through with appropriate action. Parents were considered to be ineffective disciplinarians when they succumbed ('gave in') to pressure by their children to abandon their disciplinary strategy.

- Fairness: Effective discipline involved fairness and a sense of justice. Being blamed and punished for something that was the fault of another was considered unjust and ineffective discipline. Also, the magnitude of the punishment should reflect the magnitude of the misdeed: being punished harshly for a relatively minor offence was perceived as ineffective discipline. 


\section{CHILDHOOD AND PARENTHOOD COMPARED}


The title of this chapter reflects a central theme that emerged throughout the focus group discussions. The exploration of parental roles gave rise to discussion about the generational relationships experienced by children in their families. Narratives around children's position in relation to adults, and more specifically in relation to their parents, revealed clear contrasts between childhood and parenthood. Most notably, this contrast initiated discussion on the issue of rights and responsibilities within families.

All children in the focus groups drew clear distinctions between children and parents. Distinctions were drawn along the following domains: physical differences, skills and knowledge, control and power, responsibility and fun. Children differ from parents in that they do not have control, power, responsibility and the skills and knowledge that parents have. The following exchange with children in the 1st year group illustrates this point:

Researcher: What's the difference between being a child and being a parent in a family?

C1: 'Power, I think. If you're a parent, you have more power and a child has less than the parent.'

C2: 'Parents can do way more things. They can drive, they can work, they make decisions for themselves... They can decide "I'm going to buy, mmm, I'm going to go shopping tomorrow". They can get a big shop and we [children] can't. We can only decide, like, I'm going to go buy jellies in the shop.'

C3: 'I suppose when you're a child, you're only learning about the responsibilities that you need to know in later life. So I suppose parents are always there to show you':

The physical differences between children and parents were highlighted, but only across the younger groups: 'Rowing with your mum - you shouldn't do that because your mummy knows better than you, because you're only small and they're very big' [1st class, girl]. Children were restricted from certain adult activities, such as going to the pub or driving a car. Furthermore, adults had certain skills and knowledge that enabled them to do things that children were not yet able to do. Two children in 1st class mused: 'Adults can drive and children can't' and 'Adults cook the dinner and they don't get burnt and the children do get burnt'.

Overall, it was considered that being a child was easier than being a parent: children have less work to do and fewer worries: 'All they've to do is schoolwork, homework' [1st year, boy]. In contrast, children considered that parenthood was 'hard': 'It's harder being a parent ... because you have to pay the bills and you have to work hard all the time and you have to mind your children' [1st year, boy].

By far the most common distinction between children and parents related to the issue of responsibility. It was generally accepted across all groups that parents had responsibility for their children: 'Like you have a child. That's your responsibility. No-one else is going to look after it, so you're going to have to look after it, clean it, wash it, love it unconditionally, help it, nurture it, financially, like, make sure they've got clothes on their backs and they can go to school and they have a roof over their head and all that. Enormous amount of responsibility because it's, like, a person' [Transition Year, girl].

\section{Parental responsibilities}

Children narratives on parental responsibilities broadly reflected the eight themes that defined parents' roles (sustenance and basic care-giving; protection; breadwinning; guidance; authority; emotional support; shared activities; and facilitating autonomy), as discussed in Chapter 4. Thus, it was a parent's responsibility to fulfil various aspects of the parenting role, including being a positive role model, being continually available to their children, providing shelter and love, and protecting their children from danger. Overall, it was perceived that parental responsibility brought stress, worry and hard work to the lives of parents, as this group in 1st class observed:

C1: 'When you're a parent you're mostly responsible for lots of things and when you're a child you're not really responsible for hardly anything.'

C2: 'I think being a child is easier than being a parent because you have to cope with everything and do all the washing up and my mam gets, like when she's tired and all stressed out, she gets a bit strict on me. And when you're young, you don't have to get strict or anything.' 
C3: 'Yeah, and I think when they have to drive in cars and like you're late and you've got a bit of a headache because the children were being bold, then you have to cope with all that as well.'

Childhood, unlike parenthood, was considered relatively worry-free. Comments from the Transition Year group included 'Like, at school you're with your friends. But when they're like at their jobs, sometimes if they're by themselves, they're stressed' and 'Sometimes if you'd be at school and you'd be enjoying yourself, then your mother and father would be out working, Or getting stressed, or lonely or stressed or something'.

In addition, one group in 1st year discussed how parents have a responsibility to ensure that the fun aspect of their children's childhood is preserved:

C1: 'Parents have more responsibility than children. Children are just like, they're there to make sure they behave and have fun while they're still children!

C2: 'And a parent has to be sensible and be responsible, totally grow out of childhood and get into adulthood.'

C3: 'And make sure that the child has, you know, how do you say, that they enjoy their childhood!

Finally, parental responsibility was considered to be a lifelong obligation: 'If you've a child, you've a responsibility for the rest of your life like. It doesn't matter if you're 40. You're the baby no matter what you do' [Transition Year, girl].

In summary, children's accounts of parenthood strongly reflected the theme of parental responsibility. Parenthood is 'hard' because of the many responsibilities involved and the inevitable and unending nature of those responsibilities. However, with parental responsibilities come parental rights. By virtue of children's dependence on their parents for provision and protection, children clearly accepted parents' rights over them, such as the right to monitor their activities and the right to discipline them.

\section{Parental rights}

Children across all groups clearly accepted that their parents had rights. These rights were inextricably linked to the various responsibilities that the parenting role entailed. However, a number of the children in the 1st class group struggled with the concept of rights and often confused them with responsibilities. Thus, for example, when asked about parental rights, children often described parents' responsibility to look after their children. However, children were very clear about parents' rights in terms of 'what parents should be allowed to do'. Parental rights were legitimised by 'superior' parental knowledge and skills, and the work that parents invested in raising their children.

C: 'A parent, you know what you're at, like, you're not stupid. You know what to do, you know how to live and all that, and a child, it's only forming, it's still small.' [1st year, boy]

Researcher: Do you think it's fair then that children don't have the same rights that parents have?

C: 'Well, they say they can't because you're younger ... and you wouldn't have the sort of knowledge available ... because you're kind of just starting off in life and you have to learn things.' [1st year, boy]

Parental rights were clearly underpinned by their parental responsibility, and the idea that children 'belong' to the parents, as these children in 1st year pointed out:

C1: 'They raise them and give birth to them. They should be able to control them - not control them as such, but like you know...'

C2: 'They're their children, like nobody can ever take them away. Well, like, they could take them away, but like they're going to be their children no matter what happens. Even if they are sent away, they're always going to be their children.' 
A discourse of 'ownership' also emerged throughout the focus groups. Some children expressed the idea that parents 'owned' their children: 'They own you. If anything happens the child, it goes back on them' [1st year, boy]. However, this idea of ownership was not ubiquitous, as illustrated in the following quotes from one 4th class group:

C1: 'Because like your mam and dad own you, so they can hit you once or twice and a teacher doesn't own you.'

Researcher: And do you think parents own their children then?

C2: 'Parents own their children, yeah'

C1: 'Yeah'.

C3: 'No, because you have your own life. They don't own your life.'

C4: 'I think God owns your life because He's the one that brought you into the world.'

Two specific aspects of parenting behaviour were discussed in relation to parental rights: the right to monitor and regulate children's behaviours, and the right to physically punish children.

\section{Parental right to regulate and monitor children's behaviours}

There was a general consensus among the children interviewed across all ages that parents had the right to monitor and check the behaviours their children were engaging in. For most children, this was very clearly linked to the notion that it was necessary for parents to know where and what their children were doing in order to be able to protect them from risk and harm. Young children expressed this very simply as follows: 'If your mummy and daddy doesn't know where you are, then anything could happen to you' [1st class, girl]. Thus, protection of the child underpinned parental rights to monitor their children's whereabouts and activities, as this exchange with children in one 1st year group illustrates:

Researcher: What things do parents have a right to know about?

C1: 'Like, if you were up to anything that was serious like.'

C2: 'Anything that would harm, like drink or drugs or anything like that.'

As highlighted above, other children emphasised the fact that parents 'owned them', had raised and looked after them from birth. As a result of this, parents knew what was best for their children and therefore had a right to monitor their behaviour and activities:

'They do [have a right to know where you are] because they raised you for your whole life and then just for you not to respect them anymore and not let them know where you are.' [4th class, girl]

'They've looked after you all these years and they know what's good for you ... what's good for you or not.' [1st year, boy]

As children's age increased, however, so too did the extent to which they qualified the right that parents had to monitor their behaviour. While there was still broad consensus among the older children that parents need to know the whereabouts of their children, many children pointed out that parents did not have a right to know what they were doing if this was not appropriate. This was expressed by one boy in 1st year as 'Because it's our ... like, life ... they shouldn't know what we're doing', and by another in Transition Year, 'They have a right to know where you are, but they don't have a right to know what you're doing there, like if you're with a girl or playing football or whatever'.

As outlined in Chapter 4, most children agreed that mobile phones were very useful in terms of parents being able to check on children and, consequently, better ensure their safety. However, a number of children pointed out that parents can overstep the boundaries of privacy by looking at messages on children's phones or by phoning them repeatedly when they are with their friends. For some children, this represented a lack of trust on the part of the parent.

'They can't always be on your back, like texting you and ringing you, asking you where you are and what you're at. Like, they'll know about some things.' [Transition Year, boy]

'But like it's not really fair on us... What my ma used to do like if I said "I'm going out" and I might be going to my best friend's house, but like if she doesn't see me out on the road, she rings me and says "Where are you?" and like 5 minutes later if I'm heading for the shop, she'll ring again and say "Where do you think you're going?" [Transition Year, boy] 
Thus, as children got older, limits emerged in the extent to which parents had the right to monitor and regulate their children's activities and behaviours.

\section{Parental right to use physical punishment}

A second focus of the discussion of parental rights pertained to the area of physical punishment and specifically whether parents had the right to use physical punishment with their children. Broadly, the consensus was that parents did have a right to punish their children. In answer to the Researcher's question, 'Do you think parents have a right to punish children?', a boy in Transition Year replied, 'The children have no right... You see kids at the age of 6 trying to rob cars ... like children shouldn't be dangerous, bold or causing bodily harm to themselves if they don't want to be punished'. A girl in 1st year replied simply, 'Yeah ... 'cos they own us'.

However, there was less agreement about parental rights to use physical punishment among this group of Transition Year students:

C1: 'To some extent, I think parents have the right to slap because the child is not going to know right from wrong.'

Researcher: So if a parent wants to slap a child, do you think they have the right to do that?

C2: 'Not really.'

C3: 'You can't really ... 'cos the child is kind of helpless. The child can't like hit back.'

Overall, the right to use physical punishment was contingent on specific circumstances, such as the force used by parents and the nature of the child's transgression, as one boy in 1st year observed: 'If it's something really, really bad, yes. But for something small, no. You see a lot of kids getting slapped over.'

In contrast, a small number of children stated that children have a right 'not to be slapped' and 'not to be hurt' by their parents.

In summary, children's accounts of parental rights endorsed parents' right to monitor and regulate their children's activities and to punish their children. Underpinning parental rights was the effort that parents invested in raising their children and the responsibility that parents had for their children. As children got older, however, parental rights became less absolute and certain limits to parental rights were highlighted. For example, parental rights to know about children's whereabouts and activities were constrained by a child's right to privacy and a certain amount of freedom.

Furthermore, while children considered that parents had a right to punish their children, their right to use physical force was contingent on specific circumstances.

\section{Children's rights and responsibilities}

In contrast to children's perspectives on the indisputable rights of parents, children's views on whether they had any rights within their family were questioned. A consensus within many of the groups, even some of the secondary school groups, was that children did not have any rights within their families: 'I don't think that children have rights over their parents ... The children are the children and ... the children shouldn't be standing up to the mothers and fathers because they're not in control. The parents are. And the parents shouldn't let the child take over them' [1st year, girl].

None of the children in 1st class were able to describe what rights they had in their family. By 4th class, however, children described their right to exercise, their right to play, their right to food if they were hungry and their right to say 'No' to something that they did not want to do:

'I think they [children] have the right to play out with their friends and they have the right to walk their dog or let one or two friends in the house.' [4th class, girl]

'If they were asking you to do something you really didn't want to do, you don't have to do it.' [4th class, boy]

The child's right to leisure, privacy, education, love and a good home were all highlighted among the older age groups: 'They have the right to like a warm home and a good family and food, to be loved and all' [Transition Year, girl]. 
Children also described how parents' rights were constrained, thereby reflecting children's rights and parents' responsibilities. For example, older children expressed their right not to be punished harshly; rather, it was their right to be treated fairly by parents. A parent's right to decide certain things (e.g. the choice of secondary school) was also constrained, to an extent, by the wishes of the child.

In contrast to the discussion about children's rights, children's narratives on their responsibility within the family revealed clear perspectives on this issue. Even young children were explicit about the various responsibilities they held within their families, such as cleaning their room, putting away their toys, doing the dishes and taking care of pets. The following comments came from the 1st class group:

C1: 'I think you have to be responsible for all your toys because if you lose your toy you're responsible for it. It's not your mam. Your mam doesn't go looking, so you have to.'

C2: 'She has too many things to do, like cook and wash and look after things.'

C1: 'And even if you ask your brother, they don't have to do it because it's your toy.'

C2: 'Say if you had a Nintendo and you broke it, it's not your mam's fault. It's yours. And you have to look after all your expensive toys very well.'

Some responsibility for their education also emerged within the youngest age group, with these children emphasising their responsibility with regard to going to school and doing their homework.

Similar responsibilities were highlighted by the older children. In addition to household chores, these groups also described children's responsibilities to care for their younger siblings. They considered that they could make a meaningful contribution to the household, to relieve their parents' workload. A boy in Transition Year commented: 'Yeah, kids have to be responsible as well and help everybody out. Like a family works as a unit ... everybody should look out for everybody.'

In summary, children's accounts of their rights within families revealed how they positioned themselves, or were positioned, as lacking control and power within the family arena. As children become older, however, they became more explicit about their rights: prominent among these rights were the right to play, the right to leisure and the right to be treated fairly. Childhood was not wholly without responsibility, however. Even young children considered themselves to have some responsibility within their families. The nature of children's responsibility changed somewhat over time, but common across all age groups was the need to help around the house.

\section{Childhood: A time for fun}

As stated previously, one of the rights that children highlighted was their right to play and have leisure time. Indeed, the theme of childhood as a time of freedom from worry and work emerged strongly in children's comparison of childhood and parenthood. Overall, it was considered that being a child was more fun than being a parent, despite the fact that children acknowledged that they lacked certain skills and knowledge, and the freedom to make choices. However, children also had certain skills that adults did not have, which may allow children to have fun. In answer to the Researcher's question 'Why do you think being a child is more fun than being a parent?', a girl in 4th class replied, 'Because you might be able to run faster and everything'. One of the greatest sources of children's enjoyment was play: 'I'd rather be a child and go on to slides and swings' [1st class, girl].

It was clear that the responsibilities of parenthood may outweigh any privileges that adulthood bestowed. Only a minority of children considered that having money and a job would be more fun than going to school and having time to play and socialise with friends. A group in 4th class debated the issue:

C1: 'Yeah, being an adult is way more fun because you get your job and you get your money if you're really good at the job and, er, being an adult is way more fun.'

C2: 'I think being a child is more fun'.

C3: 'But when you're an adult, you might have to do much more work than the children.'

C4: 'I think it's more fun to be a child because you don't really have responsibility. All you have to do is look after your stuff and play with your friends and worry about school work.' 
However, some children considered that adulthood was not totally without fun: play also emerged as a key source of enjoyment for adults - either playing with their children or remembering their own childhood. Furthermore, occasions such as Mother's Day, Father's Day, birthdays and holidays were also mentioned as sources of fun for parents. Children in 1st class observed the following about adults:

C1: 'I think when you're a child, you get loads of fun. But when you're an adult, you can't really have that fun anymore.'

C2: 'Adults can have some fun, if you're at a dinner.'

C3: 'They can have fun because I've got a trampoline and my dad always goes on it to have a bounce and we really enjoy it because he bounces us up and we go flying. So I think they could have fun if they went on a trampoline with their children.'

C4: 'Well, I suppose adults can have fun when they're younger and like kids, us now, can have fun in trampolines and water fights and stuff and then when we grow up you can think back and go "Oh, I remember having a water fight and that", so we can still have fun.'

C2: 'Adults have fun, like for godmother's day or godfather's day, they give presents.'

C1: 'Their birthdays, they can still have the same fun.'

In summary, despite children's lack of power, choice and autonomy, childhood bestows on them freedom from considerable responsibility and opportunities for fun.

\section{Key findings}

- This chapter considered children's perspectives on the distinction between childhood and parenthood. Childhood was conceptualised as a social status that was clearly distinct from adulthood and parenthood in terms of dependency, responsibility, rights and fun.

- Parenthood was considered difficult because of the high levels of responsibility involved in the lifelong obligation to care for and protect children. Inextricably linked to parental responsibilities were parental rights to monitor and regulate their children's activities. Children generally conceded that parents had the right to regulate, control and discipline them. For the most part, this was accepted without dispute; however, there was a tendency for the older children to question and even resist parents' authority and power.

- In contrast, children were less clear about the nature of children's rights within families. Children in the youngest age group (6-8 years) lacked a clear concept of children's rights. Other children did express their right to be treated well and fairly by their parents, as well as their right to fun, leisure and education. Older children talked about how their right to privacy needed to be balanced with parents' right to monitor and regulate their activities.

- Children of all ages also reflected on various responsibilities within their families, such as a responsibility to care for younger siblings and pets, and to contribute to household chores. In this way, children perceived that they were negotiating their way through childhood towards adulthood. 


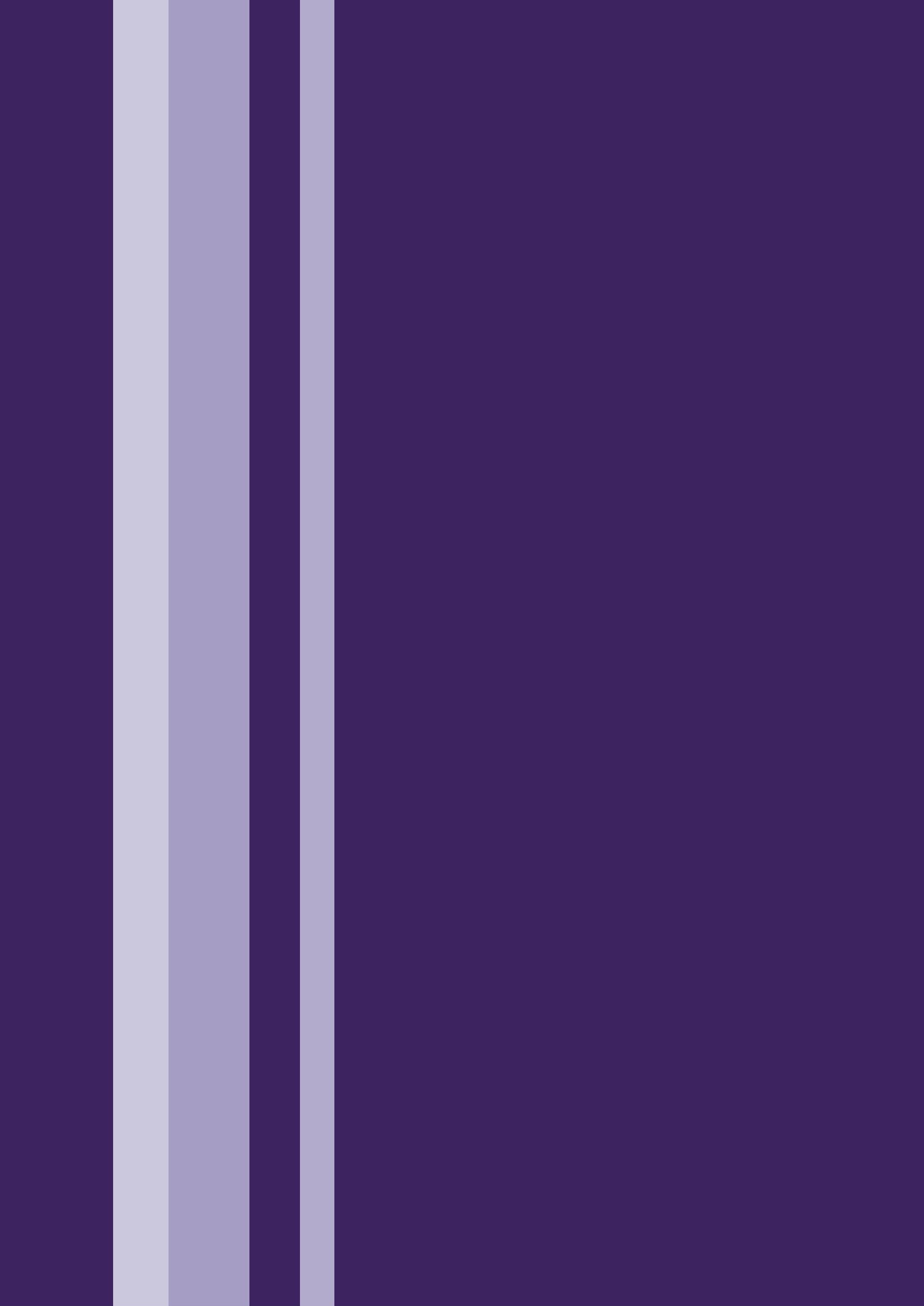




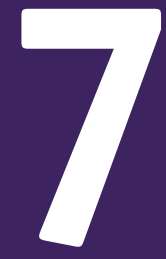

DISCUSSION AND CONCLUSIONS 
The principal aim of this study was to explore children's perspectives on parenting roles and parental approaches to control and discipline. It adopted a qualitative child-centred approach, involving focus group interviews with 132 school-aged children (aged 6-17). The following research questions were addressed:

- What are children's perspectives on the nature of parenting roles?

- What are children's perceptions of the effects of different parenting styles and disciplinary strategies, including physical punishment, on their lives?

- How do children position themselves within the family and what is their understanding of their rights and responsibilities within the family?

- Do children's understanding and perspectives change over time (i.e. as they become older)?

- What are children's perspectives on legislation and policy relating to physical punishment in the home?

Children's narratives highlighted the significance of parents in children's lives and revealed agerelated patterns in their understanding and response to parenting practices. This chapter draws together the findings of the study in light of previous research. The strengths and limitations of the research are then considered, concluding with the implications of the findings for effective policy development relevant to children and their families.

\section{Revisiting the theoretical and policy context for the study}

This study is positioned within a theoretical framework that affords a central role to children in conveying their perspectives and experiences. This approach is commensurate with Article 12 of the United Nations Convention on the Rights of the Child and the ethos of the National Children's Strategy (2000). Central to the framework of the study is the view that children are competent in expressing their perspectives. Assigning children a pivotal role in the research represents a challenge to traditional family research, where there is a tendency for children's accounts to be subsumed into those of their parents (Smart et al, 2001). In this way, the study challenges the assumption that children are unreliable and incapable of providing adequate accounts of their perspectives and experiences.

Findings from this study indicate that children clearly have an invaluable contribution to make in terms of informing policy on effective parenting practices. Family has been identified as a key socialising agent in children's lives, as reflected in the report of the Commission on the Family (1998), the National Children's Strategy (2000) and the Children Act 2001 (Government of Ireland, 2001). One of the guiding principles of the National Children's Strategy is that the family affords the best environment for supporting children's development and external intervention and services should seek to empower families in raising children. Indeed, in recent times Government policy has been re-oriented towards preventative and supportive services to assist families who may be considered to be at risk (National Children's Office, 2005). The establishment of the Family Support Agency in 2003, the national roll-out of Springboard Family Support Projects, the Teen Parenting Support Initiative and the development of a parenting support strategy ('Investing in Parenthood') all represent Government-led initiatives to provide parenting support and education. Within this current policy context, insight into how children actively process family experiences facilitates access to a more precise and nuanced understanding of parenting. This knowledge can usefully be applied to the development of policies and programmes that are responsive and relevant to children's and parents' needs and concerns.

\section{Rights and responsibilities in families}

While this study did not set out to examine children's perspectives on rights and responsibilities within families, these concepts emerged as definitive features of child and adult statuses and relations within families. An initial exploration of children's perspectives on parents' roles underscored the wide-ranging and extensive roles that parents were expected to perform in relation to their children. These ranged from providing nutrients, shelter and conditions for 
the maintenance of health, to moral guides, emotional supports, and figures of discipline and authority. These findings clearly converge with previous research in the area. For example, Brannen et al (2000) reported that children's role expectations of their parents were very high, while Morrow (1998) highlighted the centrality of parents to children, as providers of practical and emotional support.

Gender also emerged as a defining feature of parents' roles in families. While this theme was not ubiquitous, there was a tendency for certain aspects of the parenting role to be more closely aligned to one parent or the other. Similar to the findings of Morrow (1998), dominant descriptions of mother roles portrayed mothers as home-makers who were likely to be more involved in taking care of the children. The traditional gendered division of labour in the family was further illustrated by children's descriptions of dominant father roles in terms of working outside the home and financially supporting the family. However, in two-thirds of the families in the sample, fathers were identified as the main wage-earner in the home, suggesting the significance of children's own family experiences in their formation of parental role expectations.

Key developmental patterns indicated that parents' roles became less focused on the provision of basic care over time, as older children became more independent. These findings support the idea that the development of the child is an important context for parenting (Maccoby, 1984). An important facet of the parent's role during adolescence was the facilitation of the adolescent's autonomy and increasing levels of independence. The present study findings are consistent with previous research, which has documented similar changes in the nature of the parent-adolescent relationship and the nature of the parent's role during the period of adolescence (Steinberg and Silk, 2002; Laursen and Bukowski, 1997).

Together, findings pertaining to children's perspectives on parents' roles in relation to their children emphasise parents' responsibility for their children. Children differ from their parents since they do not carry serious responsibility. Relative to adulthood and parenthood then, childhood is free from responsibility as children assume they will be protected and cared for by their parents. In her study of children growing up in London, Mayall (2001) depicted similar child-adult relation structures. Thus, children position themselves as subordinate to their parents and, as such, lack power and control. A discourse of ownership, which emerged throughout some of the focus groups, strongly reflects this theme of subordination. Resonating this, children were explicit in their acknowledgement of parents' rights to monitor and control them and punish them for their (mis)behaviour. Indeed, parental control was considered necessary and good, and always underpinned by a protectionist motivation and parental concern for children's well-being.

In terms of children's rights, the findings from this study prompt further reflection on the current debate on the protection of children's rights in family settings in the Irish Constitution. Younger children lacked a clear understanding about the word 'rights', often confusing it with responsibility, and were uncertain about whether they had any rights in their families. However, they did understand that there were limits to what parents are allowed to do and also that they should have a certain amount of freedom, such as the freedom to play and exercise. Among the older children, the balance between rights and responsibilities became more explicit. With increasing age, and increasing responsibility, greater constraints emerged around parental rights. Furthermore, adolescents' rights to privacy and their own space became increasingly salient over time.

\section{Parental control and discipline}

Children's accounts of parental control and discipline strategies challenged predominant trends in research and theory on family discipline, which have previously emphasised the concept of socialising passive children (Parke and Buriel, 1998). Consistent with more recent child-centred approaches to researching family discipline (Smith et al, 2005), children and young people in the present study were competent in conveying feelings about and interpretations of parental discipline responses. Prominent in children's accounts was their conviction that parental use of discipline was both justified and motivated by concern for child safety and well-being. Equally 
significant, children and young people conveyed the sense that they were active agents in eliciting parental disciplinary responses. Related to this, children provided precise illustrations of acceptable and unacceptable behaviours, with reference to parents' behaviours as well as their own.

In describing the rules and regulations that parents enforce, three predominant categories of behaviours were targeted: moral behaviours, safety-related behaviours and social conventional behaviours. In addition, the narratives of children in the older age group focused more on rules pertaining to achievement and psychological well-being. Most children demonstrated the ability to draw conceptual distinctions between the seriousness of misdemeanours related to these categories of behaviour, with safety-related behaviours considered as warranting more severe discipline strategies, followed by transgressions in moral behaviours and, finally, social conventional behaviours. This is largely in keeping with previous research findings (Smetana and Braeges, 1991; Catron and Masters, 1993; Smith et al, 2005). Moreover, an ethic of fairness dominated children's views, with a strong emphasis on the necessity for the punishment to match the misdeed.

Classifications of the types of discipline strategy that parents adopted in the present study corresponded to three primary categories of discipline strategy outlined in the literature: powerassertive strategies, inductive strategies and love-withdrawal strategies (Grusec and Goodnow, 1994; Hoffman, 1970). Children's responses to each of these categories were individual and varied according to contextual considerations, notably age of child and nature and seriousness of the misdeed. Developmental patterns were also evident, with younger children describing more exclusively power-assertive strategies (such as time-out and instances of physical punishment), while older children placed more emphasis on inductive strategies (such as reasoning and communication) and, to a lesser extent, love-withdrawal strategies. These findings reflect trends from previous studies, which found that inductive strategies are more likely to be used with older children and power-assertive strategies are more likely to be used with younger children (Wissow, 2002; Maxwell, 1995). In keeping with Hoffman's (2000) thesis that inductive strategies are more likely to promote and encourage more effective processing and internalisation of parental standards and expectations, older children highlighted the benefits of constructive, instructional discipline strategies that acknowledged their ability to assume responsibility for their behaviours.

The effectiveness of discipline strategies was associated with four key features: loss of privilege, instructional value, consistency and fairness (the match between punishment and misdeed). Parental use of 'time-out', which involves socially isolating a child for a brief period and temporarily suspending their normal activities (Smith et al, 2005), was described by the majority of children. There was a degree of ambivalence in children's accounts about the effectiveness of this strategy, as identified in prior research (Readdick and Chapman, 2000). Children emphasised the significance of loss of privilege with reference to 'time-out', highlighting situations where they had access to other privileges to compensate for their loss (such as playing with computers or watching TV), thereby significantly diminishing the usefulness of such a strategy, and this view was expressed across all age groups. While children in the younger age groups were less discriminating in evaluating key features of effective parental responses, many of these children demonstrated clearly an ability to assess, judge and respond to the strategies that parents enforced. This finding is consistent with the research by Konstantareas and Desbois (2001).

Children also drew attention to the need for parents to be consistent in their responses and to see a strategy through to completion, once it had been enforced. The instructional value of discipline strategies was a primary component of effective discipline responses for most children, but particularly among adolescent age groups. In line with arguments put forward by Gershoff (2002), power-assertive strategies - most notably physical punishment - were associated with effectiveness in curbing and challenging serious behaviours, but typically were not associated with effective longterm outcomes. Allied to these views, children assigned increasing significance to the role that the quality of child-parent interactions played in facilitating the internalisation of parental expectations, rather than relying on external corrections. Previous researchers have also provided clear evidence for the importance of child-parent relationships in determining the utilisation of discipline strategies and the subsequent effectiveness of punishments (Parke, 2002; Holden 2002). 
As previously outlined, an ethic of fairness permeated children's narratives on effective discipline strategies, regardless of age group. Narratives underscored the necessity for parents to evaluate the seriousness of misbehaviours and to respond with strategies that corresponded in terms of severity and intensity of punishment. Where the severity of punishment enforced was perceived to exceed the seriousness of the misbehaviour, the effectiveness of the strategy was deemed to be weakened. Furthermore, some children voiced the opinion that they had experienced differential treatment on the part of parents and this was mostly with regard to parents' responses to sibling behaviours. Other studies have also drawn attention to perceptions of differential treatment of siblings (Horton et al, 2001; Konstantareas and Desbois, 2001).

Consistent with a developmental framework, children's ability to cognitively process parental expectations, societal standards and disciplinary responses with increasing age was clearly evident (Kochanska, 1993; Grusec and Goodnow, 1994). Specifically, younger children relayed accounts of parental monitoring and regulating strategies that placed central importance on concrete elements such as physical proximity and personal possessions. In contrast to this, older children displayed the ability to cognitively process information using more abstract and hypothetical constructs, and demonstrated greater abilities in terms of empathising with parental views and anxieties. Moreover, older children highlighted the necessity for parents and children to adjust their monitoring and regulating strategies though greater emphasis on flexibility and negotiation in their interactions with adolescents. Finally, the narratives of children in the older age groups provided evidence of adolescents' ability to be self-critical and open in communicating their views on parental discipline strategies. Vertical interactions, typical of the child-parent relationship, yielded on occasion to more horizontal interactions, where children exercised their agency and power through negotiation and manipulation of parental responses. More specifically, the potential for children to manipulate parents emerged as a result of more complex processing of parental responses within particular contexts. Thus, the developmental context emerged as highly significant.

\section{Physical punishment}

Ambivalence permeated children's perspectives on the use of physical punishment as a discipline strategy. Narratives conveyed negative affect on the part of all children in response to the use of physical punishment, with descriptions of feeling sore, sad, mad and unloved included in children's responses, in line with previous studies (Horgan, 2002; Dobbs, 2002). In spite of these negative affective responses, however, there was a general consensus among children that they accepted the use of physical punishment as a parental right. As highlighted in a similar study of children's perspectives in the USA (Graziano et al, 1996), most children in the present study expressed feelings of hurt, upset and anger in their responses, but acknowledged that it was effective and appropriate in addressing misbehaviour in specific and precise contexts. Prominent in children's accounts was the lack of any ambiguity or confusion when differentiating between parental rights to punish physically and the rights of a teacher or other individuals to administer this punishment. For all children, parental rights were embedded in the view that the relational history between parent and child was unique, privileged and endowed with knowledge that was specific to the experience of family life. Such views are in contrast to previous research findings where children regarded physical punishment as more acceptable when administered by a teacher rather than by a babysitter or even their own mother (Catron and Masters, 1993).

\section{Rationales for physical punishment}

Children's perspectives on the rationales for physical punishment were context-dependent, with specific reference to the age of the child, frequency and intensity of the administration of such punishment and the severity of the misdeed that elicited such a response. Consistent with other studies, children across all ages clearly stipulated that slapping a child was only acceptable and appropriate for serious transgressions, most notably in the case of safety-related behaviours (Catron and Masters, 1993). Younger children also expressed views that were more broadly accepting of physical punishment as outlined in previous studies (Willow and Hyder, 1998). Context 
was a central component in rationales for physical punishment and developmental patterns were revealed, with older children elaborating and providing more detailed qualification when arguing in favour of physical punishment. Specific contexts highlighted as warranting physical punishment included younger children's engagement in dangerous behaviours. It is worth noting that most children clarified that such a strategy would involve a light slap or tap, and were unanimously against frequent or severe physical punishment. Children also expressed the view that physical punishment was both more effective and more acceptable when used with younger children. A key argument in favour of physical punishment centred on the effectiveness of such a severe strategy in curbing or preventing health-risk behaviours, such as smoking and drug-related activities.

\section{Rationales against physical punishment}

Children's rationales against physical punishment centred on two primary issues: the potential for causing distress and pain to a child, and the lack of constructive or instructional value inherent in such a strategy. Negative consequences of physical punishment were expressed by children both in terms of the physical and psychological distress that it inflicted. Narratives underscored the fact that not only did physical punishment cause physical pain and discomfort to children, but also it had the potential to cause long-term emotional distress. Moreover, children also expressed their concern that slapping children had serious implications for the quality of child-parent relationships. Such a finding is consistent with a large body of research that emphasises the potentially damaging effects of physical punishment, which children themselves highlight (Cutting, 2001; Horgan, 2002; Dobbs, 2002). Much research has documented the lack of constructive learning inherent in physical punishment (Smith et al, 2005; Holden, 2002; Straus and Stewart, 1999) and these findings were overwhelmingly supported in children's narratives in the present study.

Developmental patterns were also apparent in these accounts, with some children acknowledging younger children's lack of ability to internalise standards and expectations as effectively as older children. Related to the lack of constructive instructional value inherent in slapping a child, a number of children voiced their concerns that such a strategy had the potential to generate increased anti-social behaviours and aggressive responses in later life. Modelling of parental aggressive and violent responses in childhood was, therefore, considered as contributing to negative patterns of behaviour. Such influences were deemed to be relevant to children's behaviour with peers and to the risk of the inter-generational transmission of more violent practices in parenting, all of which is consistent with other findings (Cutting, 2001; Willow and Hyder, 1998).

\section{Perspectives on banning parental use of physical punishment}

Finally, children's views on the possibility of banning parental use of physical punishment also reflected a substantial degree of ambivalence. A minority of children were unequivocally in favour of banning parental use of physical punishment and rationales in support of this action centred on causing injury to a child. As previously outlined, there was a strong consensus that despite negative responses to physical punishment, parents had the right to use this strategy in selective and appropriate circumstances. Significantly, children assigned this right exclusively to their parents, but not to other authority figures, such as teachers. Many children expressed some reluctance to ban physical punishment and these views were primarily associated with the difficulties of monitoring parental behaviours in the home and the fear that parents would be imprisoned for using such disciplinary strategies.

\section{Methodological strengths and limitations of the research}

This report does not make any claims regarding the prevalence of different parenting styles or parental approaches to discipline within Irish families. Rather, the study seeks to explore children's perspectives on a range of issues related to parenting and parents' use of discipline in the home. Caution should be exercised in extrapolating the findings of the study to all families in Ireland. The sample size is relatively small and although children were recruited through schools, which are optimal settings for accessing the broad population of children, there is likely to be some bias 
in the type of parent who is willing to allow a researcher to invite their child to participate in a focus group about parenting. Indeed, one school Principal remarked that she felt that parents were reluctant to return the consent forms because they may have feared that their own parenting behaviour was under scrutiny in some way.

A further methodological issue relates to the use of focus group methods. Generally, the focus groups appeared to work well in stimulating discussion among children and young people, and in eliciting a variety of perspectives. However, group processes within focus groups may not always yield a positive dynamic. For example, as highlighted by Hennessy and Heary (2005), some participants may feel intimidated within the group and may be inhibited from expressing their true opinion. Furthermore, individuals may be unwilling to express a perspective that diverges from the majority opinion. Within the present study, there were numerous examples within the focus groups of contradictory perspectives being discussed and debated. However, it is also possible that divergent voices were not heard within the groups and consensus on particular issues may have emerged due to shyness or lack of confidence on the part of some participants.

The use of focus groups to explore children's perspectives on issues such as parenting roles and discipline also presented the researchers with particular ethical challenges. The principles of informed consent and confidentiality were central throughout data collection. However, within the context of a focus group, confidentiality can never be guaranteed since disclosures are shared with all group members. While our primary interest was in children's perspectives, as opposed to their experiences, we were aware of the potential for children to disclose information on parenting behaviours that indicated that they were being physically harmed in some way. Children were made aware of the limits to confidentiality and this may have inhibited some children from freely expressing their perspectives.

Notwithstanding these issues, the focus group discussions did yield rich insight into the complexity of children's understanding of parents and parenting practices. Given the group format of data collection, not every child was required to respond to every question and children had the choice to opt out of the discussion at particular points if they wished to do so. Furthermore, the dynamics within a number of the groups gave rise to particular perspectives being challenged and questioned, thus yielding a deeper understanding of the ambiguous and complex nature of children's perspectives on these issues. One recommendation for future research would be to use a mixed methods approach to explore these issues. Specifically, the use of individual interviews, as an adjunct to focus groups, may overcome some of the limitations of focus groups. Individual interviews with children and adolescents may also provide a forum for going beyond exploring children's perspectives on these issues, to tap into their experiences of different styles of parenting and the meaning attached to those experiences.

\section{Conclusions}

It is clear that children have a seminal contribution to make to our understanding of parenting in Ireland. Children clearly position themselves as subordinate to their parents and affirm parents' rights to control and monitor their behaviour in the interest of their safety and wellbeing. A discourse of 'ownership' surrounded some of the children's narratives on parents and some younger children questioned whether they had any rights within their families. Further work is needed to examine children's understanding of their rights in a family context. A children's rights perspective is desirable in order to access the meaning of parental practices and use of physical punishment for children within their families.

Parents relied on a range of disciplinary strategies, including inductive responses, powerassertive strategies and love withdrawal. According to the children, four principles underpinned effective discipline: loss of privilege, instructional value, consistency and fairness. Grounding children, restricting their activities and depriving them of privileges were identified as effective means of disciplining children, while physical punishment was considered to be less effective. There was no clear consensus regarding children's perspectives on parental use of physical 
punishment. While children generally accepted the use of physical punishment as a parental right, their endorsement of physical punishment was clearly dependent on the context of the discipline encounter. Children acknowledged that parents are more likely to use physical punishment as a result of feeling frustration, anger or lack of control. Across all age groups, mild physical punishment was only acceptable and appropriate for more serious transgressions, such as when the child is in danger or at risk. Children were unanimously against frequent or severe physical punishment. Children's rationales against parental use of physical punishment centred on the potential for causing distress and pain to a child and damage to the parentchild relationship, as well as the lack of instructional value inherent in the approach. While many children expressed a reluctance to legally prohibit physical punishment, a number of children argued that such a ban could protect children whose parents used physical punishment excessively.

Children's ability to articulate their views on parenting suggests that family policy development could benefit from a child-centred ethos, which takes account of the developmental needs and rights of individual children within their families. Messages arising from this research could usefully inform the development of a public information campaign on safe and effective discipline of children. Children's views on these issues could also be incorporated into existing parenting programmes that seek to provide support for parents. Through disseminating the findings of this research, parents' awareness of their children's perspectives on discipline and punishment could be heightened. This may be beneficial in helping to curb practices which children deemed to be inappropriate and harmful. On the other hand, the prevalence of inductive disciplinary practices highlighted in the study suggests that there is scope for building on existing practices in order to promote effective, constructive and positive discipline of children. 
REFERENCES 
Alanen, L. and Mayall, B. (eds.) (2001) Conceptualising child-adult relationships. London: Routledge Falmer.

Anderson, S., Murray, L. and Brownlie, J. (2002) Disciplining Children: Research with Parents in Scotland. Edinburgh: Scottish National Executive.

Anyan, S.E. and Pryor, J. (2002) 'What is in a family? Adolescent perceptions', Children and Society, Vol. 16, pp. 306-17.

Arendell, T. (1997) 'A social constructionist approach to parenting'. In: T. Arendell (ed.), Contemporary Parenting: Challenges and Issues. Thousand Oaks, CA: Sage, pp. 1-44.

Bainham, A., Sclater, S.D. and Richards, M. (eds.) (2003) What is a parent? A socio-legal analysis. 0xford: Hart.

Baldwin, A.L. (1955) Behaviour and development in childhood. New York: Dryden Press.

Barnardos (2007) The Case for Constitutional Change. Dublin: Barnardos.

Basch, C.E. (1987) 'Focus group interview: An underutilized research technique for improving theory and practice in health education', Health Education and Behaviour, Vol. 14, pp. 411-48.

Baumrind, D. (1967) 'Child care practices anteceding three patterns of pre-school behaviour', Genetic Psychology Monographs, Vol. 75, pp. 43-88.

Baumrind, D. (1968) 'Authoritarian v. authoritative parental control', Adolescence, Vol. 3, pp. 255-72.

Baumrind, D. (1978) 'Parental disciplinary practices and social competence in children', Youth and Society, Vol. 9, pp. 239-76.

Baumrind, D. (1991) 'Does causally relevant research support a blanket injunction against disciplinary spanking by parents?', Invited Address at the 109th Annual Convention of the American Psychological Association, August 2001.

Baumrind, D., Larzelere, R.E. and Cowan, P.A. (2002) 'Ordinary Physical Punishment: Is it harmful? Comment on Gershoff (2002)', Psychological Bulletin, Vol. 128, No. 4, pp. 580-89.

Baumrind, D. and Thompson, R.A. (2002) 'The ethics of parenting'. In: M.H. Bornstein (ed.), Handbook of Parenting. Volume 5: Practical Issues in Parenting (2nd edition). Mahwah, NJ: Lawrence Erlbaum Associates, pp. 3-34.

Belsky, J. (1981) 'Early human experience: A family perspective', Developmental Psychology, Vol. 17, pp. 2-23.

Borkowski, J.G., Ramey, S.L. and Bristol-Power, M. (eds.) (2002) Parenting and the child's world: Influences on academic, intellectual and social-emotional development. Mahwah, NJ: Lawrence Erlbaum Associates.

Bornstein, M.H. (ed.) (2002) Handbook of Parenting. Volumes 1-5 (2nd edition). Mahwah, NJ: Lawrence Erlbaum Associates.

Bradley, R.H. (2002) 'Environment and Parenting'. In: M.H. Bornstein (ed.), Handbook of Parenting. Volume 2: Biology and Ecology of Parenting (2nd edition). Mahwah, NJ: Lawrence Erlbaum Associates, pp. 281-314.

Brannen, J. and O'Brien, M. (eds.) (1996) Children in families: Research and policy. London: Falmer Press.

Brannen, J., Heptinstall, E. and Bhopal, K. (2000) Connecting children. Care and family life in later childhood. London: Routledge Falmer.

Braun, V. and Clarke, V. (2006) 'Using thematic analysis in psychology', Qualitative Research in Psychology, Vol. 3, pp. 77-101.

Brownlie, J. and Anderson, S. (2006) 'Beyond anti-smacking. Rethinking parent-child relations', Childhood, Vol. 13, pp. 479-98.

Catron, T.F, and Masters, J.C. (1993) 'Mothers' and children's conceptualisations of corporal punishment', Child Development, Vol. 64, pp. 1815-28.

Central Statistics Office (2007) Census 2006. Volume 3: Household Composition, Family Units and Fertility. Dublin: The Stationery Office.

Children's Rights Alliance (1998) Children's Rights: Our Responsibilities. Concluding Observations of the United Nations Committee on the Rights of the Child following Examination of the First National Report of Ireland on the Implementation of the Convention on the Rights of the Child. Dublin: Children's Rights Alliance. 
Clarke-Power, F. and Hart, S.N (2005) 'The Way Forward to Constructive Child Discipline'. In: Eliminating Corporal Punishment: The Way Forward to Constructive Child Discipline. Paris: UNESCO Publishing, pp. 91-123.

Cleary, A., Ni Ghiolla Phadraig, M. and Quin, S. (eds.) (2001) Understanding Children. Volume 2: Changing Experiences and Family Forms. Cork: Oak Tree Press.

Colgan McCarthy, I. (ed.) (1995) Irish Family Studies: Selected papers. Dublin: Family Studies Centre.

Collins, W.A. and Madsen, S.D. (2003) 'Developmental change in parenting interactions'. In: L. Kuczynski (ed.), Handbook of Dynamics in Parent-Child Relations. Thousand Oaks, CA: Sage, pp. 49-66.

Commission on the Family (1998) Strengthening Families for Life: Final Report of the Commission on the Family. Dublin: The Stationery Office.

Cooper, C.R., Grotevant, H.D. and Condon, S.L. (1983) 'Individuality and connectedness in the family as a context for adolescent identity formation and role-taking skill'. In: H.D. Grotevant and C.R. Cooper (eds.), Adolescent development in the family: New directions in child development, Volume 22. San Francisco: Jossey-Bass, pp. 43-59.

Council of Europe (2007) Abolishing Corporal Punishment of Children: Questions and Answers. Strasbourg: Council of Europe Publishing.

Council of Europe (2008) Eliminating Corporal Punishment: A Human Rights Imperative for Europe's Children. Strasbourg: Council of Europe Publishing.

Coyne, I., Hayes, E., Gallagher, P. and Regan, G. (2006) Giving Children a Voice: Investigation of children's experiences of participation in consultation and decision-making in Irish hospitals. The National Children's Strategy Research Series, Office of the Minister for Children and Youth Affairs. Dublin: The Stationery Office.

Crouter, A.C. and Booth, A. (eds.) (2003) Children's Influence on Family Dynamics: The neglected side of family relationships. Mahwah, NJ: Lawrence Erlbaum Associates.

Cutting, E. (2001) It doesn't sort anything out: A report on the views of children and young people about the use of physical punishment. Edinburgh: Save the Children, Scotland.

Department of Education and Science (2006) School Matters: The Report of the Task Force on Student Behaviour in Second-level Schools. Dublin: The Stationery Office.

Department of Health and Children (1999) Children First: National Guidelines for the Protection and Welfare of Children. Dublin: The Stationery Office.

Department of Health and Children (2000) The National Children's Strategy: Our children - Their lives. Dublin: The Stationery Office.

DeWolff, M. and Van Ijzendoorn, M.H. (1997) 'Sensitivity and attachment: A meta-analysis on parental antecedents of infant attachment', Child Development, Vol. 69, pp. 129-39.

Dietz, T.L. (2000) 'Disciplining children: Characteristics associated with the use of corporal punishment', Child Abuse and Neglect, Vol. 24, pp. 1529-42.

Dobbs, T. (2002) The missing voice: What are children's views on physical punishment? Unpublished manuscript, University of Otago, Dunedin, New Zealand.

Dornbusch, S.N., Ritter, P.L., Leiderman, P.H., Roberts, D.F. and Fraleigh, M.J. (1987) 'The relation of parenting style to adolescent school performance', Child Development, Vol. 58, pp. 1244-57.

Durrant, J.E, Ensom, R. and Coalition on Physical Punishment of Children and Youth (2004) Joint Statement on Physical Punishment of Children and Youth. Ottawa: Coalition on Physical Punishment of Children and Youth. Available at: www.cheo.ca/english/pdf/joint_statement_e.pdf (accessed May 2009)

Eisenberg, N., Losoya, S. and Fabes, R.A. (2001) 'Parental socialisation of children's dysregulated expression of emotion and externalising problems', Journal of Family Psychology, Vol. 15, pp. 183-205.

French, D.J., Carroll, A. and Christie, M.J. (1998) 'Health-related quality of life in Australian children with asthma: Lessons for the cross-cultural use of quality of life instruments', Quality of Life Research, Vol. 7, pp. 409-19.

Garcia Coll, C.T., Meyer, E.C. and Brillon, L. (1995) 'Ethnic and Minority Parenting'. In: M.H. Bornstein (ed.), Handbook of Parenting. Volume 2: Biology and Ecology of Parenting (2nd edition). Mahwah, NJ: Lawrence Erlbaum Associates, pp. 189-209. 
Gershoff, E.T. (2002) 'Corporal punishment by parents and associated child behaviours and experiences: A meta-analytic and theoretical review', Psychological Bulletin, Vol. 128, No. 4, pp. 539-79.

Ghate, D., Hazel, N., Creighton, S., Finch, S. and Field, J. (2003) The National Study of Parents, Children and Discipline in Britain. London: Policy Research Bureau.

Government of Ireland (2001) The Children Act 2001. Dublin: The Stationery Office.

Graziano, A.M., Hamblen, J.L. and Plante, W.A. (1996) 'Sub-abusive violence in child rearing in middle-class American families', Pediatrics, Vol. 98, pp. 845-51.

Greene, S. and Hill, M. (2005) 'Researching children's experience: Methods and methodological issues'. In: S. Greene and D.M. Hogan (eds.), Researching children's experience: Approaches and methods. London: Sage, pp. 1-21.

Greene, S. and Hogan, D.M. (2005) (eds.) Researching children's experience: Approaches and methods. London: Sage.

Greene, S., Nugent, K. and Wieczorek-Deering, D. (1995) 'Eighteen months old in Dublin', Children and Society, Vol. 9, pp. 86-98.

Grotevant, H.D. and Cooper, C.R. (eds.) (1983) Adolescent development in the family: New directions in child development, Volume 22. San Francisco: Jossey-Bass.

Grusec, J. (2002) 'Parental socialisation and children's acquisition of values'. In: M.H. Bornstein (ed.), Handbook of Parenting. Volume 5: Practical Issues in Parenting (2nd edition). Mahwah, NJ: Lawrence Erlbaum Associates, pp. 143-68.

Grusec, J.E. and Goodnow, J.J. (1994) 'Impact of parental discipline methods on the child's internalisation of values: A reconceptualisation of current points of view', Developmental Psychology, Vol. 30, pp. 4-19.

Halfon, N., McLearn, K.T. and Schuster, M.A. (eds.) (2002) Child Rearing in America: Challenges facing parents with young children. New York: Cambridge University Press.

Hastings, P.D., Zahn-Waxler, C., Robinson, J., Usher, B. and Bridges, D. (2000) 'The development of concern for others in children with behaviour problems', Developmental Psychology, Vol. 36, pp. 531-46.

Heary, C. and Hennessy, E. (2002) 'The use of focus group interviews in pediatric health care research', Journal of Pediatric Psychology, Vol. 27, pp. 47-57.

Hendricks, A.K. (1999) Fathers who care: Partners in parenting. Children's views on fathering. Wellington, NZ: Office of the Commissioner for Children.

Hennessy, E. and Heary, C. (2005) 'Exploring children's views through focus groups'. In: S. Greene and D.M. Hogan (eds.), Researching children's experience: Approaches and methods. London: Sage, pp. 236-52.

Higgins, E.T., Ruble, D. and Hartup, W. (eds.) (1983) Social Cognition and Social Development: A Socio-Cultural Perspective. Cambridge: Cambridge University Press.

Hill, M., Laybourn, A. and Borland, M. (1996) 'Engaging with primary-aged children about their emotions and well-being: Methodological considerations', Children and Society, Vol. 10, pp. 129-44.

Hoffman, M.L. (1970) 'Moral development'. In: P.H. Mussen (ed.), Carmichael's Manual of Child Psychology, Volume 2. New York: Wiley, pp. 261-360.

Hoffman, M.L. (1983) 'Affective and cognitive processes in moral internalisation'. In: E.T. Higgins, D. Ruble and W. Hartup (eds.), Social Cognition and Social Development: A Socio-Cultural Perspective. Cambridge: Cambridge University Press, pp. 236-74.

Hoffman, M.L. (2000) Empathy and Moral Development: Implications for Caring and Justice. Cambridge: Cambridge University Press.

Hogan, D.M. (1996) 'Valuing the child in research: Historical and current influences on research methodology with children'. In: D.M. Hogan and R. Gilligan (eds.), Researching Children's Experiences: Qualitative Approaches. Dublin: Children's Research Centre, Trinity College Dublin, pp. 1-9.

Hogan, D.M. and Gilligan, R. (eds.) (1996) Researching Children's Experiences: Qualitative Approaches. Dublin: Children's Research Centre, Trinity College Dublin. 
Hogan, D.M., Etz, K.E. and Tudge, J.R. (1999) 'Reconsidering the role of children in family research: Conceptual and methodological issues'. In: C.L. Shehan (ed.), Through the eyes of the child: Revisioning children as active agents of family life. Stamford, CT: JAI Press Inc., pp. 93-105.

Hogan, D.M., Halpenny, A.M. and Greene, S. (2002) Children's experiences of parental separation. Dublin: Children's Research Centre, Trinity College Dublin.

Holden, G.W. (2002) 'Perspectives on the effects of corporal punishment: Comment on Gershoff (2002)', Psychological Bulletin, Vol. 128, No. 4, pp. 590-95.

Horgan, G. (2002) It's a Hit, Not a 'Smack'. Belfast: Save the Children.

Horton, N.K., Ray, G.E. and Cohen, R. (2001) 'Children's evaluations of inductive discipline as a function of transgression type and induction orientation', Child Study Journal, Vol. 31, pp. 71-93.

Houghton, S., Carroll, A. and Odgers, P. (1998) 'Young children, adolescents and alcohol. Part I: Exploring knowledge and awareness of alcohol and related issues', Journal of Child and Adolescent Substances Abuse, Vol. 7, pp. 1-29.

Iona Institute (2007) Marriage breakdown and family structure in Ireland. A report based on Census 2006. Dublin: Iona Institute.

James, A. (1998) 'From the child's point of view: Issues in the social construction of childhood'. In: C. Panter-Brick (ed.), Biosocial perspectives on children. Cambridge: Cambridge University Press, pp. 45-65.

James, A. (2003) 'Parents: A children's perspective'. In: A. Bainham, S.D. Sclater and M. Richards (eds.), What is a parent? A socio-legal analysis. 0xford: Hart, pp. 181-95.

James, A., Jenks, C. and Prout, A. (1998) Theorizing Childhood. Cambridge: Polity Press.

Janssens, J.M. and Gerris, J.R. (1992) 'Child rearing, empathy and prosocial development'. In: J.M. Janssens and J.R. Gerris (eds.), Child rearing: Influence on prosocial and moral development. Amsterdam: Swets and Zeitlinger, pp. 57-75.

Kerr, M. and Stattin, H. (2003) 'Parenting of adolescents: Action or Reaction?' In: A.C. Crouter and A. Booth (eds.), Children's Influence on Family Dynamics: The Neglected Side of Family Relationships. Mahwah, NJ: Lawrence Erlbaum Associates, pp. 121-52.

Kiely, G. (1995) 'Fathers in families'. In: I. Colgan McCarthy (ed.), Irish Family Studies: Selected papers. Dublin: Family Studies Centre, pp. 147-58.

Kiely, G. (2001) 'The Changing Role of Fathers'. In: Anne Cleary, Maire Ni Ghiolla Phadraig and Suzanne Quin (eds.), Understanding Children. Volume 2: Changing Experiences and Family Forms. Cork: Oak Tree Press, pp. 3-19.

Kitzinger, J. (1994) 'The methodology of focus groups: The importance of interaction between research participants', Sociology of Health and Illness, Vol. 16, pp. 103-21.

Knapp, S.J. (1999) 'Facing the child. Rethinking models of agency in parent-child relations'. In: C.L. Shehan (ed.), Through the eyes of the child. Revisioning children as active agents of family life. Stamford, CT: JAI Press Inc., pp. 53-75.

Kochanska, G. (1993) 'Towards a synthesis of parental socialisation and child temperament in early development of conscience', Child Development, Vol. 64, pp. 325-47.

Konstantareas, M.M. and Desbois, N. (2001) 'Pre-schoolers' perceptions of the unfairness of maternal disciplinary practices', Child Abuse and Neglect, Vol. 25, pp. 473-88.

Kreuger, R.A. (1994) Focus Groups: A practical guide for applied research. London: Sage.

Kuczynski, L. (ed.) (2003) Handbook of Dynamics in Parent-Child Relations. Thousand Oaks, CA: Sage.

Ladd, G.W. and Pettit, G.S. (2002) 'Parenting and the development of children's peer relationships'. In: M.H. Bornstein (ed.), Handbook of Parenting. Volume 5: Practical Issues in Parenting (2nd edition). Mahwah, NJ: Lawrence Erlbaum Associates, pp. 269-309.

Larzelere, R.E. (2000) 'Child outcomes of non-abusive and customary physical punishment by parents: An updated literature review', Clinical Child and Family Psychology Review, Vol. 3, pp. 199-221.

Laursen, B. and Bukowski, W.M. (1997) 'A developmental guide to the organisation of close relationships', International Journal of Behavioural Development, Vol. 21, pp. 747-70. 
Levine, I.S. and Zimmerman, J.D. (1996) 'Using qualitative data to inform public policy: Evaluating "Choose to defuse" ', American Journal of Orthopsychiatry, Vol. 66, pp. 363-77.

Lewis, A. (1992) 'Group child interviews as a research tool', British Educational Research Journal, Vol. 18, pp. 413-21.

Loeb, R.C., Horst, L. and Horton, P. (1980) 'Family interaction patterns associated with self-esteem in pre-adolescent girls and boys', Merrill-Palmer Quarterly, Vol. 26, pp. 205-17.

Maccoby, E.E. (1984) 'Socialisation and developmental change', Child Development, Vol. 55, pp. 317-28.

Maccoby, E.E. (1992) 'The role of the parents in the socialisation of children: An historical overview', Developmental Psychology, Vol. 28, pp. 1006-17.

Maccoby, E.E. and Martin, J.A. (1983) 'Socialization in the context of the family: Parent-child interaction'. In: P.H. Mussen (Series Ed.) and E.M. Hetherington (Volume Ed.), Handbook of Child Psychology. Volume 4: Socialization, personality and social development (4th edition). New York: Wiley, pp. 1-101.

Mauthner, M. (1997) 'Methodological aspects of collecting data from children: Lessons from three research projects', Children and Society, Vol. 11, 16-28.

Mayall, B. (2001) 'Understanding Childhoods: A London Study'. In: L. Alanen and B. Mayall (eds.), Conceptualising child-adult relationships. London: Routledge Falmer, pp. 114-28.

Maxwell, G. (1995) 'Physical punishment in the home in New-Zealand', Australian Journal of Social Issues, Vol. 30, pp. 291-309.

McGroder, S. (2000) 'Parenting among low-income African-American single mothers with pre-schoolage children: Patterns, predictors and developmental correlates', Child Development, Vol. 71, pp. 752-71.

McHale, J., Khazan, I., Erera, P., Rotman, T., DeCourcey, W. and McConnell, M. (2002) 'Coparenting in diverse family systems'. In: M.H. Bornstein (ed.), Handbook of Parenting. Volume 3: Being and Becoming a Parent (2nd edition). Mahwah, NJ: Lawrence Erlbaum Associates, pp. 75-107.

McKeown, K. (2001) Family well-being and family policy: A review of research on benefits and costs, Department of Health and Children. Dublin: The Stationery Office.

Morgan, D.L. (1996) 'Focus Groups', Annual Review of Sociology, Vol. 22, pp. 129-52.

Morrow, V. (1998) Understanding families: Children's perspectives. London: National Children's Bureau/Joseph Rowntree Foundation.

Mussen, P.H. (ed.) (1970) Carmichael's Manual of Child Psychology, Volume 2. New York: Wiley.

National Children's Office (2005) United Nations Convention on the Rights of the Child. Ireland's Second Report to the UN Committee on the Rights of the Child. Dublin: The Stationery Office.

Nixon, E., Greene, S. and Hogan, D.M. (2006) 'Concepts of family among children and young people in Ireland', Irish Journal of Psychology, Vol. 27, pp. 79-87.

Nixon, E., Hogan, D.M. and Greene, S. (2003) Developmental change in children's understanding of parental roles, Poster presented at the Biennial Meeting of the Society for Research in Child Development, Tampa, Florida, 2003.

Nobes, G. and Smith, M. (1997) 'Physical punishment of children in two-parent families', Clinical Child Psychology and Psychiatry, Vol. 2, pp. 271-81.

O'Brien, M., Alldred, P. and Jones, D. (1996) 'Children's constructions of family and kinship'. In: J. Brannen and M. O'Brien (eds.), Children in families: Research and policy. London: Falmer Press, pp. 84-100.

0'Connor, T.G. (2002) 'Annotation: The "effects" of parenting reconsidered: Findings, challenges and applications', Journal of Child Psychology and Psychiatry and Allied Disciplines, Vol. 43, pp. 555-72.

O'Loughlin, J., Kishchuk, N., Difranza, J., Tremblay, M. and Paradis, G. (2002) 'The hardest thing is the habit: A qualitative investigation of adolescent smokers' experience of nicotine dependence', Nicotine and Tobacco Research, Vol. 4, pp. 201-09.

Panter-Brick, C. (ed.) (1998) Biosocial perspectives on children. Cambridge: Cambridge University Press.

Parke, R.D. (2002) 'Punishment Revisited - Science, Values and the Right Question: Comment on Gershoff (2002)', Psychological Bulletin, Vol. 128, No. 4, pp. 596-601. 
Parke, R.D. and Buriel, R. (1998) 'Socialisation in the family: Ethnic and ecological perspective'. In: W. Damon (Series Ed.) and N. Eisenberg (Volume Ed.), Handbook of Child Psychology. Volume 3: Social, emotional and personality development (5th edition). New York: Wiley, pp. 463-552.

Patterson, G.R., DeBaryshe, B.D. and Ramsey, E. (1989) 'A developmental perspective on antisocial behavior', American Psychologist, Vol. 44, pp. 329-35.

Patterson, G.R., Reid, J.B. and Dishion, T.J. (1992) Antisocial Boys: A Social-Interactional Approach. Eugene, OR: Castalia Press.

Patterson, G.R. and Stouthamer-Loeber, M. (1984) 'The correlation of family management practices and delinquency', Child Development, Vol. 55, pp. 1299-1307.

Peltzer, K. and Promtussananon, S. (2003) 'Black South African children's understanding of health and illness: Colds, chicken pox, broken arms and AIDS', Child: Care, Health and Development, Vol. 29, pp. 385-93.

Pinheiro, P.S. (2006) World Report on Violence against Children: United Nations Secretary-General's Study on Violence against Children. Geneva: United Nations.

Ramey, S.L. (2002) 'The art and science of parenting'. In: J.G. Borkowski, S.L. Ramey and M. Bristol-Power (eds.), Parenting and the child's world: Influences on academic, intellectual and social-emotional development. Mahwah, NJ: Lawrence Erlbaum Associates, pp. 47-71.

Readdick, C.A. and Chapman, P.L. (2000) 'Young children's perception of time out', Journal of Research in Childhood Education, Vol. 15, pp. 81-87.

Rigg, A. and Pryor, J. (2006) 'Children's perceptions of families: What do they really think?', Children and Society, Vol. 21, pp. 17-30.

Save the Children Scotland (2000) The Physical Punishment of Children in Scotland: A Consultation. Response from Save the Children, Scotland Programme. Edinburgh: Save the Children, Scotland.

Schaefer, E.S. (1959) 'A circumplex model for maternal behaviour', Journal of Abnormal and Social Psychology, Vol. 59, pp. 226-35.

Sears, R.R., Maccoby, E.E. and Levin, H. (1957) Patterns of child rearing. Evanston, IL: Row Peterson.

Shannon, G. (2005) Child Law. Dublin: Thomson Round Hall.

Shehan, C.L. (ed.) (1999) Through the eyes of the child: Revisioning children as active agents of family life. Stamford, CT: JAI Press Inc.

Smart, C., Neale, B. and Wade, A. (2001) The changing experience of childhood: Families and divorce. Cambridge: Polity Press.

Smetana, J.G. and Braeges, J.L. (1991) 'The development of moral and conventional judgments', Merrill-Palmer Quarterly, Vol. 36, pp. 329-46.

Smith, A.B., Gollop, M., Taylor, N.J. and Marshall, K. (2005) The discipline and guidance of children: A summary of research. Dunedin and Wellington, NZ: Children's Issues Centre and Office of the Commissioner for Children.

Steinberg, L., Elmen, J.D. and Mounts, N.S. (1989) 'Authoritative parenting, psychosocial maturity and academic success among adolescents', Child Development, Vol. 60, pp. 1424-36.

Steinberg, L. and Silk, J.S. (2002) 'Parenting Adolescents'. In: M.H. Bornstein (ed.), Handbook of Parenting. Volume 1: Children and Parenting (2nd edition). Mahwah, NJ: Lawrence Erlbaum Associates, pp. 103-33.

Stern, B.L. and Peterson, L. (1999) 'Linking wrong-doing and consequence: A developmental analysis of children's punishment orientation', Journal of Genetic Psychology, Vol. 160, pp. 205-24.

Straus, M.A., and Stewart, J.H. (1999) 'Corporal punishment by American parents: National data on prevalence, chronicity, severity and duration in relation to child and family characteristics', Clinical Child and Family Psychology Review, Vol. 2, pp. 55-70.

Symonds, P.M. (1939) The psychology of parent-child relationships. New York: Appleton-CenturyCrofts.

Teti, D. and Candelaria, M.A. (2002) 'Parenting Competence'. In: M.H. Bornstein (ed.), Handbook of Parenting. Volume 4: Social Conditions and Applied Parenting (2nd edition). Mahwah, NJ: Lawrence Erlbaum Associates, pp. 149-80.

Tovey, H. and Share, P. (2000) A Sociology of Ireland. Dublin: Gill and Macmillan. 
UN (1989) United Nations Convention on the Rights of the Child. Geneva: United Nations. Available at: www.unhchr.ch/html/menu2/6/crc/treaties/crc.htm (accessed May 2009)

Willow, C. and Hyder, T. (1998) It hurts inside: Children talking about smacking. London: National Children's Bureau.

Wissow, L.S. (2002) 'Child discipline in the first three years of life'. In: N. Halfon, K.T. McLearn and M.A. Schuster (eds.), Child Rearing in America: Challenges facing parents with young children. New York: Cambridge University Press, pp. 146-77.

Whyte, J. (2006) General Guidelines for Good Research Practice with Children. Dublin: Children's Research Centre,Trinity College Dublin. Available at: www.tcd.ie/childrensresearchcentre/Docs/ GoodResearchPracticewithChildren.pdf (accessed May 2009) 
APPENDICES 


\section{Appendix 1: Information Sheet for Parents, Parental Consent Form and Questionnaire}

\section{INFORMATION SHEET FOR PARENTS}

\section{What is the study about?}

The study aims to explore what children think about parenting approaches and discipline.

\section{Who are the study researchers?}

The study is commissioned by the Office of the Minister for Children and Youth Affairs, and is being jointly carried out by the School of Psychology in Trinity College, Dublin, and the Department of Social Sciences in DIT. Both researchers are lecturers in Child Development, with training in psychology.

\section{What happens if I agree to my child taking part?}

We are asking parents for permission to invite their children to take part in one of our focus groups. Children who return parental consent forms will be invited to take part in a 30 to 40-minute focus group discussion, with their classmates in the school.

The aim of the focus group will be explained to children beforehand and they are free to decide whether they are happy to take part in the study or not.

We also request parents to provide basic family background details in order to give us a profile of the children's families - this means that children will not have to be asked for any details on their families.

\section{What happens if my child agrees to take part? \\ If children decide to take part, they will be asked about their attitudes and responses to different parenting approaches, including parents' approaches to care, support, control, monitoring and discipline. Children will not be asked for any specific information on their own families. \\ As these are group discussions and children will hear the ideas of the other children in their group, the confidentiality of what children tell us cannot be totally guaranteed. However, children are asked not to discuss what other children said in the focus group afterwards in school. No information will be shared with the teachers or school principal.}

If a child discloses information that causes the researcher to worry about his/her safety or well-being, the researcher will inform the child's parents, but not without discussing this with the child first.

\section{What will happen to the information?}

All information will be stored, on a confidential basis, on a computer and used for the purpose of the research only. The interviews will be analysed in terms of themes and topics which emerge in the discussions. No child will be identified in anything that is published from the study.

We hope that the results of the study will make an important contribution to our understanding of children's views on this central aspect of their lives and inform related policy decisions.

If you have any queries, please feel free to contact us: Dr. Elizabeth Nixon (Tel: (01) 896 2867) or Dr. Ann Marie Halpenny (Tel: (01) 402 4255). 


\section{PARENTAL CONSENT FORM}

I confirm that I have read the information provided.

I am happy for my child to be invited to take part in a focus group discussion at school.

Child's name:

Parent's signature:

Date:

\section{QUESTIONNAIRE}

To avoid asking children about their own family backgrounds, we would be very grateful if you could fill in the details on your child's family below. This information is confidential and will only be used to build an overall profile of the family contexts of the children in the study.

\section{Which family type best describes your family?}

Two-parent (both biological parents)

Two-parent (biological + step-parent)

Single parent (never married)

Single parent (separated, divorced, widowed)

Other (please describe)

\section{Socio-demographic information}

Is there somebody in the household who is employed? Yes $\square$ No

Who is the main wage-earner in the home?

What is their job/occupation?

\section{Ethnic or cultural background}

Irish

Non-National

If not Irish, please specify nationality

\section{Please return to the school in the envelope provided.}




\section{Appendix 2: Information Sheet for Children and Child Consent Form}

\section{INFORMATION SHEET FOR CHILDREN}

\section{Who are we?}

We work in Trinity College and the Dublin Institute of Technology. We teach child development and we do research to find out different things about children and young people's lives.

\section{What do we want to find out?}

We want to find out what you think about what parents do for their children and the different ways in which parents look after and take care of their children. We are asking children and young people, like you, whether they would like to take part in a group discussion with ourselves and 4 or 5 of their classmates. Each discussion will take between 20 to 40 minutes, in a classroom in your school.

We will be asking you what you think about how parents care for and help their children grow up. We will also be asking you how parents make sure that their children are safe and what parents do when their children misbehave. We will not be asking you any questions about your own family though. There are no right or wrong answers to our questions - we just want to hear your ideas.

\section{What happens if I agree to take part?}

Your parent has already read our letter and sent back a form saying that we can ask you whether you would like to be part of one of our group chats. But this does not mean that you have to - we will only talk to you if you are happy to talk to us. Also, if you decide that you do want to be part of a group discussion and then you change your mind, that's 0K! You can just tell us and leave the group discussion at any time.

Because we will be talking in a group, you will hear the ideas of other children and they will hear your ideas. Sometimes people will have ideas that are different from your ideas. But that's 0K. We ask you not to talk about what other children said in the group discussion. Our ideas are just shared within the group and not talked about afterwards in the classroom or in the school yard. No information will be shared with the teachers or school principal. Of course, you can talk to your parent about what happened when you go home, if you want to. Also, if you tell us something that makes us worry about you, we will want to tell your parent or teacher, just so that we can make sure that you are $0 \mathrm{~K}$. We will not do this without telling you first.

After we visit your school, we will write about what you and your classmates told us. But we will not use your name.

If you have any questions, you can talk to us after the group discussion, or telephone us: Dr. Elizabeth Nixon (Tel: (01) 896 2867) or Dr. Ann Marie Halpenny (Tel: (01) 402 4255).

\section{THANK YOU VERY MUCH!}

\section{CHILD CONSENT FORM}

I have read the information sheet.

I am happy to take part in a group chat about parents at school.

I understand that the other people in the group will also hear about my ideas.

I understand that if I say something that causes the researcher to worry about me, she will have to tell my parent or teacher, but will not do this without telling me first.

Child's name:

Date: 


\section{Appendix 3: Topic Guide for Focus Groups}

1. Roles in the family - obligations and expectations specific to parenting role; gendered division of parenting role.
a. What do parents do in a family? What is their job in a family?
b. Is there a difference between mothers and fathers?
c. Is there anything that mothers are better at and fathers are better at?

2. Experiences of care and support - including responsiveness and sensitivity to children's needs.

a. How do parents look after their children?

b. Examples of caring activities; how does the nature of the parent's role change over time? Are there differences for boys and girls?

3. Experiences of monitoring and control - including discipline.

a. What about rules and expectations? Rules about whereabouts, activities. Expectations about behaviour that is 'acceptable'. How does this change over time? Are there differences for boys and girls?

b. How do parents know about what their children are up to? What works, what doesn't work? What role do children play in this? Do parents have a right to know?

4. Strategies of punishment - perceptions of 'acceptable' forms of punishment, including verbal and physical punishment.

a. What do parents do when their children misbehave, break the rules? How does this change over time? Are there differences for boys and girls?

b. What's your view on parents using physical punishment with their children?

c. What rights do parents have? What rights do children have?

d. Why do parents use these forms of punishment?

e. Does it depend on the age of the child, whether the child is a boy or a girl, what the child has done wrong?

f. Do you think physical punishment should be banned/made illegal? Why? Why not?

5. Effective parenting strategies - emotional, behavioural and relational impact of different approaches.

a. What works as a good way of punishing children? Why does this work?

b. What doesn't work? Why does this not work? What might be better?

c. Does this depend on the age of the child? What the child does wrong? Whether the child is a boy or a girl?

6. Childhood and parenthood compared - exploration of rights and responsibilities in families.
a. What is the difference between being a child and being a parent in a family?
b. Do parents have rights over their children? Do children have rights over their parents? Why/Why not?
c. What responsibilities do parents have for their children?
d. Do children have any responsibilities in their families?

\section{Concluding questions:}

a. How would you describe your ideal parent?

b. Any questions, further comments? 



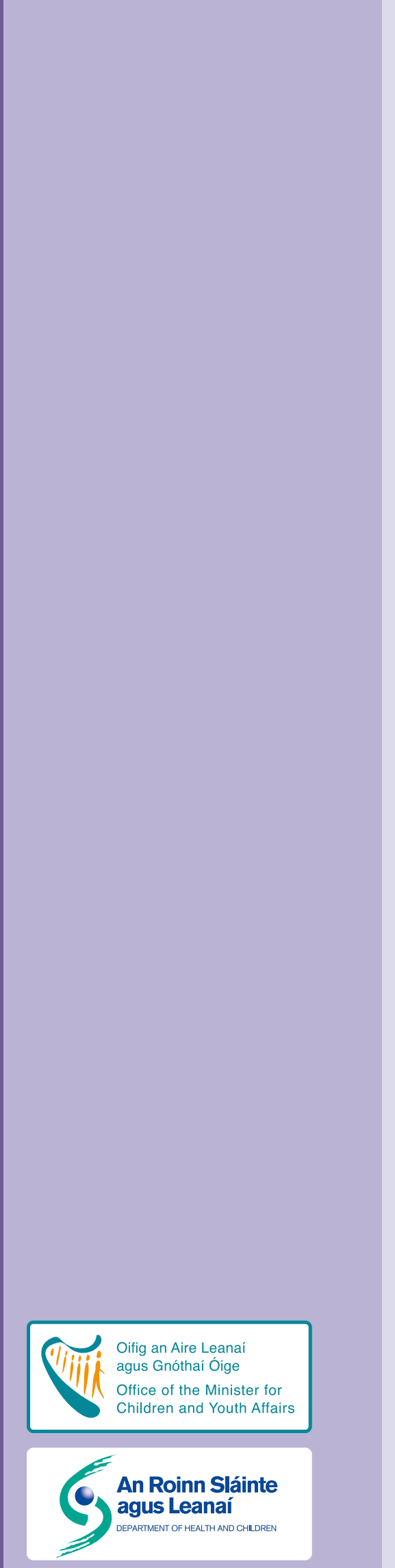

Office of the Minister for Children and Youth Affairs Department of Health and Children

Hawkins House

Hawkins Street

Dublin 2

Tel: +353 (0)1 6354000

Fax: +353 (0)1 6743223

E-mail: omc@health.gov.ie

Web: www.omcya.ie 